\title{
SMITHSONIAY
}

LIBRARIES 


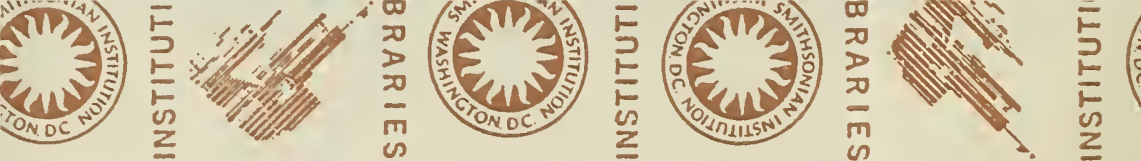

INIIISNI NVINOSHLIWS SBIYYQ $177^{2}$ LIBRARIES SMITHSONIAN IN
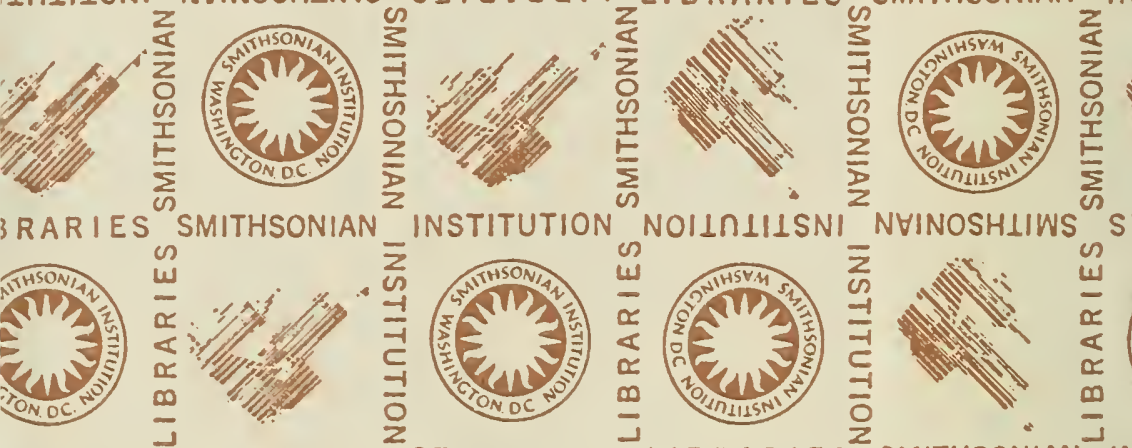

INIIISNI NHINOSHIIWS S IYYYGI7 LIBRARIES SMITHSONIAN IN

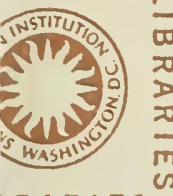

RARIES
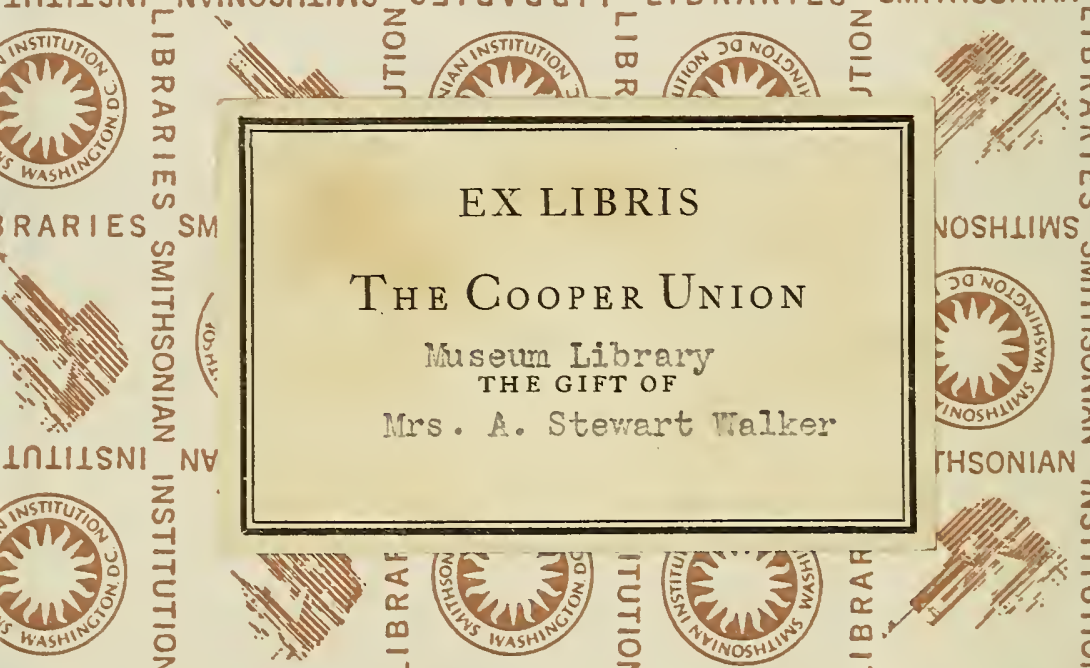

RARIES
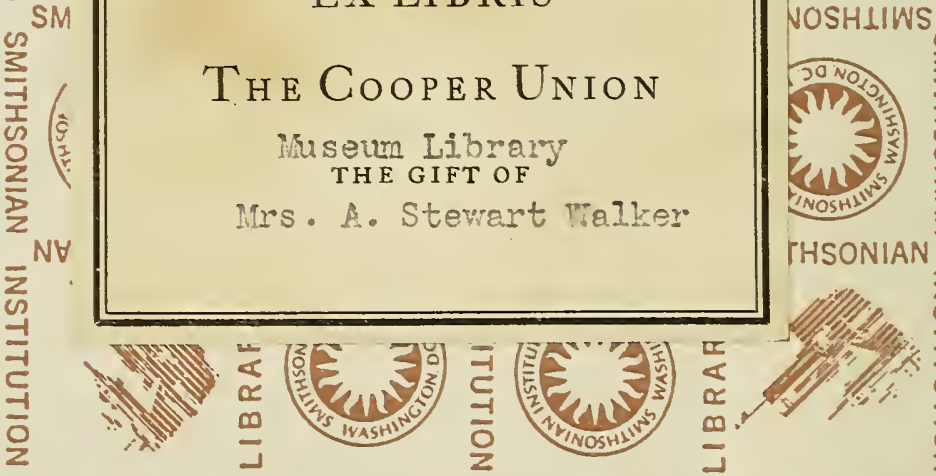

$\frac{e^{2}}{2}$
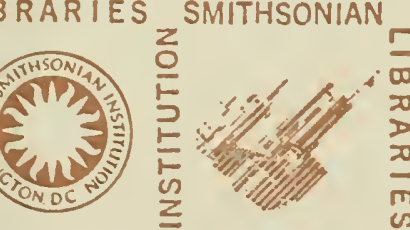

INSTITUTION
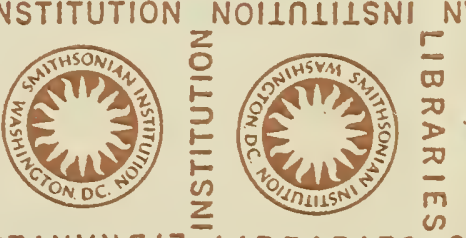

VINOSHIIWS S

InIIISNI
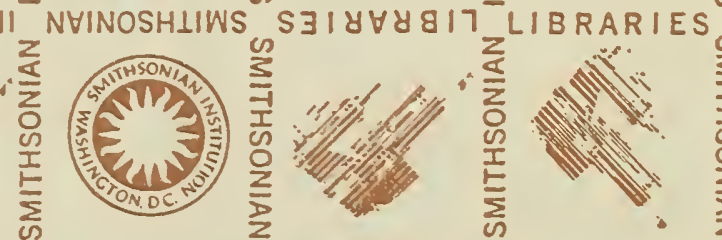

BRARIES SMITHSONIAN
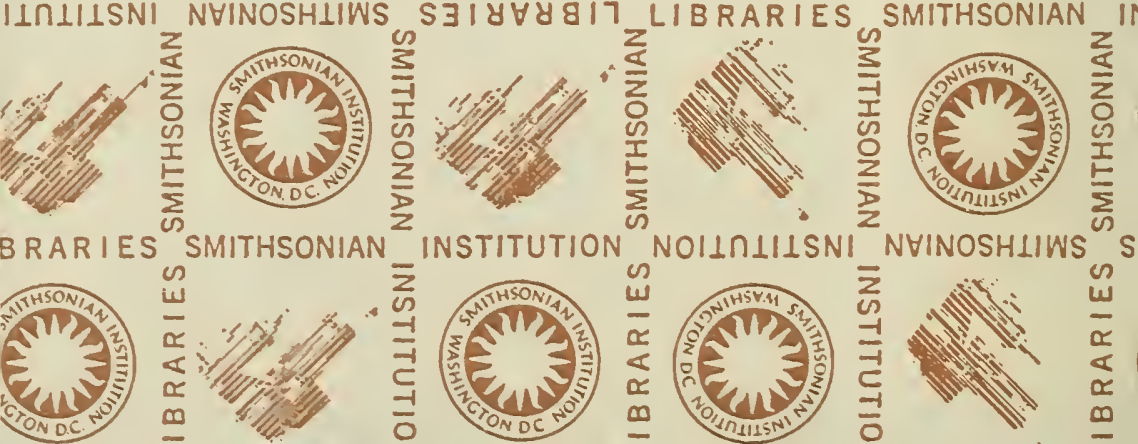



THE CONNOLSSEUR SERIES of BOOKS her COILLETORS

Edited by C. RIGINALD GRUNDK

\section{OLD IRISH GLASS}

BY

Mrs. Graydon Stannus

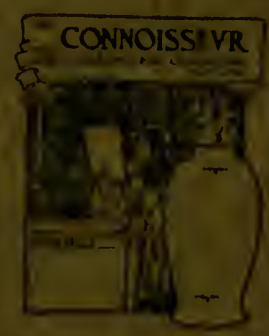

ILLUSTRATBD 
THE CONNOISSEUR SERIES OF BOOKS FOR COLLECTORS

Edited by C. REGINALD GRUNDY

OLD IRISH GLASS 

THE CONNOISSEUR SERIES of BOOKS for COLLECTORS

Edited by C. REGINALD GRUNDY

\section{OLD IRISH GLASS}

BY

\section{Mrs. Graydon Stannus}

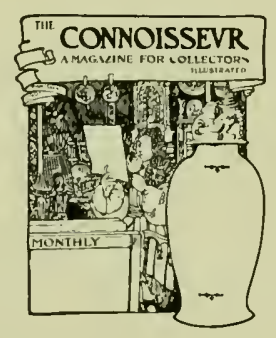

I I, L, U STRATE D

LONDON MCMXX

THE CONNOISSEUR 


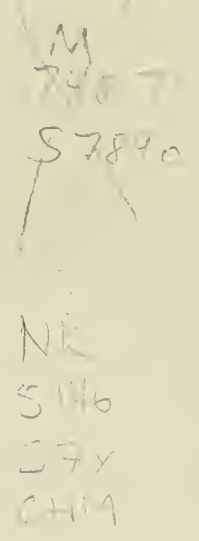

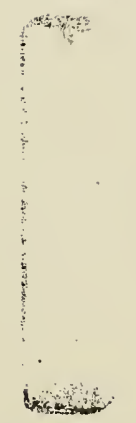

FEB 221950

-8960\% 


\section{THE FASCINATION OF IRISH GLASS}
$A^{\text {LL old glass is interesting, but old lrish glass possesses }}$ A certain unique qualities which make its collection peculiarly fascinating.

In it we find an unsurpassed heauty and depth of coloura poetry of design and a relvet softness of touch which are a pure joy to the connoisseur.

But hefore descrihing lrish glass let me first give some idea as to where and when it was produced.

Glass appears to have been made in Ireland to a very small extent during the Middle Ages, but its manufacture was

THE BEST PERIODS OF IRISH GLASS not seriously commenced there until the close of the sixteenth century. What types of glass were made at this early period, or exactly where the glass-houses were situated, there are no authentic records to show, only the glass-lore handed down from father to son through the ages.

Some was undoubtedly made as early as 1332 . It is a fact that the coloured windows of Dublin Castle were made at that date in Dublin.

Window glass, coloured glass, and drinking glasses were also made in Ireland in 1585 , and their manufacture appears to have been carried on more or less steadily from that time onwards in various parts of the country.

It was not until the second quarter of the eighteenth century that the great period of Irish glass-making arrived, and pieces were produced rivalling, or cren surpassing, the 
best wares of their lind made in England and on the Continent. During the next hundred years nearly all the Irish glass was made that now possesses a distinctive interest to the collector. Earlier pieces that can be authenticated are both excessively rare and possess few typical qualities, whilst by the end of that period Irish glass-makers had attained the summit of their ambition and produced glass absolutely indistinguishable from contemporary English pieces, and thus robbed it of its chief fascination to the connoisseur and collector.

It is a curious irony of human endeavour that the makers of Waterford glass, now deservedly famous for its unique and beautiful dark grey blue tone, tried to eradicate it from quite an early date. They endeavoured to make their glass whiter and clearer like that of Bristol, and in this they succeeded after 1815. Little did these glass artists think that a century later people in all parts of the world would be trying to reproduce that self-same colour without success.

\section{GLASS FACTORIES IN IRELAND}

From time to time humorists over here state that "no glass was ever made in Ireland," so that the following list of localities where a few of the best known glass-houses stood will be of interest:-

ANTRIM :

(BALLYCASTLE)

1755 TO 1790

Fine flint glass, heary, wher white handsome deep cutting and very fine bold engraving. Glass was BELFAST : 1781 TO 1870
Bottles, heavy rummers, and very coarse but useful glass. brought here from other parts of Ireland to be decorated. Foreign engravers were employed and excellent work done. 
Finely cut glass of every description, delicate engraving on

CORK :

1782 TO 1844 blown ware, gilding; particularly famous for its rummers, heavy and light-blown decanters, and in the thirties whole dessert services of beautiful colour and various cutting.

As the card of membership of the Cork Glass Cutters" Union (shown on page 96) proves, "lustre" cutting originated here.

There were numbers of houses here in which every lind of white and coloured glass was made. Many fine specimens still exist, of which Pugh's productions (though

DUBLIN :

CIRCA 1700 TO 1896 rather late) are worthy of note, particularly his "lustre" cutting. The early moulded pieces were very elegant and quaint, very much lilic Bristol, but, so far as I have ohserved, heavier, ard, of course, not so white or clear, neither did they ever show the richness of the Southern glass.

DRUMREA :

(DUNGANNON)

1771 TO 1776

for chandeliers.

\section{NEWRY:}

1790 TO 1847
Nuch the same lind of glass as Corli, hut clearer; noted for fine green and amber coloured glass both in hottles and drops

A great variety of flint glass, both cut and plain, very heavy. A great deal of tahle glass was made here.

Produced every possible kind of glass of the most beatutiful colour and cutting. The chandeliers, candelabra, boat-shaped and turnover bowls, were perfect. The WATERFORD : 1729 TO 1852 finest period was round about 1780 . After 1820 the glass became much whiter. About 1815 some wonclerful deep "step" cutting was done, which made the glass, in some lights, look like silver plate: while dessert services were a great feature, and I constantly comc in contact with parts of these services (tuclied away in cellars and odd places) of the most surprisingly beautiful workman. ship and colour. 
One of the very earliest glass-houses was erected here on the Stannus property, but very little is PORTARLINGTON: known about it or its particular productions,
1670 and it closed down in a few years from lack of financial support. I believe drinking glasses were its chief output.

Foreign workmen were largely employed in 1reland, particularly cutters, engravers, and gilders. 1rish gilding rather IRISH GILDING stands alone. It is rery hard, and cannot be rubbed off in the usual way. When deliberately scraped off it leaves the glass underneath quite rough, consequently it has survived ordinary wear and tear almost intact. The process was chemical, and it is a great pity that more of it was not done. Very fine bright gilding was executed for some years, about 1786, by a German called Grahl.

The industry died out about 1896, Pugh, of Dublin, being the last malier of flint glass in Ireland. He is often credited THE LAST MAKER with being the first to introduce "lustre" cutting, hut the rare plate of the Cork Glass Cutters' Union, already referred to, shows that this decoration must have been done in Cork about 1785, since it may be presumed that the pieces they have chosen as being representative of their own craft would be those most largely produced. The fine old jug in the centre, for instance, is a splendid specimen of "lustre" worli.

While on the subject of the worliers, it will be of interest, in these days of high wages, to recall the remuneration paid to these artists in glass as recorded in the GLASS-MAKERS: WAGES

Dublin Museum. The founder received the princely sum of $7 \mathrm{~s}$. for his weelis worli. while the fireman only got 6s. The glass-maker himself (not the cutter or the engraver) was evidently a piece-worker, earning at most 50s. a week, and was douhtless a mightywealthy man. 
Naturally the extraordinary cheapness of fuel in lreland was a great help to the owner of a glass-house, as wood was the chief thing he burnt. But late in the seventecnth century an Act was passed prohibiting the felling of trees for this purpose, so even in those early days manufacturers had their troubles. However, 1 do not think this interfered rery much. If an lrishman wants a thing, it will talic a sreat deal more than an Act of Parliament passed by the yuiet, easyogoing Englishman on the ofher side of the werter to stop lim.

As late as the nineteenth century, in my father's time, our village carpenter would come and buy a good-sized ash tree for 1s. Gid. Those not so well off freely helped themselves by the light of the moon. We do not bring people to justice in Ireland for little slips of that sort: we should have no, time left to ourselves if we did.

\section{THE CHARACTERISTICS OF IRISH GLASS}

Irish glass, more especially IVaterford, of the typical period, may be distinguished from contemporary English and foreign and modern fakes of all nationalities by a number of characteristics which may be srouped under the headings of Weight, Colour, Resilience, Feeling to the Touch, and Ring. Let me take these one by one.

Jrish wass is generally rery heary, though there are exceptions to this rule, maliedly in the blown specimens from

WEIGHT about 1735 to 1750 , which were extremely light. These pieces were never cut, but only engraved or left quite plain. But even these can be distinguished from the foreign pieces, as they never show the little speclis of sand in the metal peculiar to the foreign glass. Air bubbles often appear, but never sand. 
All Irish glass has a peculiar depth of tone, but the early glass of Cork and Vaterford is especially distinguished in COLOUR this respect. Its steel or grey-blue stands alone. There is very little to distinguish between the products of the two factories, as both places produced the same mysterious grey colour (supposed to be caused by impure ingredients), and the worlimen employed at both places frequently changed factories. But 1 have noticed that some Corli glass has a decided yellowish tint, which II aterford never has. Sometimes it is impossible to say from which county a piece came, and this has led experts to refer to the products of these factories indiscriminately as "Munster glass." Most of the pieces I have come across, actually inpressed with the mark "Cork Glass Co.," were of the bluegrey tinge, commonly exclusirely attributed to Waterford, which is an error. It is very frequently suggested that the chemical action of the air on old lrish glass as the years roll by has something to do with the mystery of this wonderful tint, and, strange as it may seem, it is an undoubted fact that glass does change its tone with time.

No description of Waterford glass would be complete without some reference to the peculiar cloudy bloom so often found covering the metal, which can be THE BLOOM ON
WATERFORD GLASS rubbed off, but will assuredly return. This "bloom" must not be confused with the milliness found in decanters, etc., which is caused by water or wine being allowed to remain in them for long periods. It is quite different: a soft bloom, exactly like that on grapes. the same colour, or even darlier, than the glass, and often it will be found forming a beautiful band of rainbow hue running round the piece. We do not for certain linow the cause, but it is probably some atmospheric action on the lead in the metal, and is only found on very early darli pieces. 
These pieces are most interesting, hut not always appreciated as they should be. Some time ago I parted with a mannificent Wateriord bowl of this type, only to find a week later it had heen chemically polished clear and bright, with not a tithe of its beauty left.

1rish glass is far tougher and stronger than any other, hence its wonderful survival even when in constant use. It takes a severe blow to break it, or even RESILIENCE OF IRISH GLASS

chip it, and 1 have seen solid piece's fall on a hard floor without being any the worse, beyond "singing" loudly. It has a wonderful elasticity, and actually bounces in a way that 1 have never found in any other glass. Recently the ring securing a large and valuable chandelier to the ceiling of one of my rooms gave way, with the result that the chandelier fell to the ground from a height of twelve or fifteen feet. It was, of course, broken with the fall from such a height, but the centre pendant, a large solid piece of cut glass, had not heen broken in the least, though the force of the fall had flattened its point.

lrish glass does not feel harsh or cold like most English or foreign, hut gives a sense of soft warmth to the touch. There

THE FEEL OF IRISH GLASS TO THE TOUCH is something of the same distinction as between porcelain and earthenware, though not nearly to such a marked extent. One has to acquire a knowledge of it hy experience; and though the tyro may at first perceive little or no difference between the feel of Irish or English glass, if he will cultivate his sense of touch by feeling authenticated pieces of both varieties, he will soon find that there is a small but perfectly distinguishable difference between them.

1 must make special mention of the ring of lrish glass, as

THE RING OF

IRISH GLASS

to anyone with a musical ear it will be interesting to listen this is an important point. All British glass has a clear, definite, bright ring, hut a musical ear it will be interesting to listen 
to the peculiar throb in Irish glass, not so much a ring as a rich throb, sometimes (particularly in large pieces) almost like a vibrato between two notes. I do not say that jou get this in all lrish glass, only in the greater part of it.

No one, for instance, would expect a candlestick to ring, or a salt-cellar, or a thick shallow piece heavily cut. Jugs, as a rule, also have a special dislike to displaying their voices, so, naturally, people must use their discernment.

\section{FAKES}

These are innumerable, and belong to all periods, old and modern, since Irish glass first became popular.

No glass in the world has been so much copied, and none has, in the long run, stood out so successfully in defying the faker. This constitutes one of the great attractions of Irish glass to the collector, for though many imitations of it have been made of sufficient excellence to deceive the inexperienced and unwary, it cannot he copied sufficiently well to deceive the connoisseur.

The finest reproductions from France, Belgium, Holland, and even Germany, all fail in colour and texture, though some of the cutting is exceedingly clever.

At the present moment there is an enormous amount of spurious glass on the market, and some time ago a lot of remarkable copies were in circulation. They were the best that have yet appeared, especially the urns and candlesticks, and numbers fell into the hands of the unwary. One special weakness, however, was very noticeable-the colour fell in the tall pieces, leaving the tops whiter than the bases. 
As has already been pointed out, nearly all Irish glass is heary, and a very large proportion of the modern fakes fail to attain the recuired weight. A marked exception to the general rule of weight is to be found in lrish blown specimens, produced from about 1735 to 1750 , which were very light, and only engraved or quite plain, never cut. The falier frequently forgets the latter point. When, however, he remembers it, and produces plain or engraved pieces similar to the lrish, there is yet another point of distinction. The Irish pieces often show air-bubbles, but never the little specks of sand which, as I have already said, almost invariably appear in the metal peculiar to foreign glass.

The most important distinction between lrish glass and foreign imitations is to be found in their colours, and in this

DifFERENCE OF COLOUR respect it is the early glass of Corli and Waterford which defies the copyist more than any other. Its steel or grey-blue tone stands alone, although, alas, the thin cobalt and ultramarine colours have been, and in all probability will continue to he, sold as the genuine article. In the analysis of Irish slass there is no trace of cobalt.

Some copies of an almost emerald green have changed hands in good faith as IVaterford glass. How could green be produced from lead oxide, potash, soda, and silica? - for this is the analysis of an carly piece of Waterford "pot metal" glass of the dark grey hue.

The peculiar ring of Irish glass has already heen described. The foreign copies are quite different. Sometimes they will not ring at all, especially the wine-glasses; DIFFERENCE IN THE the better ones give a sound of sorts, but RING OF OTHER GLASSES it is very dead, and, if carefully listened to, the note is never true, just a little flat, quite unlike the "singing Waterford." 


\section{THE INCREASING POPULARITY OF IRISH GLASS}

The multitude of fakes on the market bear testimony to the increasing demand for 1rish glass.

During the last six years, those members of the public who have a linowledge of glass have realised more and more the value of the genuine lrish article, which, of course, is due to the fact that it cannot be copied sufficiently well to deceive the connoisscur. The direct outcome of this is a steady increase in the market value, and rare specimens, which were made at from $25 \mathrm{~s}$. to $f 4$, now readily fetch anything from $£ 10$ to $£ 400$; in fact, a single piece sold recently for $£ 750$, and a beautiful bowl passed through my hands at $£ 550$.

Magnificent specimens of Irish glass have found their way into English collections, as will be seen by the plates shown in this article. Photographs of most of the well-linown pieces in the Dublin Museum, and in private Irish houses, have already been reproduced in various publications: hut the accompanying photographs are exceptional specimens, talien exclusively from English collections, and a very lange number of them have passed through my own hands.

It is absolutely impossible to become a sound judge of lrish glass without years of experience, and, above all, without the constant actual handling of pieces

EXPERIENCE ESSENTIAL of all dates and descriptions, conseguently the genuine lrish dealer who has lived amongst it all his life has a rery great pull with regard to actual linowledge.

So many specimens were made to order, and were therefore of special shape and cutting, that it is very difficult for the uninitiated to recognise a piece as heing of any certain 
factory or period, and he is naturally mystificd when lie tries to classify such pieces into more or less well-known categories. For instance, an ancestor of minc lod in his possession an early deep coloured bowl, cover, and stand of exceptional quality, made about 1750. His son, in 1790, had it cut in "that diamonds" (a cutting then much in vogue), the result being a specimen of early darls "wavy" wlass, adorned with the heantiful cutting of forty years later, and this is only one instance of many which could be quoted.

Great quantitics of lrish glass were made, and the ollicial Irish records show that large numbers of pieces were exported

IRISH GLASS

SOLD ABROAD to) America, Spain, Portugal, and the West Indies, etc. Many of our finest specimens were also taken to Holland, where they found a permanent home, and were extensively copied by the foreign glass-malsers.

France was very keen on lrish glass, and I have unearthed there some very lovely and absolutely gemine specimens, especially wall-lights and chandeliers.

Needless to say, a very hig trade was done hy the glasshouses direct with old lrish families, who gave large orders for glass-ware, ranging from single pieces to complete table services, of which few records appear to have been kept.

A large amount of Irish glass was made and put by, uncut, as Irish families (especially those who lived near the onlassUNCUT PIECES houses) preferred to choose their own cuttings from drawings, so as to have something different from their neighbrurs. This accounts for the number of uncut pieces still to be found in various parts of lreland, especially thick finger-bowls, which were, undoubtedly, made in great quantities to await orders. 
The following plates give some idea of the beautiful pieces of glass which have left Ireland, but there are magnificent The illustrations specimens still there, which will probably never be placed on the market-pieces as poetic in design as their owners are in mind; pieces that will live for the sons and heirs to love and cherish with the many other treasures of Ireland's finest periods, long after Sinn Feiners have ceased their endeavours to destroy all that is best and loveliest in the old country.

At the time of writing this, I find an enormous amount of spurious "1rish" glass on the market, and I take this opportunity of warning all collectors and dealers (many of whom are my friends) to be exceedingly careful. It is essential that all lovers of Irish glass should keep their collections pure, and some of these fakes are so clever that dealers will have to exercise the greatest vigilance and care if they are to avoid the ignominy of having pieces which they have sold in good faith returned to them as "wrong." At the present time, all the best known dealers in Irish glass are trusted by their customers, and their advice is taken without question. It is in the best interests of their great profession that this sense of confidence should remain-hence my friendly and well-meant warning.

In conclusion, I would like to add that I hope this bookletwritten, as it is, at the request of many lovers of 1rish glassmay be a real help to the novice, and assist him to distinguish between "right" and "wrong." To those who wish to go deeper into glass-lore, I would strongly recommend the excellent little book written by Mr. Dudley Westropp, the well-known curator of the Dublin Museum. 


\section{ILLUSTRATIONS}

Photos by Hana. 


\section{BOWLS, DISHES, PLATES AND TAZZE}

WATERFORD Bowl, circa 1780. Very flat diamond cutting, on three feet carved as paws. This bowl, which is one of the finest the author has ever seen, is exceptionally notable from the fact that the pontil has been worked $u p$ into an ornament instead of being broken off.

In the collection of Commander Swithinbank, R.N.

NOTE.-According to official records the Waterford Glass Houses closed down from 1750 to 1780 , but there exists a good deal of glass traditionally made within this time, and certainly having all the attributes of Waterford, and being fashioned in contem. porary styles.

Oval Bowl and Dish, cut in flat diamonds, and of unusual shape. Waterford.

In the collection of Mr. Bliss. 

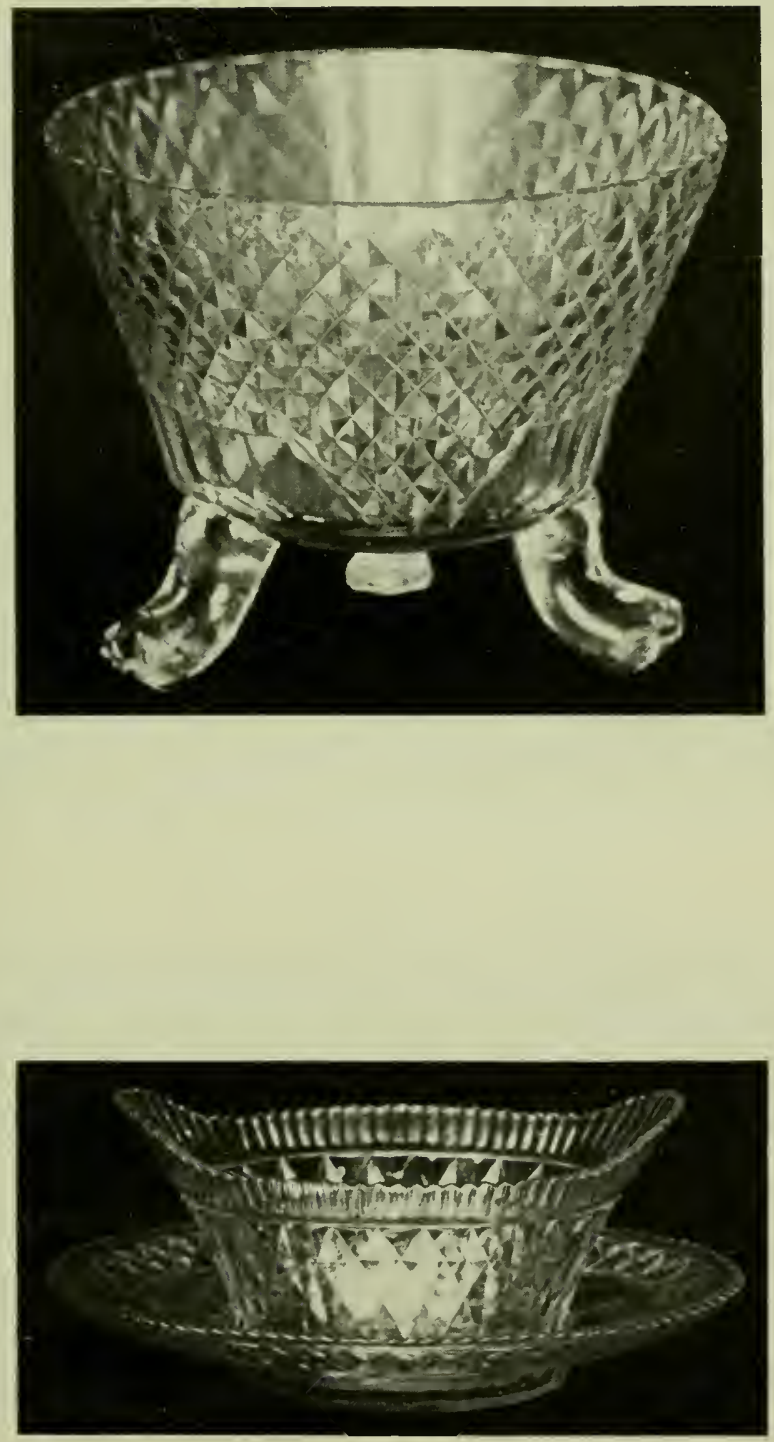
Munster Glass Bowl, circa 1780. Heavily but beautifully cut. $11 \mathrm{in.} \mathrm{high.}$

In the collection of Mrs. Hall.

Waterford Orange Bowl. Unusually large. Circa 1790. In Major Pope's collection. 
40. $1 \mathrm{Nos}=$

(N2.8.19)
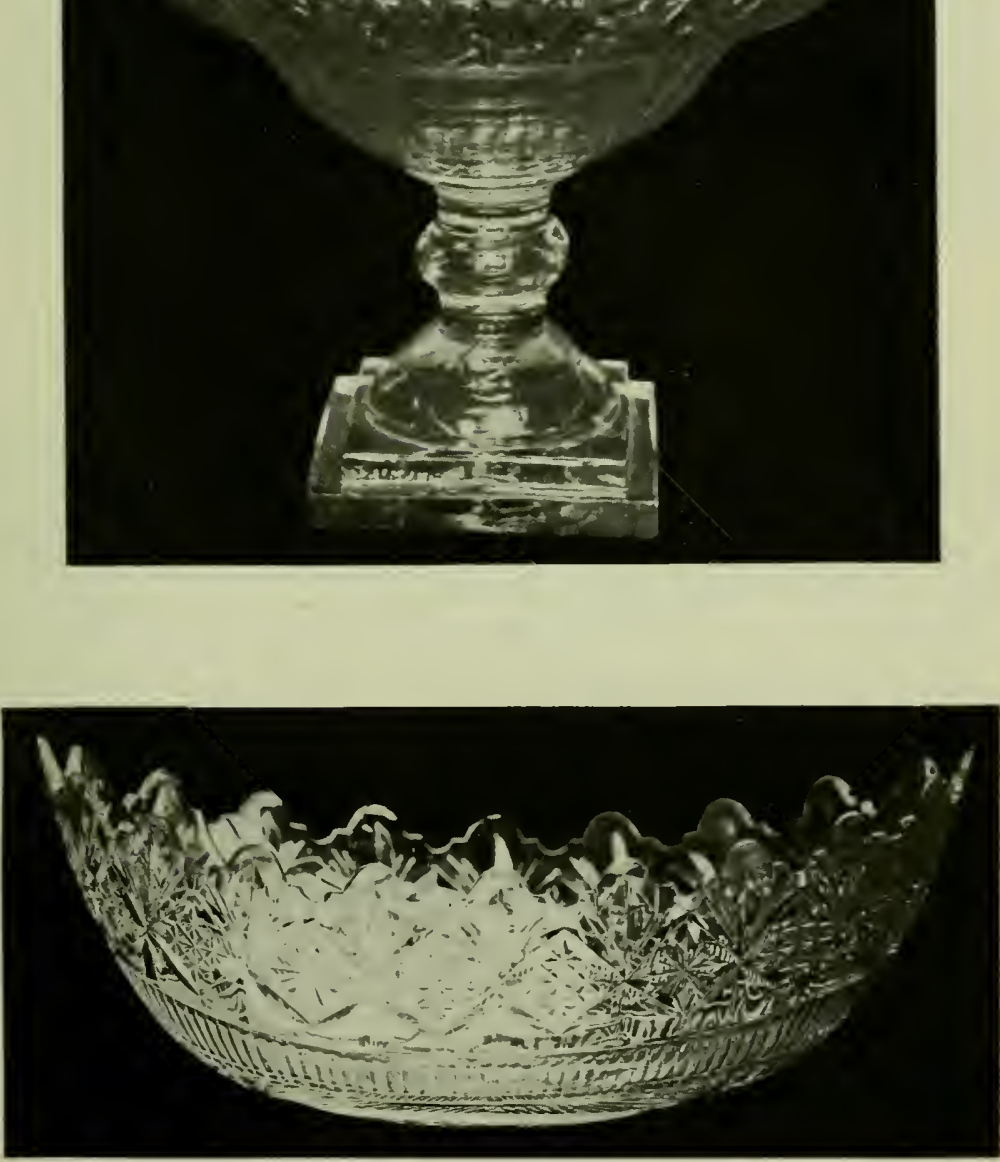
Rare heavily chiselled Christenna Bowl. Irish, 1760. 26 in. across.

In the Author's collection.

"Pinchel," Siden Bowi. on round domed foot.: $11 \mathrm{in.}$ wide, $s$ in. high.

In the Author's collection. 

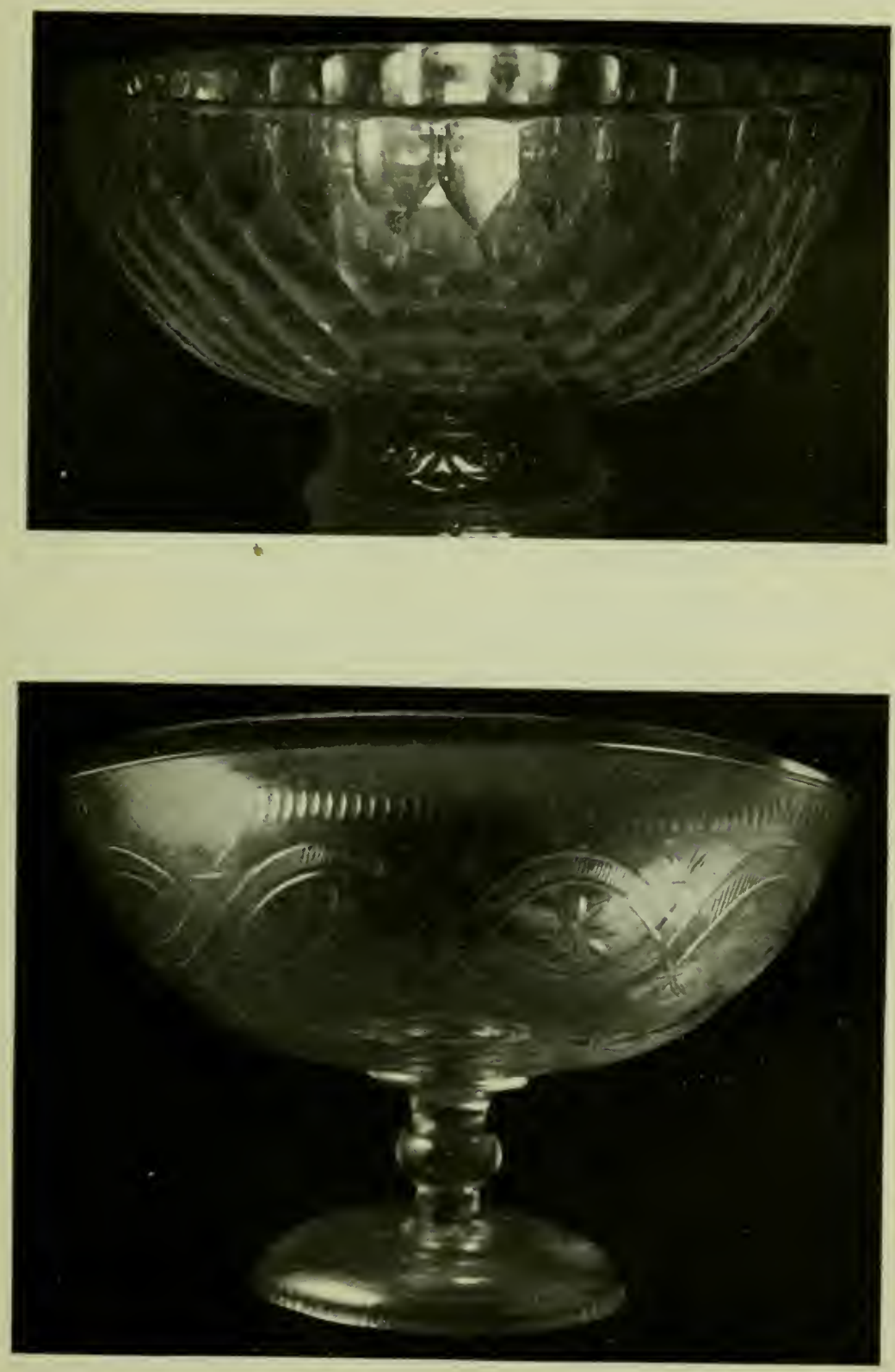
Waterford Flower Bowl, 12 in. high. Heavy early glass, finely cut, with castellated edge. Circa 1780 . In the collection of Commander Swithinbank, R.N. 


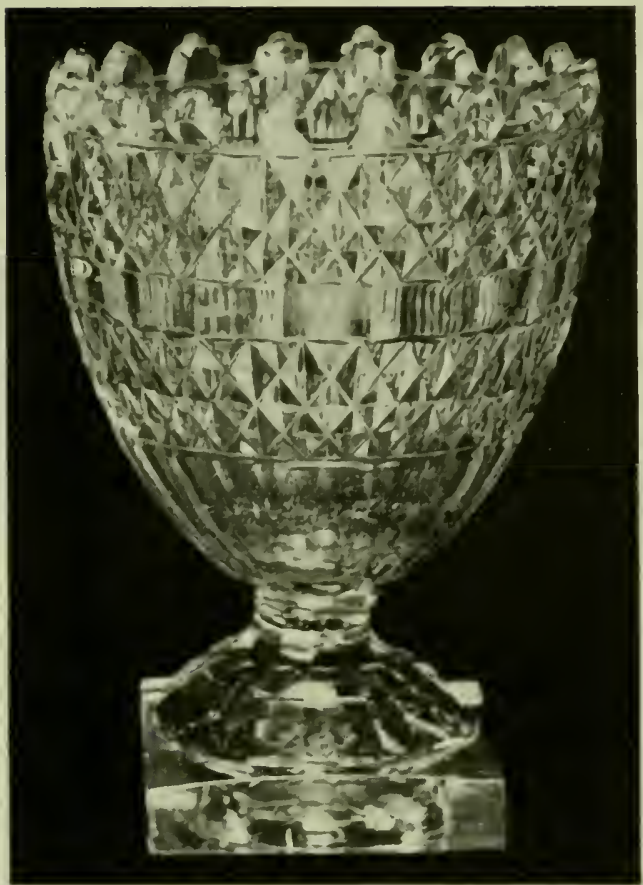


A wonderful early "Pixched" Bowl, showing the remarkable "rainbow" band of faint colour running round the body. The foot is square and moulded in a "dome." Note that the waste metal running from the square base has not been cut away, proving that this piece, for some reason unknown, has been left unfinished. There is no trace of "milkiness" about this bowl. The small one ( 3 in. high) beside it is a traveller's sample, made this minute size for convenience in carrying about. In the Author's collection.

Shallow diamond-cut Waterford Revolving Centre DisH. The glass all fits together without any metal mounting. Circa 1780.

In the Hon. Mrs. York's collection. 

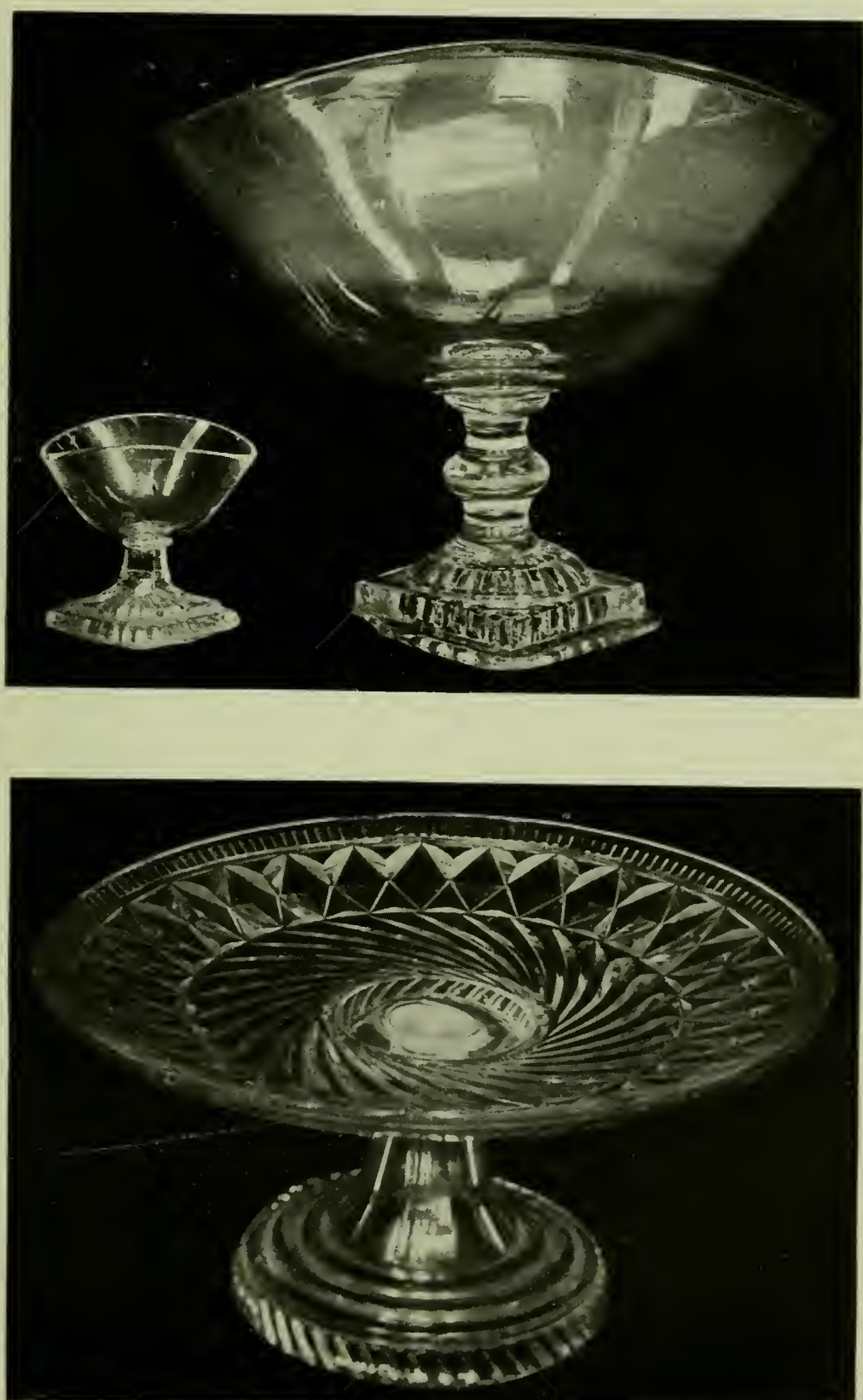
Large Two-handed Posset Bowl. Possibly as early as 1750 . 1rish.

In the collection of Mrs. Hall.

Rare heavy, dark, plain Ogee Bowl. Irish, about 1760. In the collection of Mr. Robert Frank. 


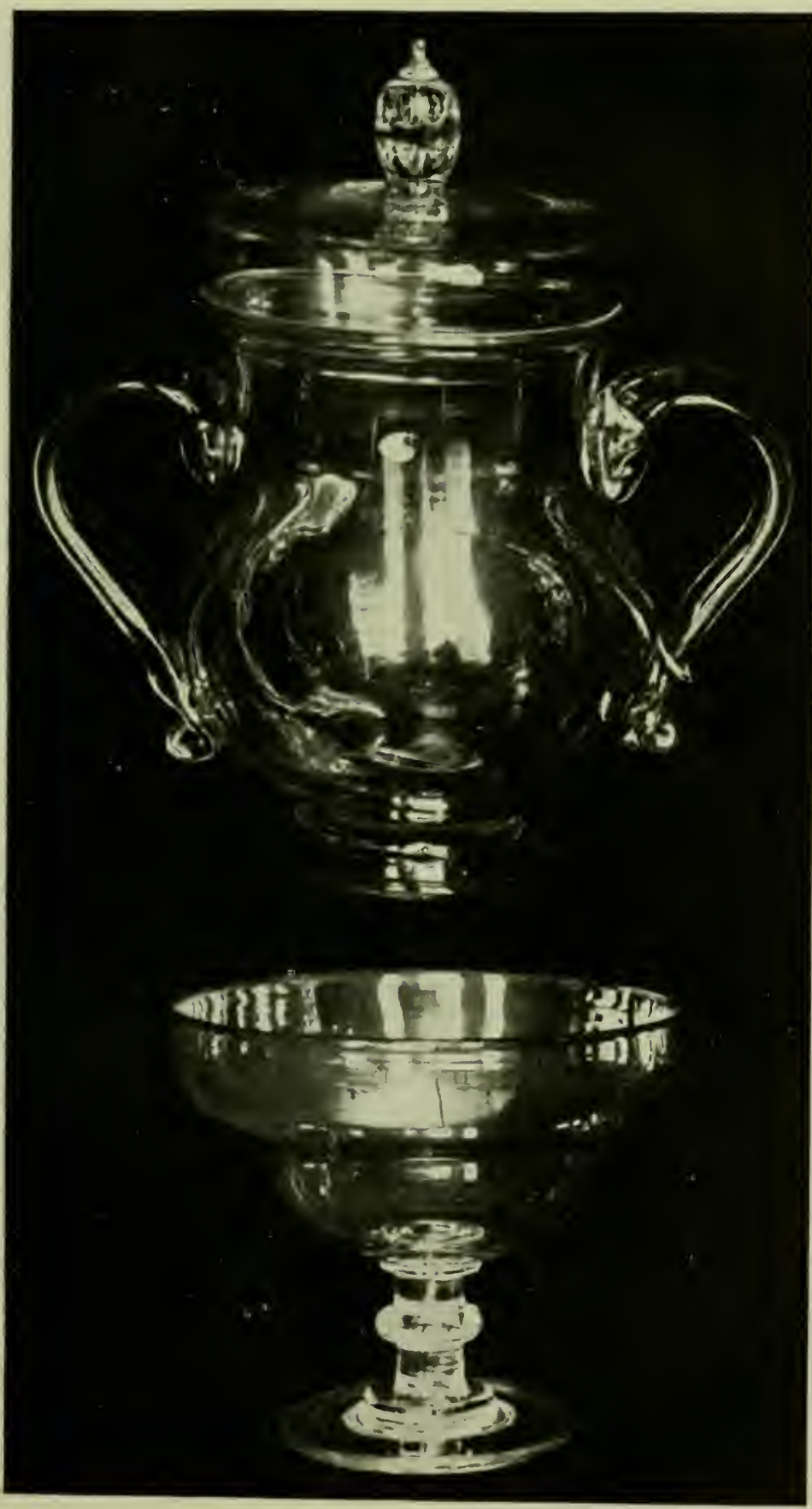


An exceptionally large "Turnover" Cork Bowl, on heavily domed base; early. Flat cutting. 12 in. high. In the collection of Mrs. Magee.

Waterford Canoe-shaped Bowl; deep colour and rare shape; 1780 .

In the Author's collection. 

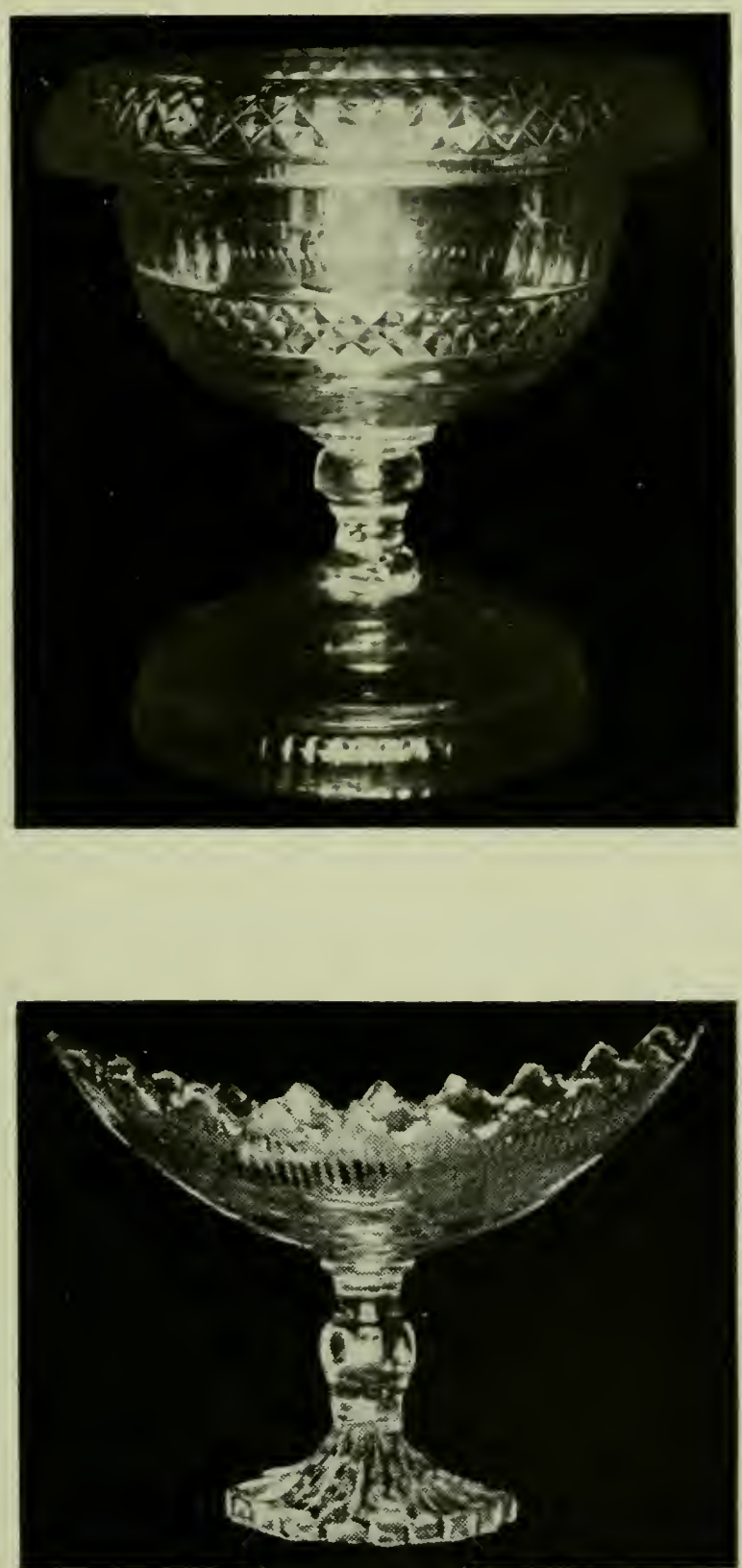
Curious specimen of early IRISH GLASS, engraved. Munster glass. Of a beautiful deep colour. The stand is of Irish bog-oak, Celtic carving, the Irish wolfhound being very carefully executed. In the collection of Commander Swithinbank, R.N. 


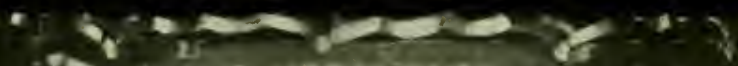

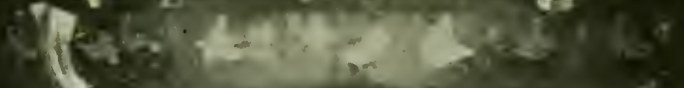

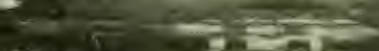

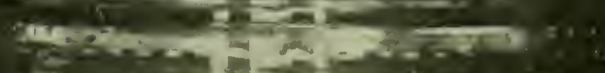

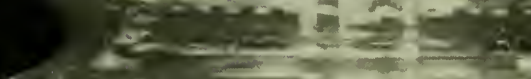

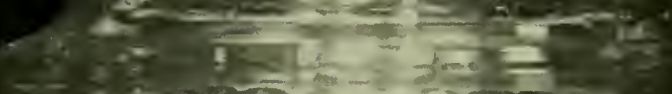$$
\text { (it) }
$$$$
\text { (1) }
$$

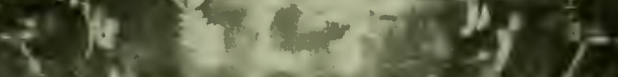

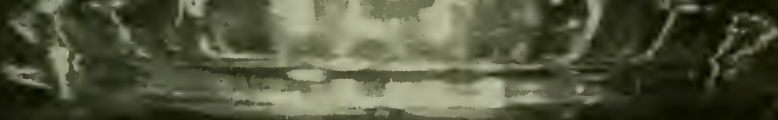

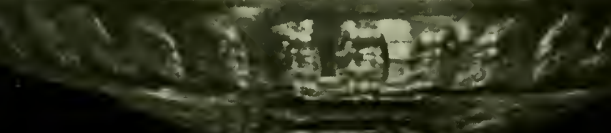

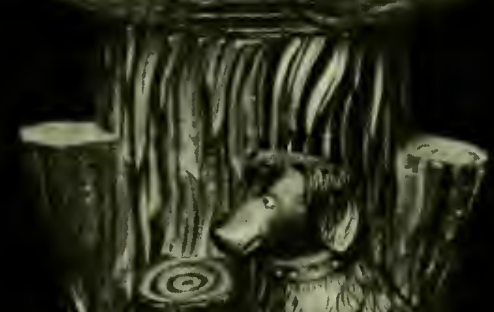

(1) $=1,120$

5.)

20 -

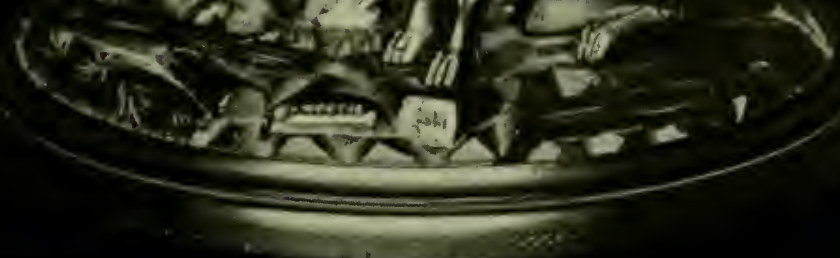


Two-handled Cup and Cover, heavy clear glass; circa 1780. Dublin (copy of Bristol but much heavier). Author's collection.

Waterford Bowl and Stand, cut all over with large, flat double stars; circa 1780.

Author's collection.

Strawberry and Fan Cut Bowl. Made at Waterford in 1790 , and bearing the Stannus crest, finely engraved. Author's collection. 


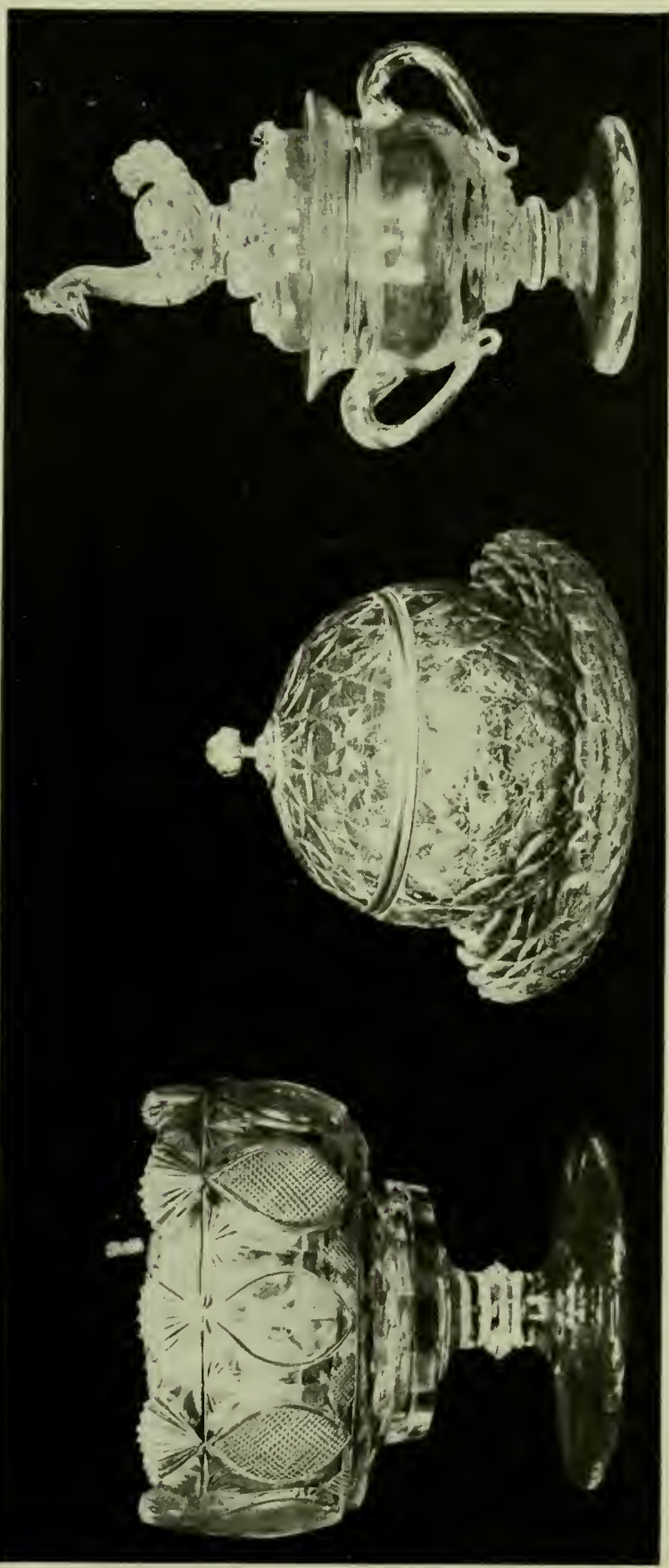


A giant "Turnover" Round Bowl and Dish. Waterford, circa 1815.

In the Author's collection.

Octagonal Deep "Step" Cut Waterford Dish, circa 1825. A very unusual specimen.

In the collection of Mrs. Oliver. 

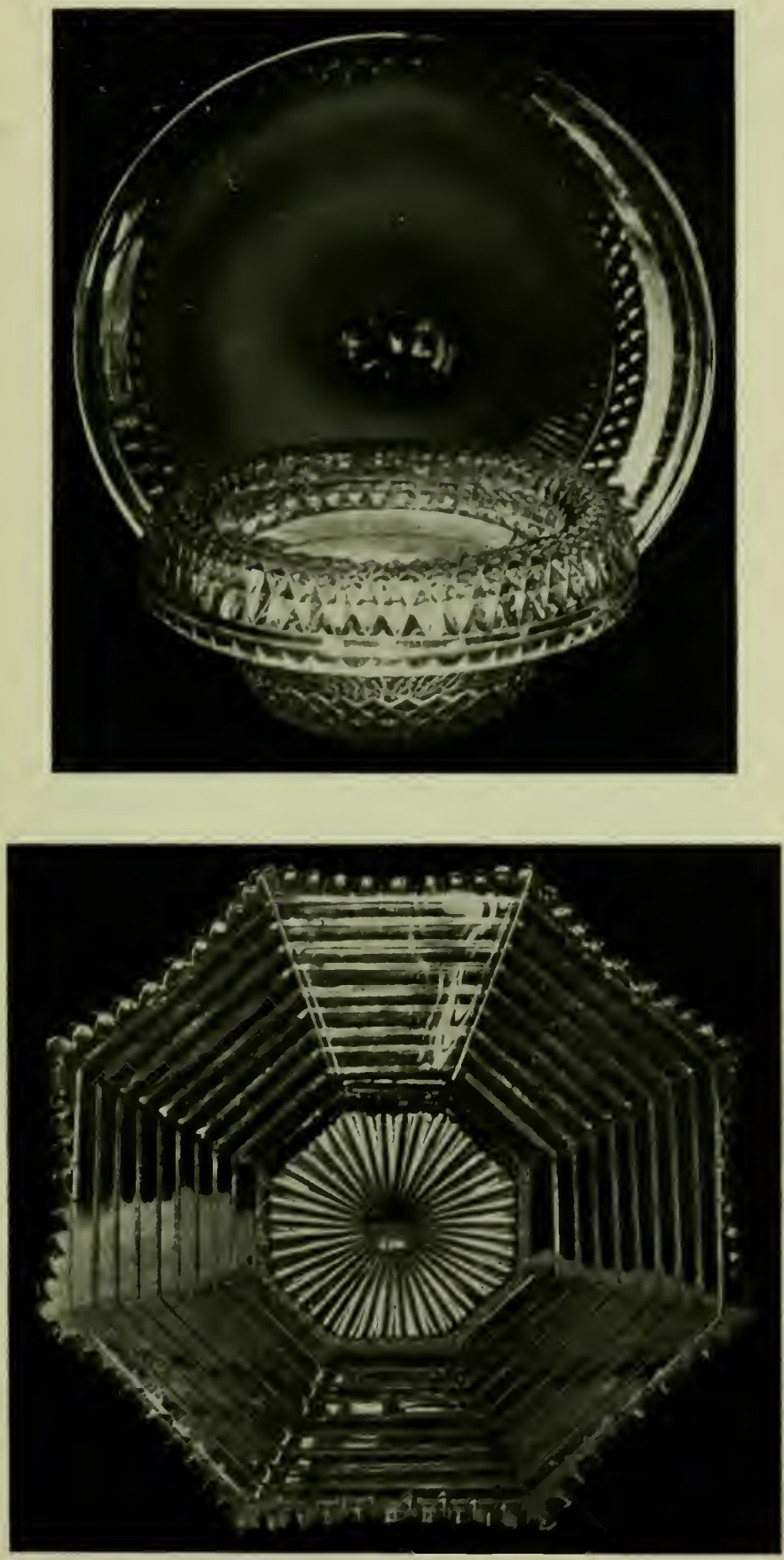
Set of "Step" Cut Dishes with fan handles. Waterford, circa 1820.

In the collection of Mrs. Hall. 


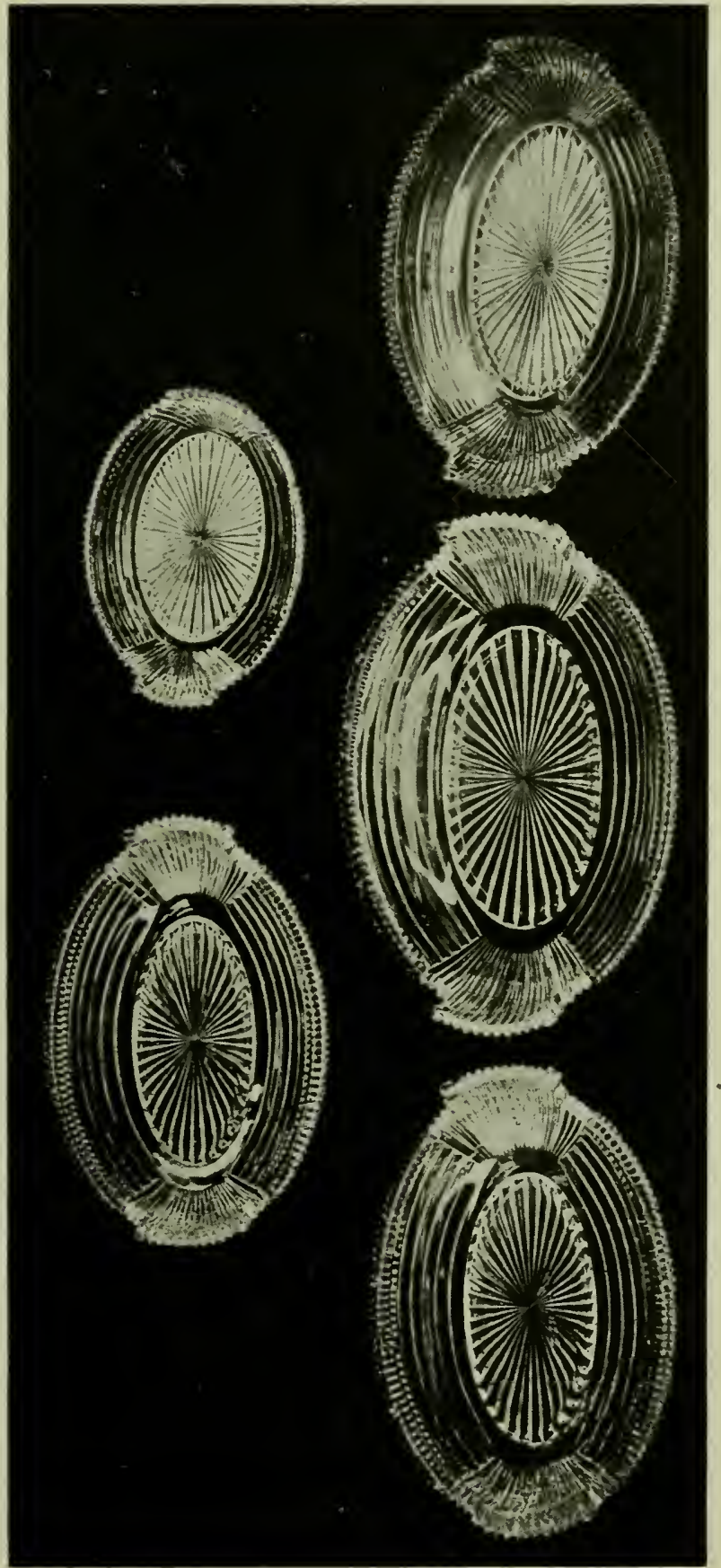


Pair of Baxqueting Tazze, Munster glass of about 1790. Made of heavy.dark glass in one piece, with a heavily domed foot, and finely cut in slash and diamonds. They are $13 \mathrm{in.} \mathrm{high,} \mathrm{and} \mathrm{weigh} 32 \mathrm{lbs}$. each. In the collection of Mrs. Hall. 

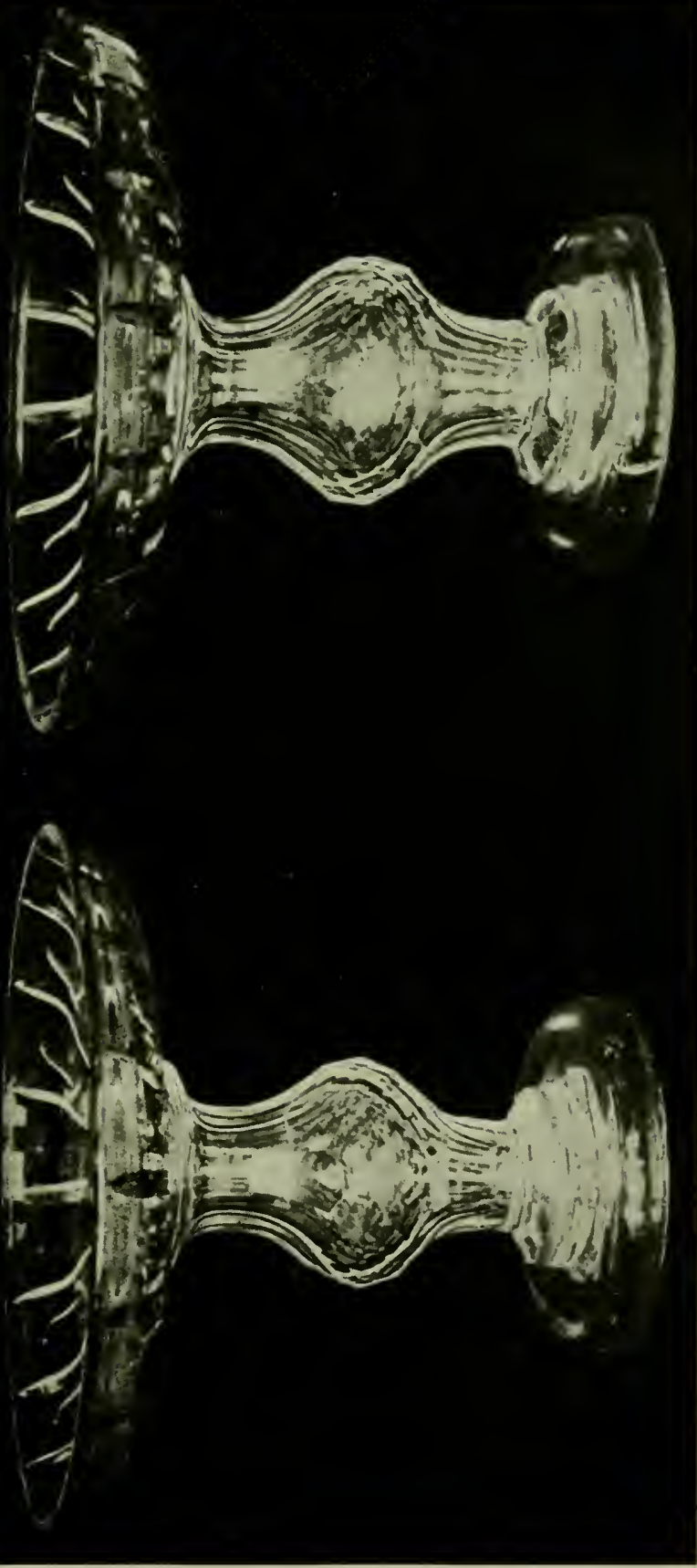


\section{CANDELABRA, CANDLESTICKS AND CHANDELIERS}

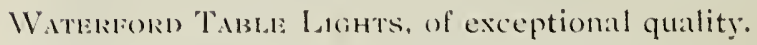
In the collection of Mr. Fitzroy Chapman.

IVAtakford Guass Chimney Sizt, draped with deep "potmetal" blue drops. Probably Dublin, circa 1790. Author's collection. 

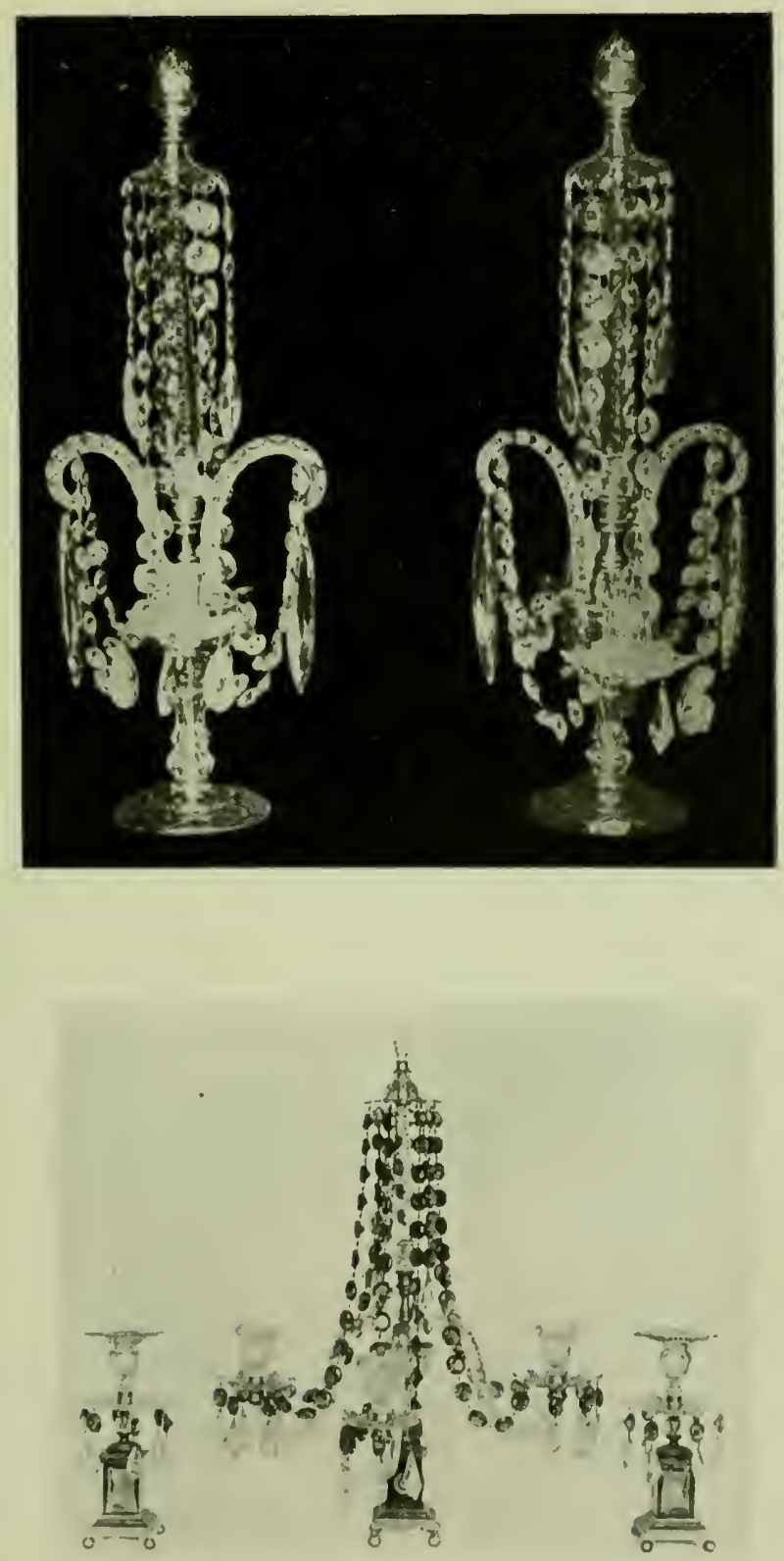
Pair of Adam Table Lights on Ormolu. Irish glass, with very pale amber drops cut in flat facets. Circa 1780. In the possession of $\mathrm{Mr}$. Hobson.

Pair of Waterford Table Lights, hung with the palest amber round drops (Dublin), and mounted on Wedgwood urns. Late Adam period.

Mr. Hugh IVeguelin's collection. 

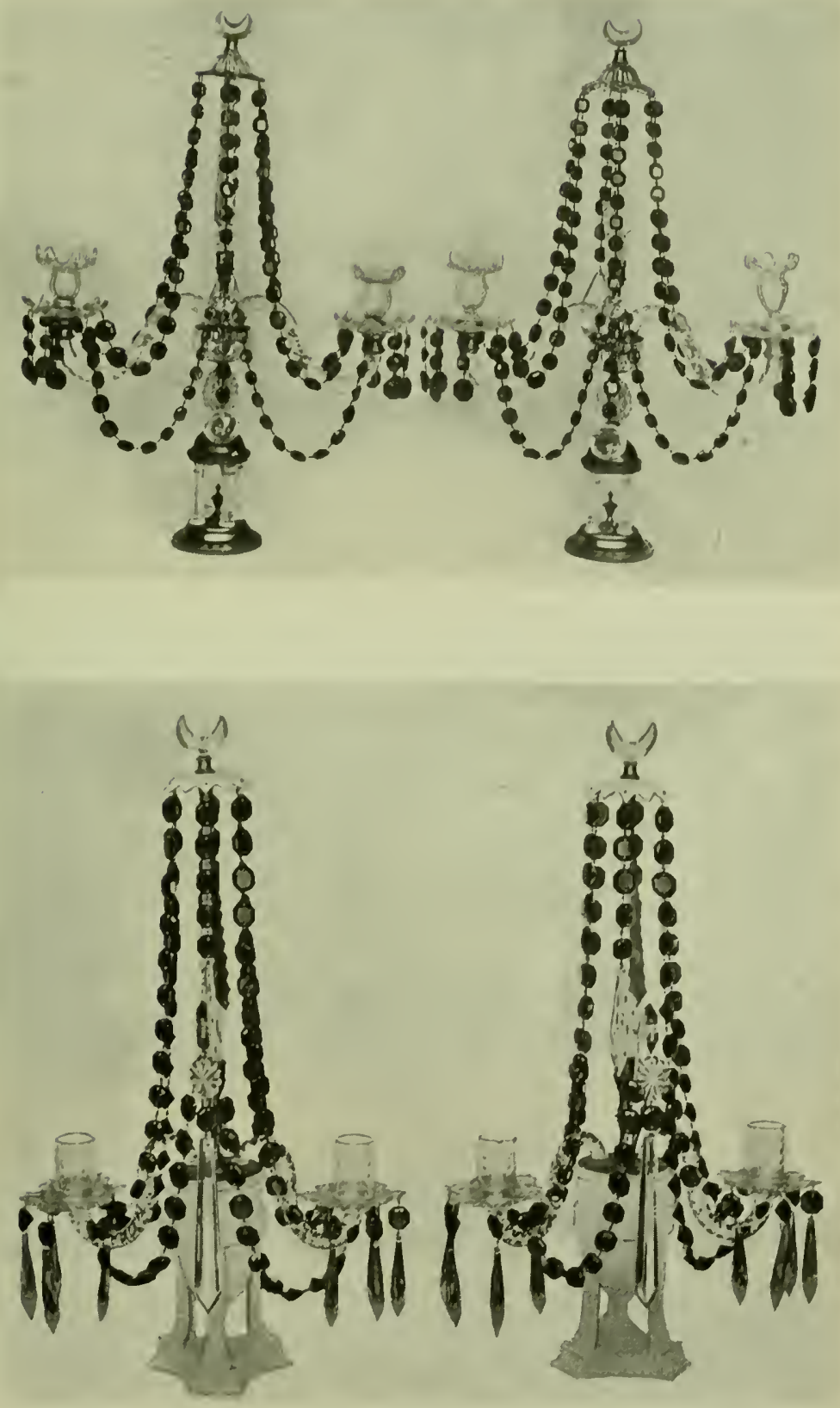
Three Waterford Facet-cut Table Lights, with almondshaped drops. 1780 ( $\operatorname{circa})$.

Mr. E. Parsons' collection.

Three Waterford Table Lights, Adam period, 24 in. high, with "almond" drops.

Major Pope's collection.

Collection of Early Coris, Waterford, and Dublin - Glass Candlesticis, from one moulded heavy toned glass (1750), to the tall facet-cut varieties of $1780-1830$. 

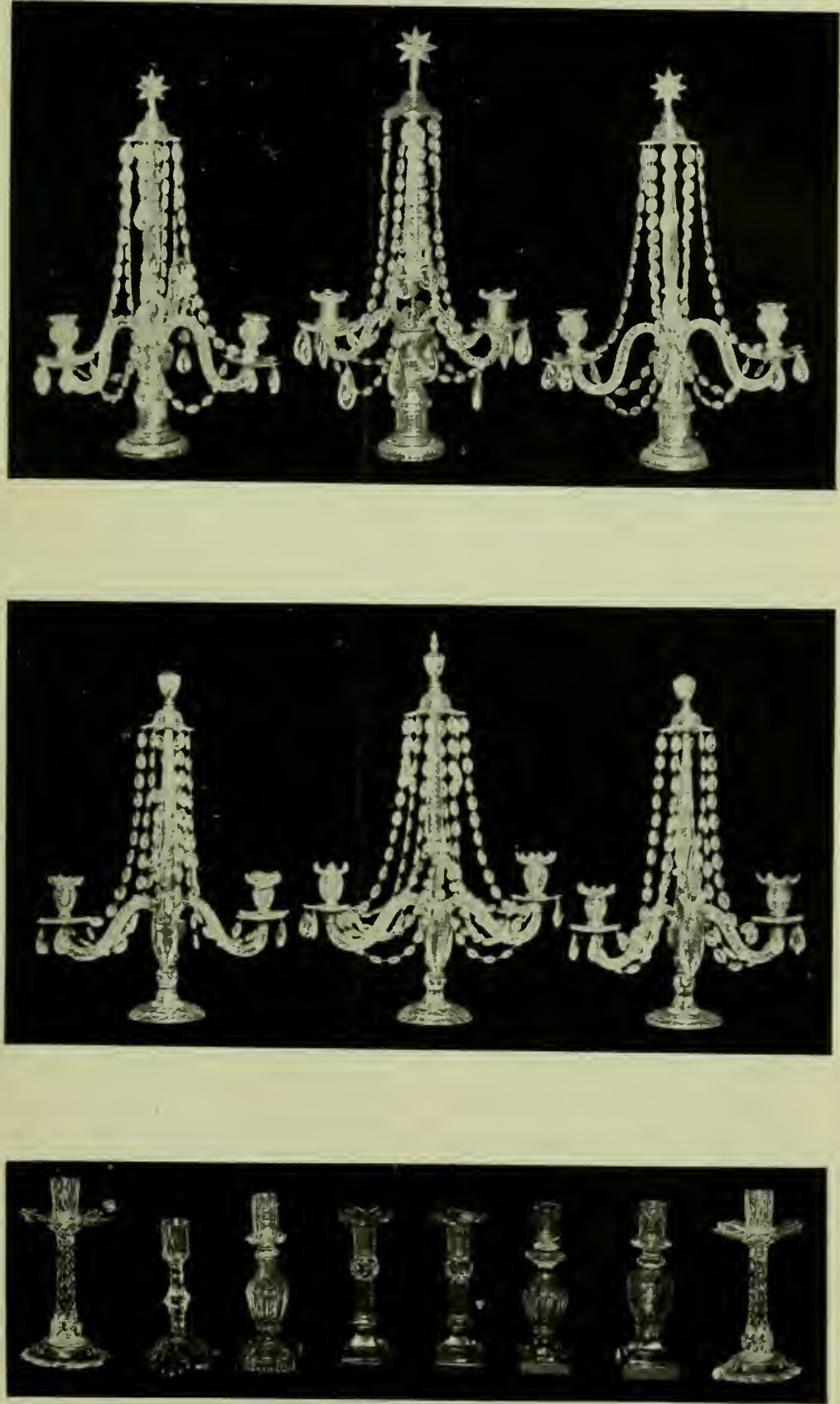
One of a pair of Aman Lisints, $4 \mathrm{ft}$. high. Waterford glass, on old marble "Bosi" work pedestals. Slightly restored.

Author:s collection. 


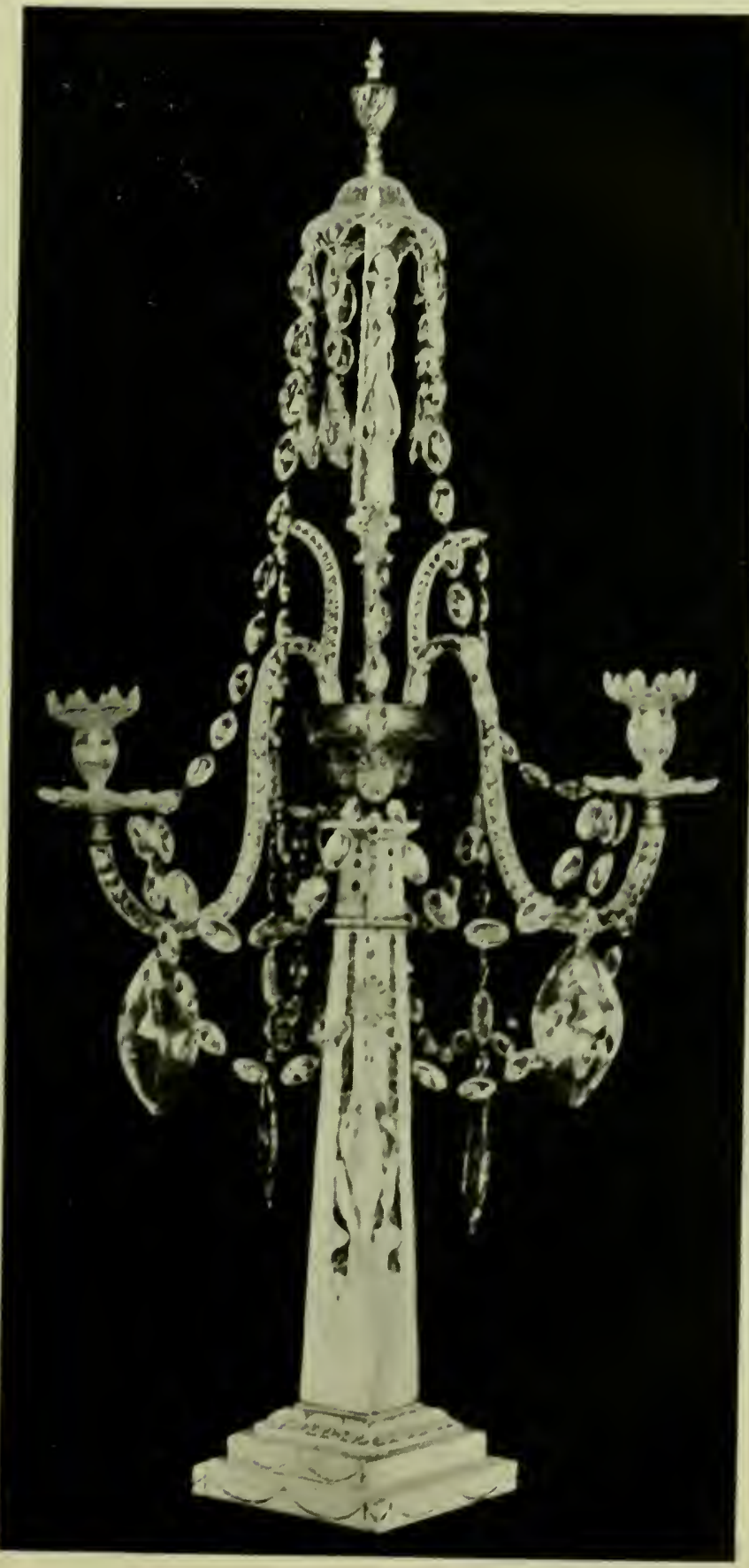


Typical pair of IVATERford Table Lights, early Adam period, with facet-cut "reflecting" drops, which throw out prismatic colours when the candles are lighted. 20 in. high.

Mr. J. Parson's collection. 


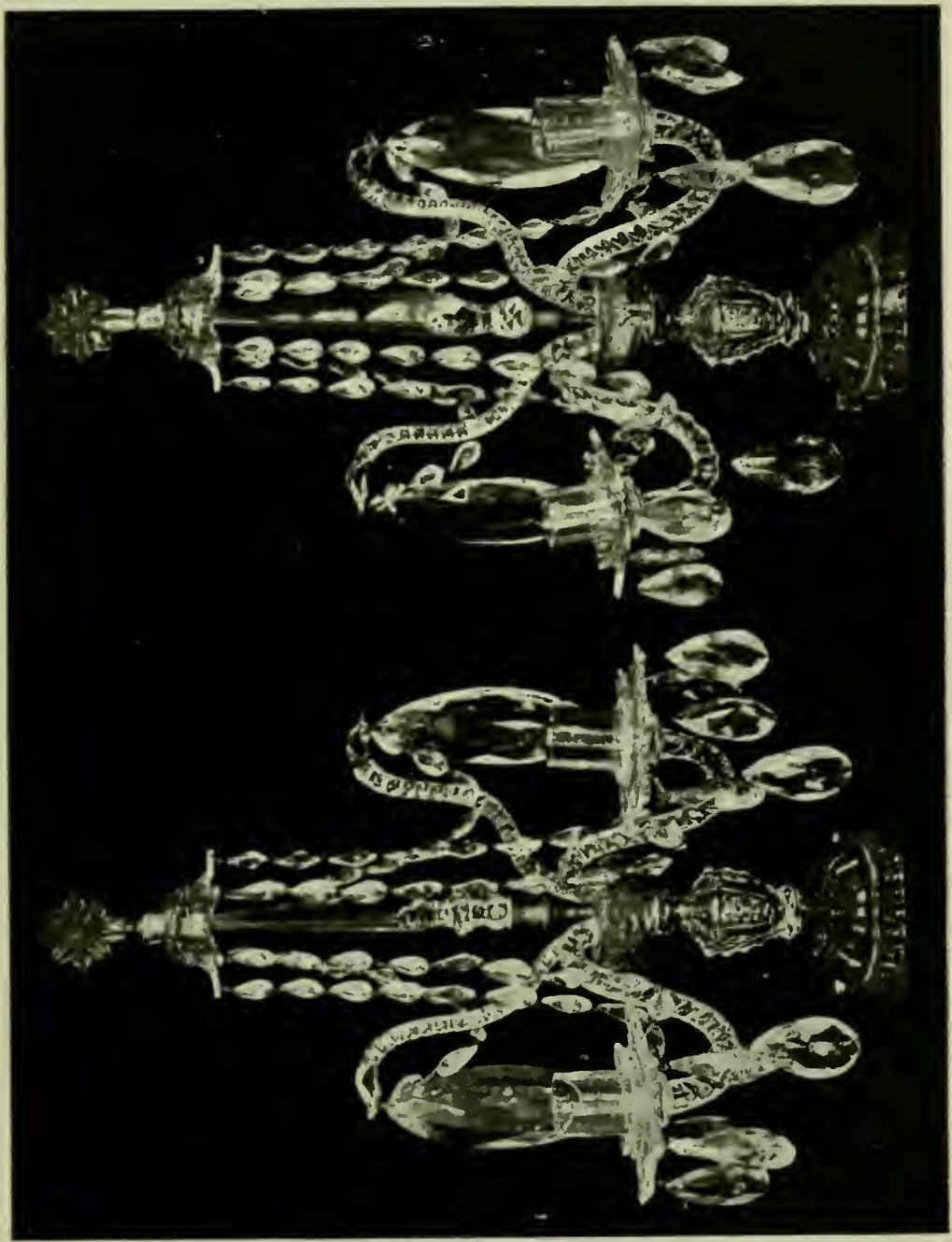


Wathrfori) Chandelihr, circa 1780.

Mrs. Cox's collection.

Eariy Watirford Candisabra and pair of Canidissrrers with facet-cut ormament.

Colonel Jenner's collection. 


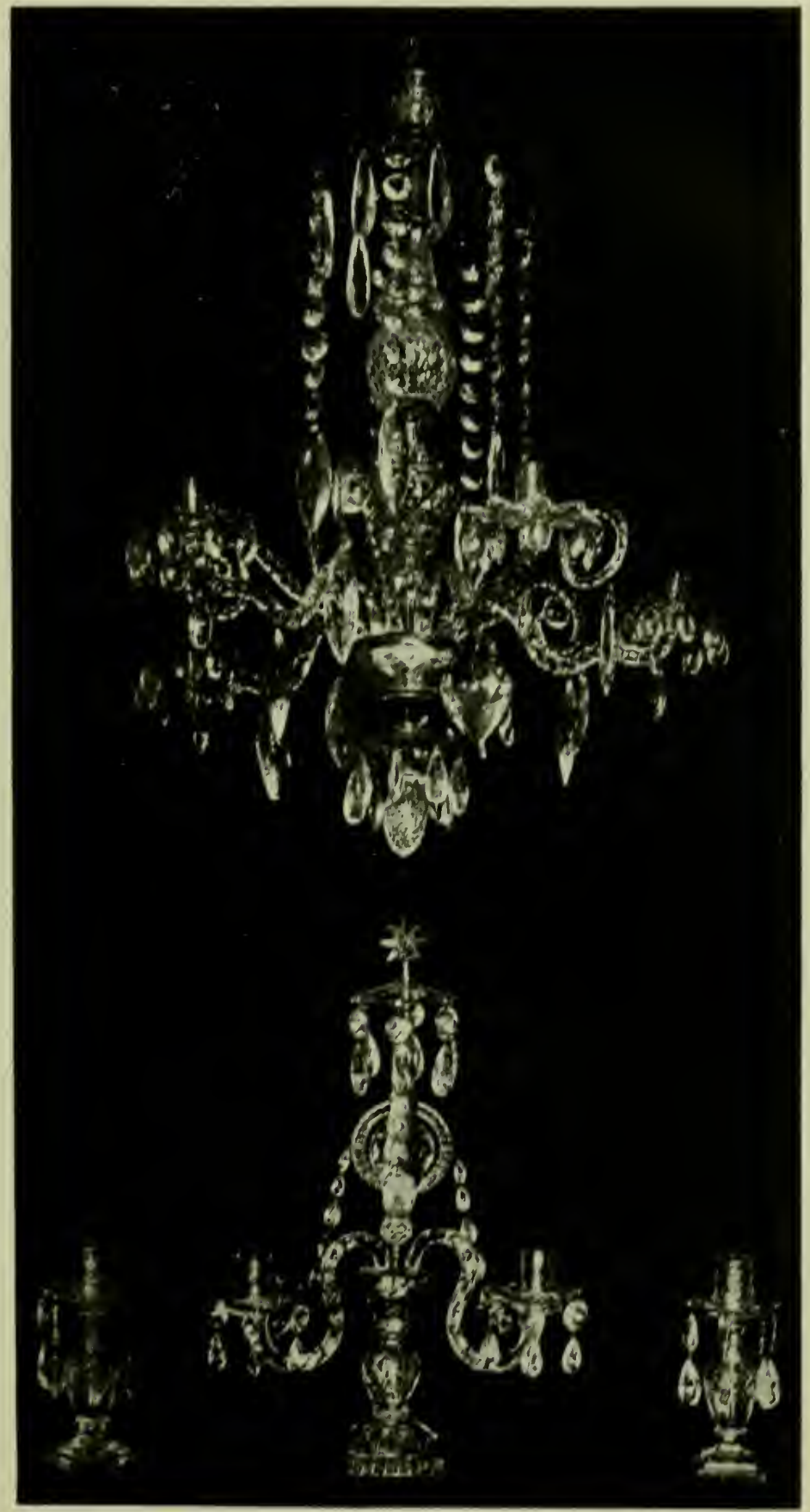




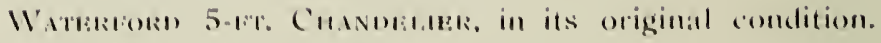
Aram period.

In the Author's collecturn. 

() 1.11

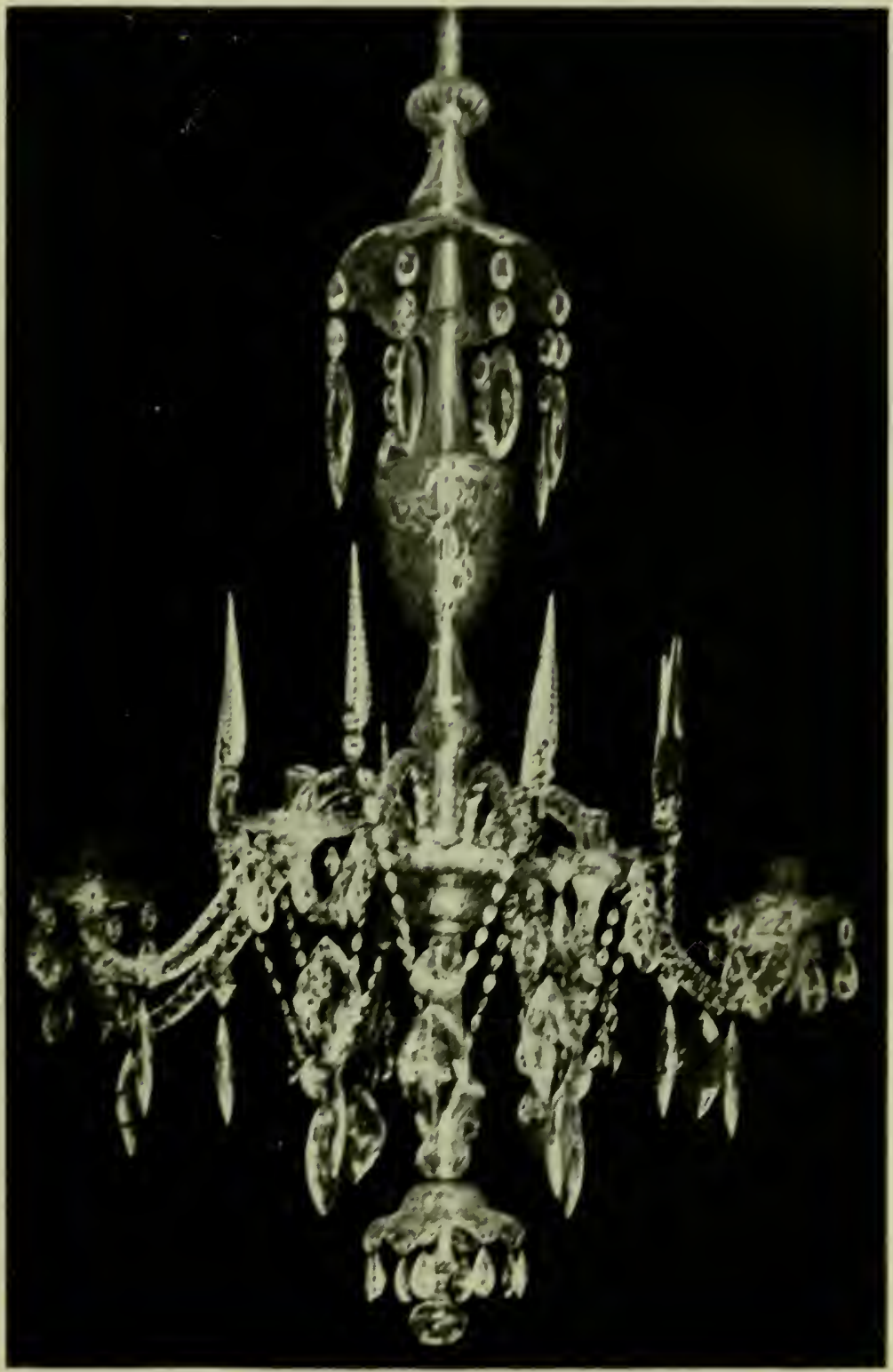


Adam Chandelier, Waterford, in its original condition. In the Author's collection. 


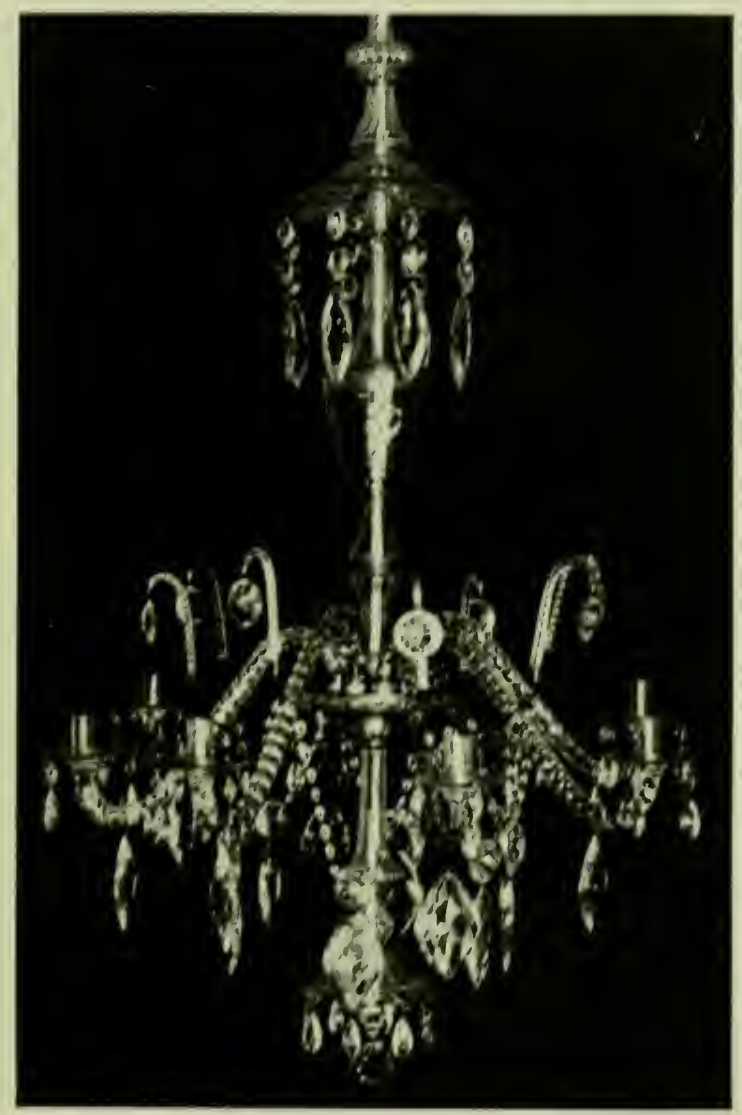




\section{DECANTERS, JUGS, AND BOTTLES}

Shapen Waterforn Jug.

Author's collection.

Unique Jus, ordinarily termed a freak piece, $25 \mathrm{in.} \mathrm{high.}$ Irish giass, circo 1760 .

Author's collection. 

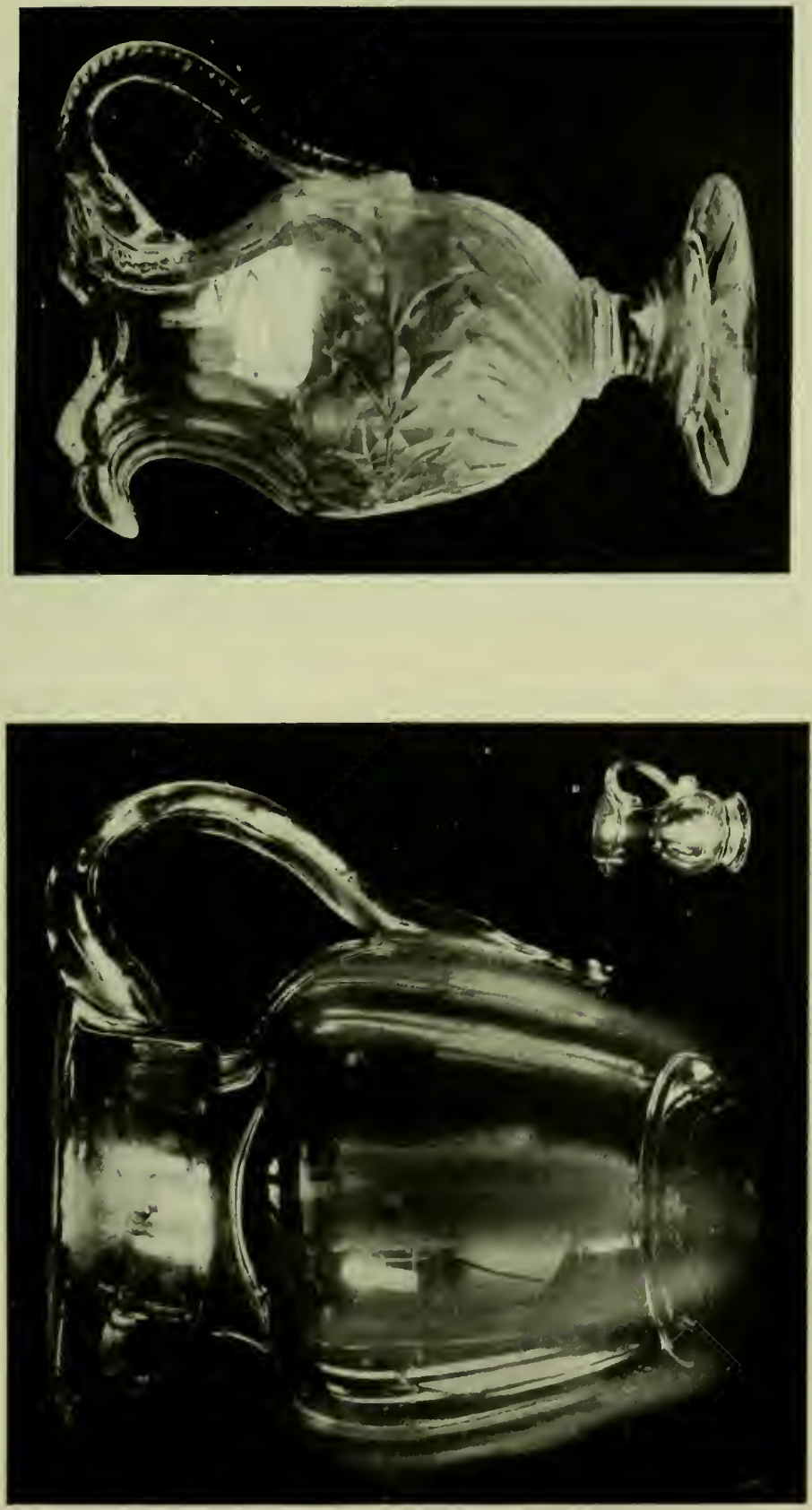
Pair of heavy old Munster Glass Liqueur Bottles and an Early Blown Irish Glass Decanter, engraved. Author's collection.

Early Blown Cork Decanters, with the primitive engraving of the period. These decanters are impress marked "Cork Glass Co."

Author's collection. 

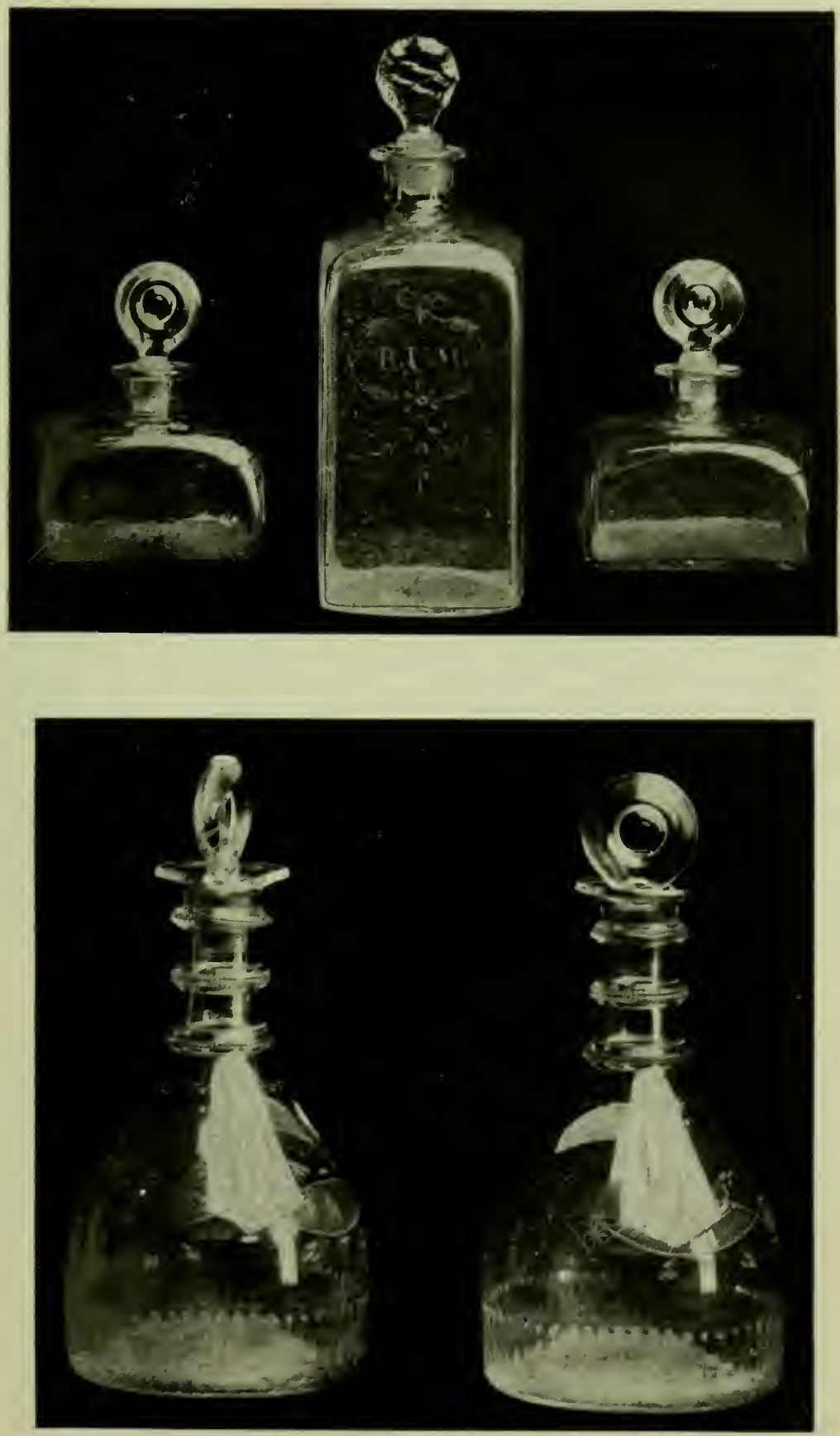
Tankard, Waterford or Cork, circa 1780.

Tivo-handeed Spur Cup, probably Dublin, 1750; deep toned glass, very soft to the touch.

Author's collection.

Heavy Lustre Cut Jug, flint glass, circa 1800.

Commander Swithinbank's collection.

Swag and Diamond Cut Watelpford Decanters, circa $1780-90$.

Author's collection.

Step and Prismatic Cut Liglielr Bottles, Waterford, $1820-50$. 

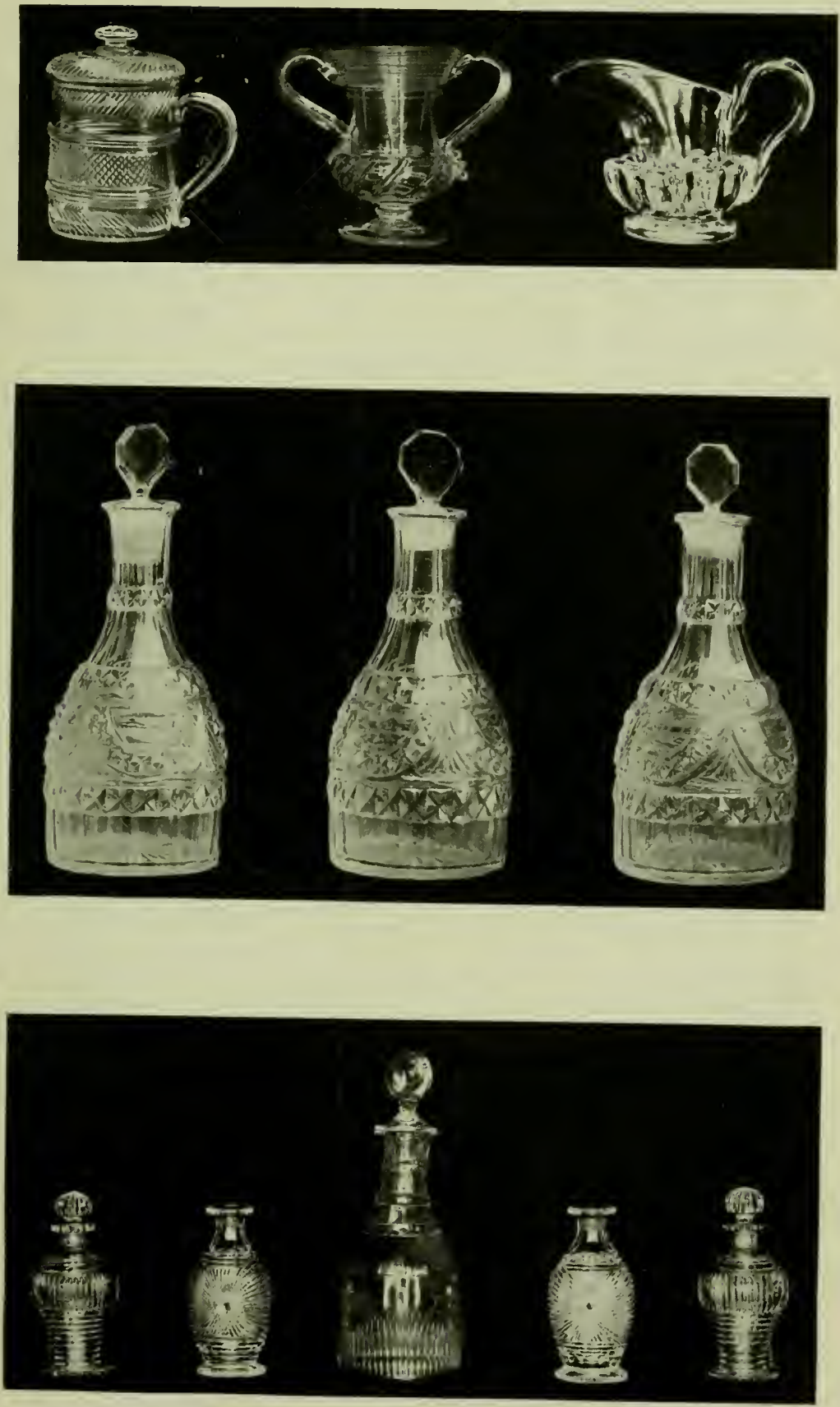
Set of Earty " Mlunster" Jugis.

In the Author's collection. 

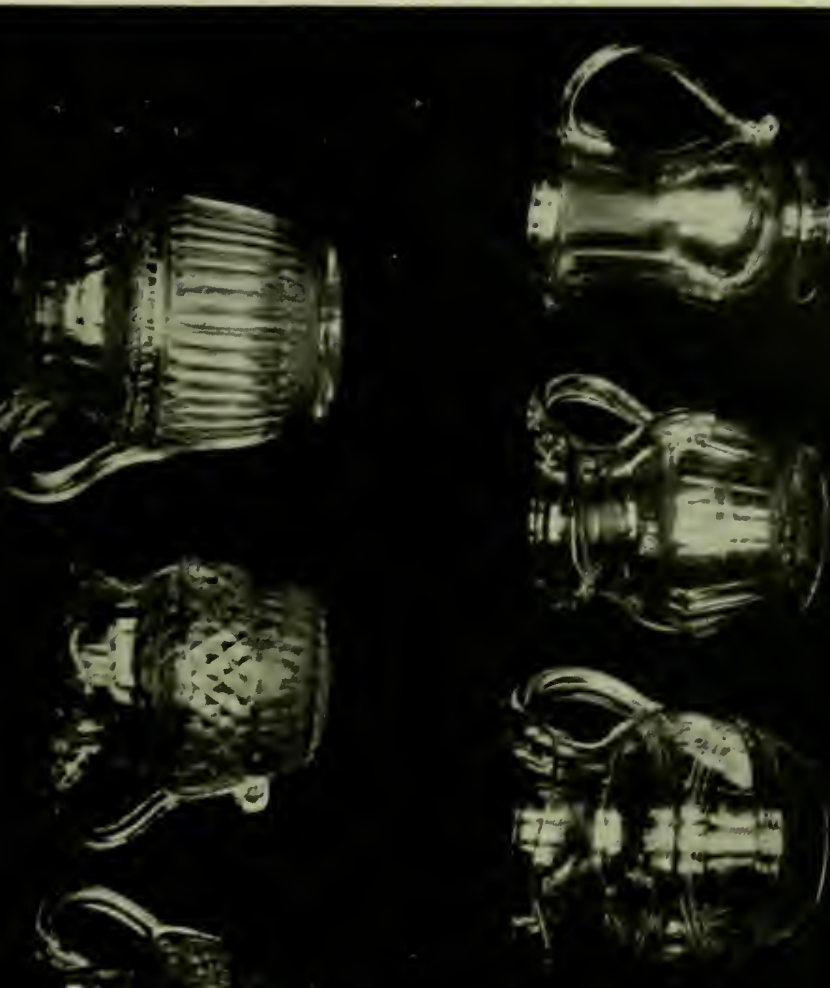

$-1$
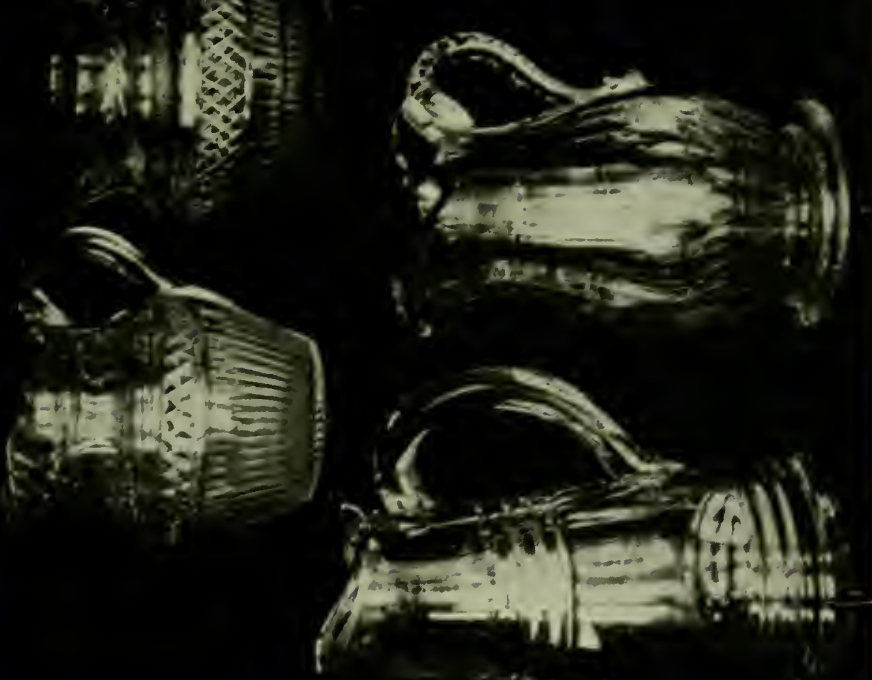
Set of Eariy "MUNSTER" Decantzks. In the Author's collection. 


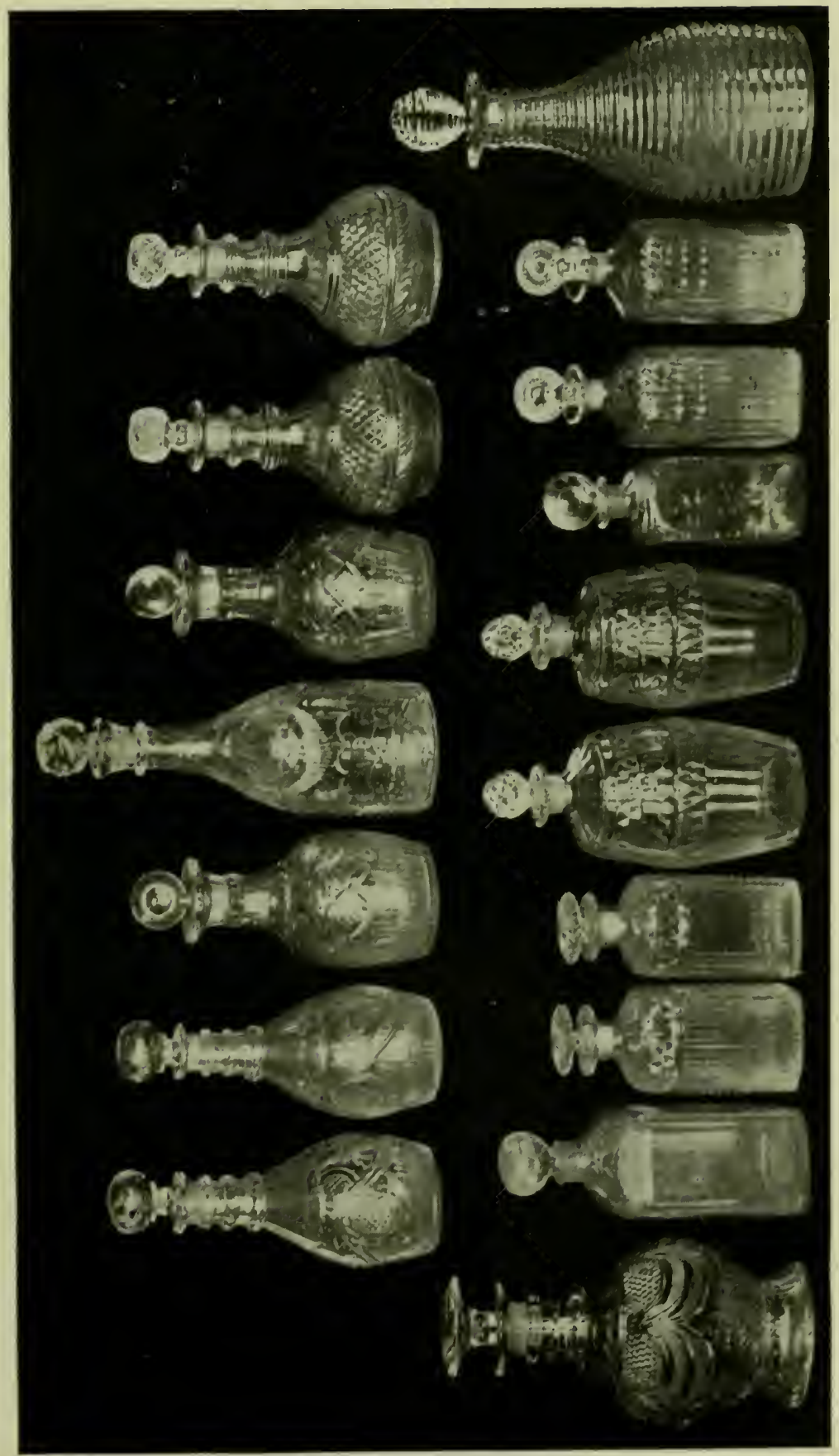




\section{GOBLETS, CUPS, AND CHALICES}

Chalice, 1790-1800. Sharp diamond cut, 13 in. high. One of the rarest pieces of Irish glass.

In the collection of Mrs. Hall. 


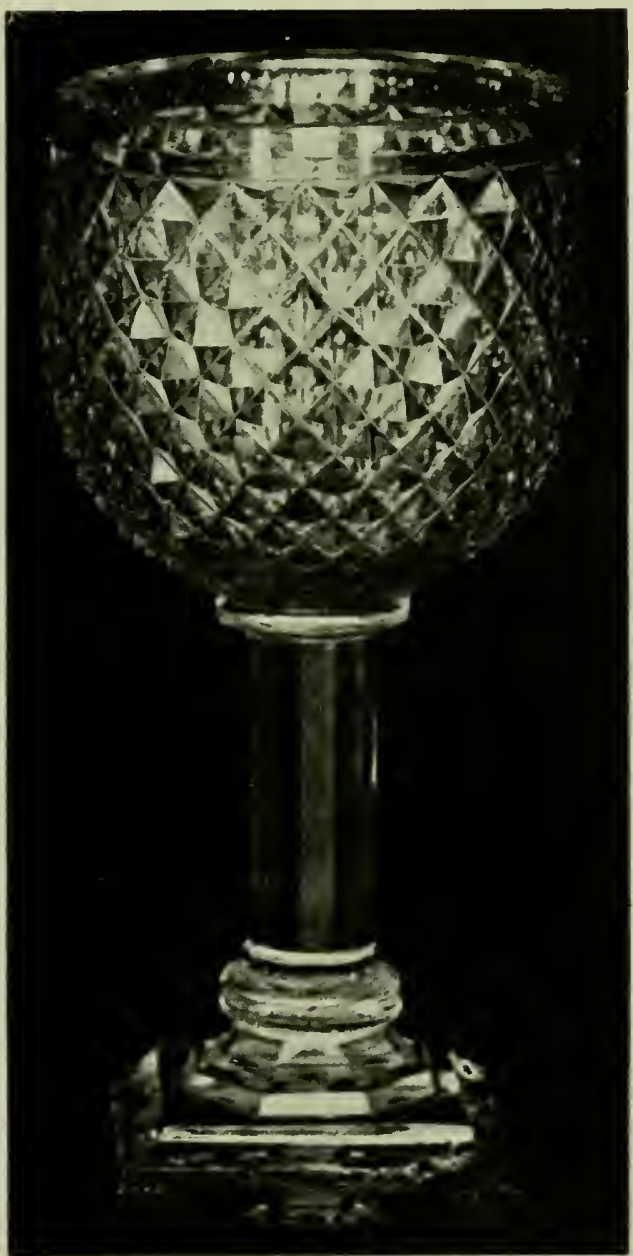


A rare Chalice. Munster glass, 1790-1800. Author's collection. 


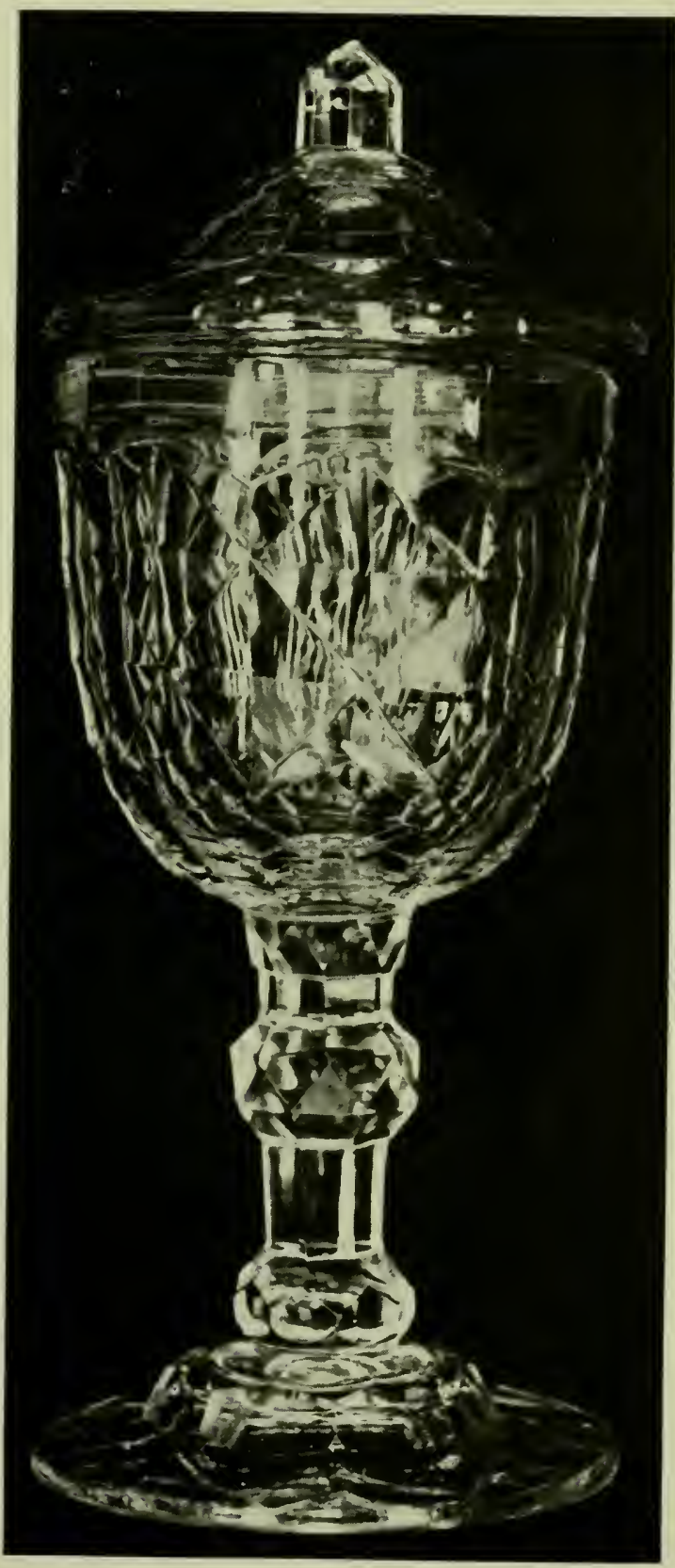


Irish Goblets. "Cheering Glasses," and three remarkahly heary Salt-cellars. Waterford.

A set of Dublix "Lustre Cut" Goblets, circh 1850 . The property of Mr. David Blair, who has a similar set of tumblers.

EARLy Sweiminats. Irish glass, moulded 1760-70. Author's collection. 


\section{OLD IRISH GLASS}
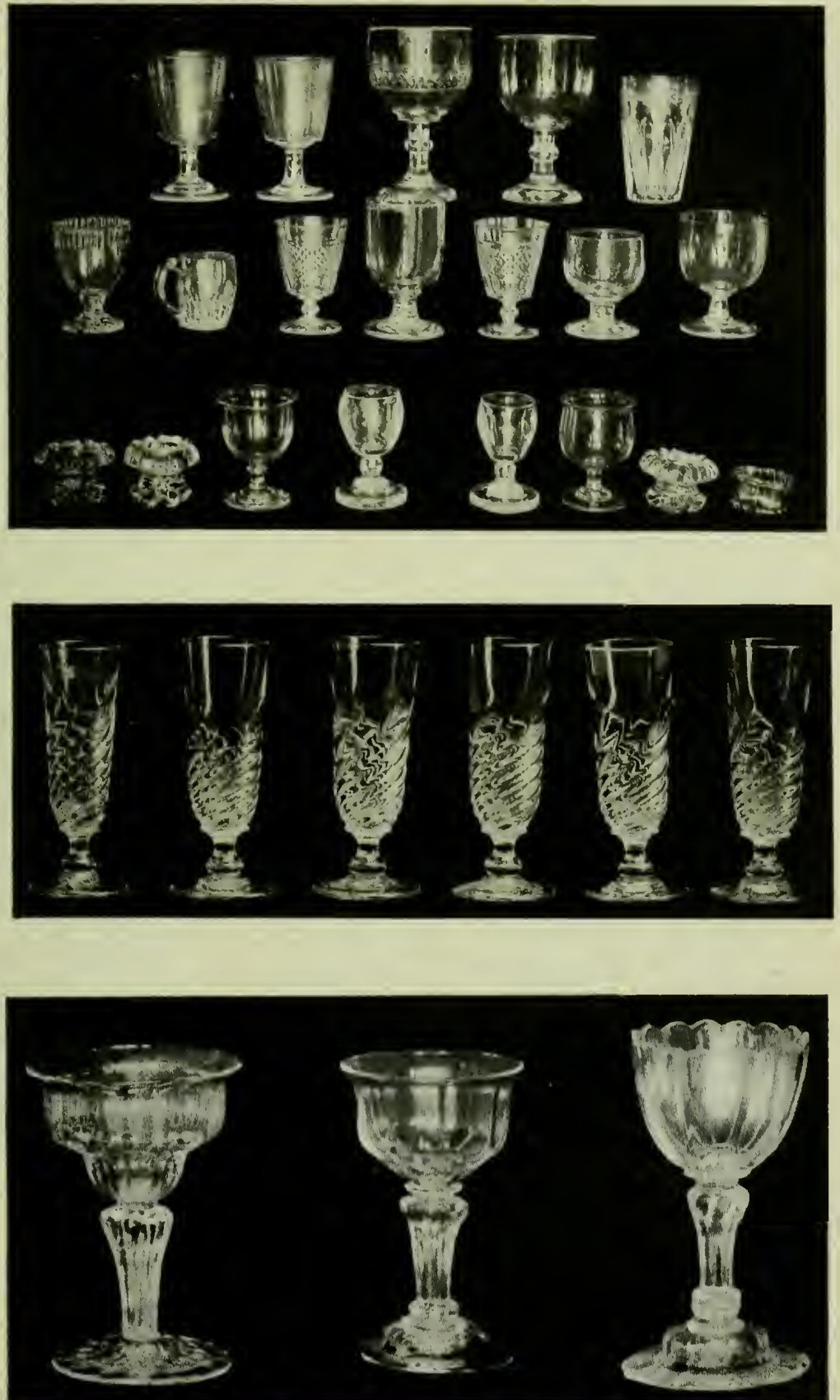


\section{SWEETMEAT STANDS}

Moulded Sweetueat Staxd, with two candle sconces. Early Cork.

Mrs. Magee's collection. 


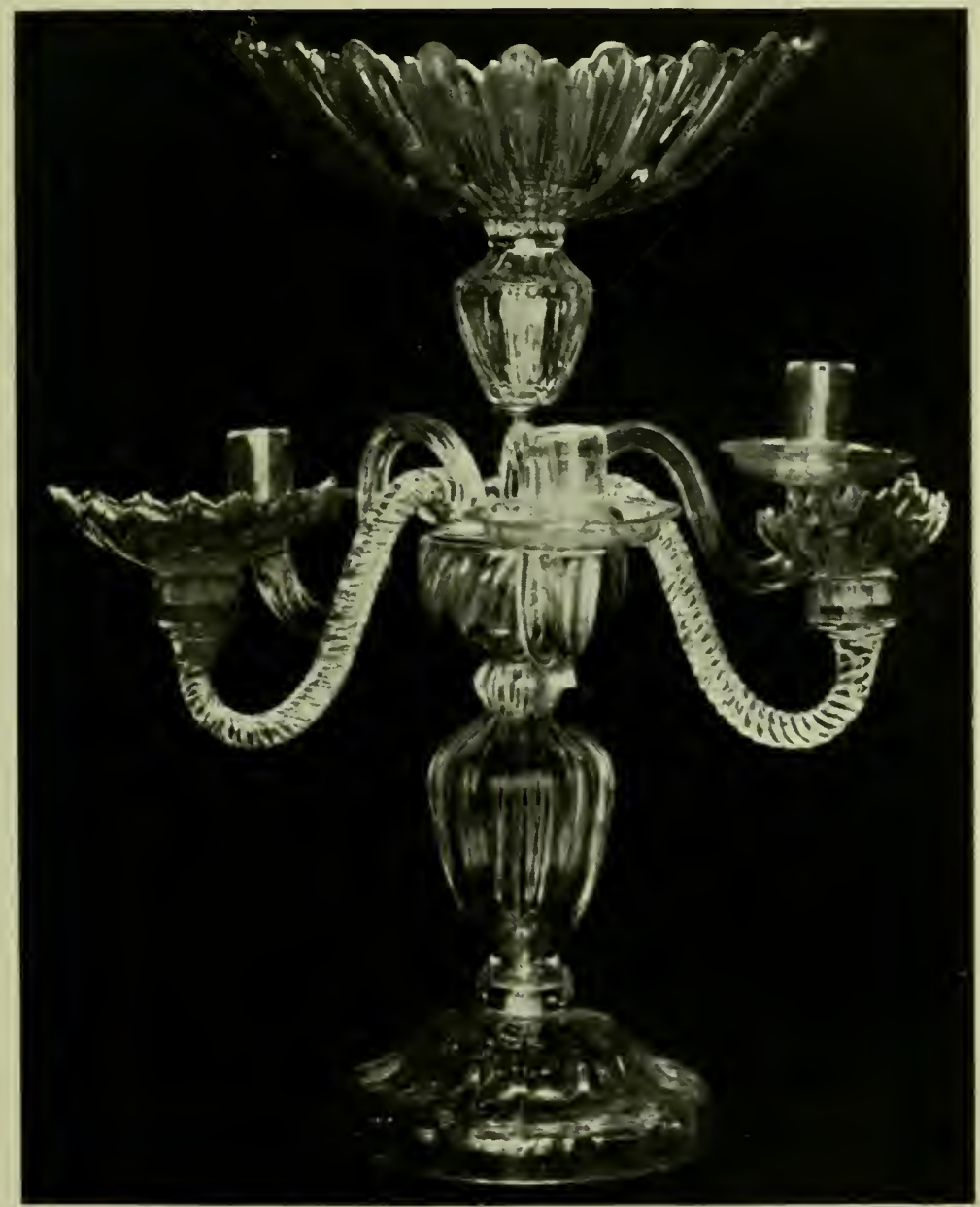


A Wateklord Baslet Sweetmeat Staxd, $24 \mathrm{in.} \mathrm{high.}$ Author's collection. 


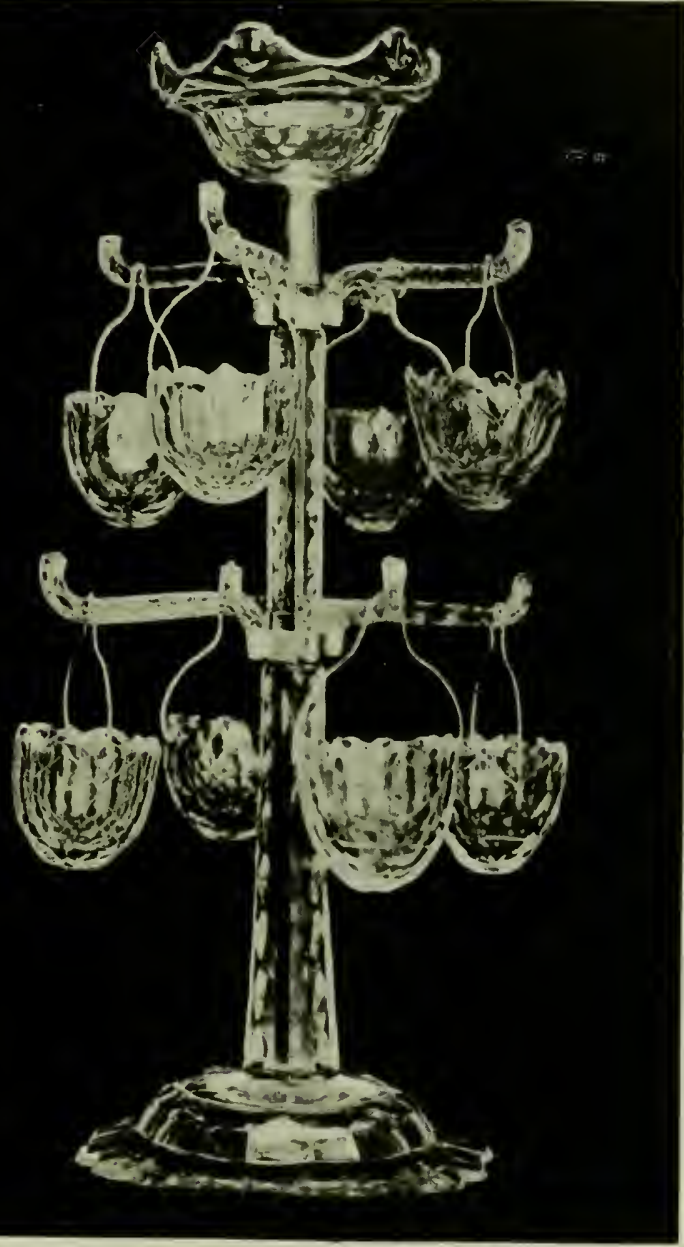




\section{TABLE SERVICES}

An entire early Waterford Dessert Service. Early leaf cutting, "drawn stem" wine-glasses.

In the possession of the Hon. Mrs. Vicliers. 


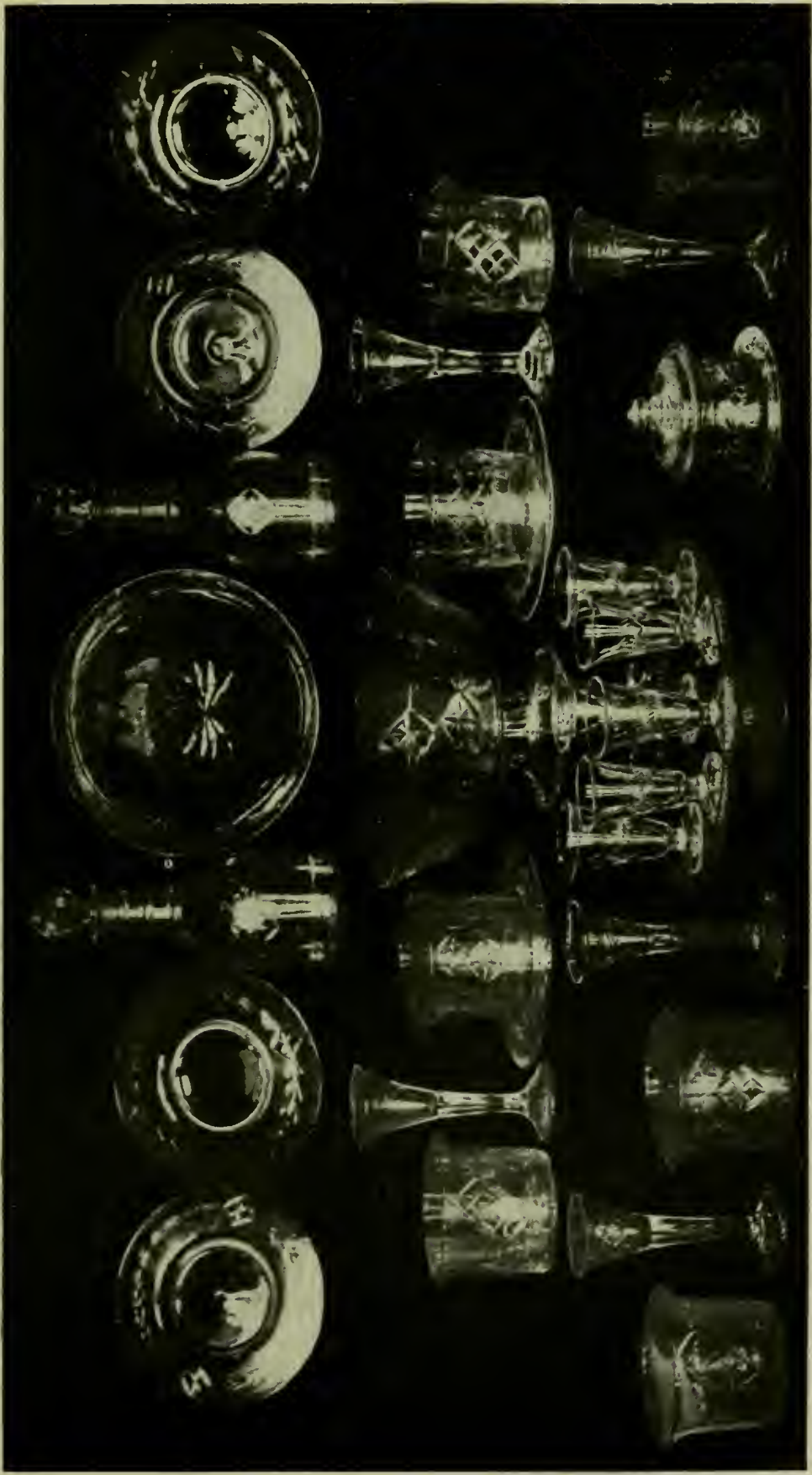


IVATERFORI) DESSERT SERVICE, circa 1770.

In the collection of Major Pope.

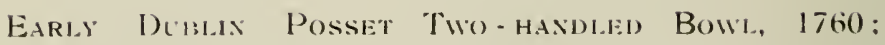
Fiat Fiask, 1770: Goblets, Mugs, and Tea Canmo of early dates. 

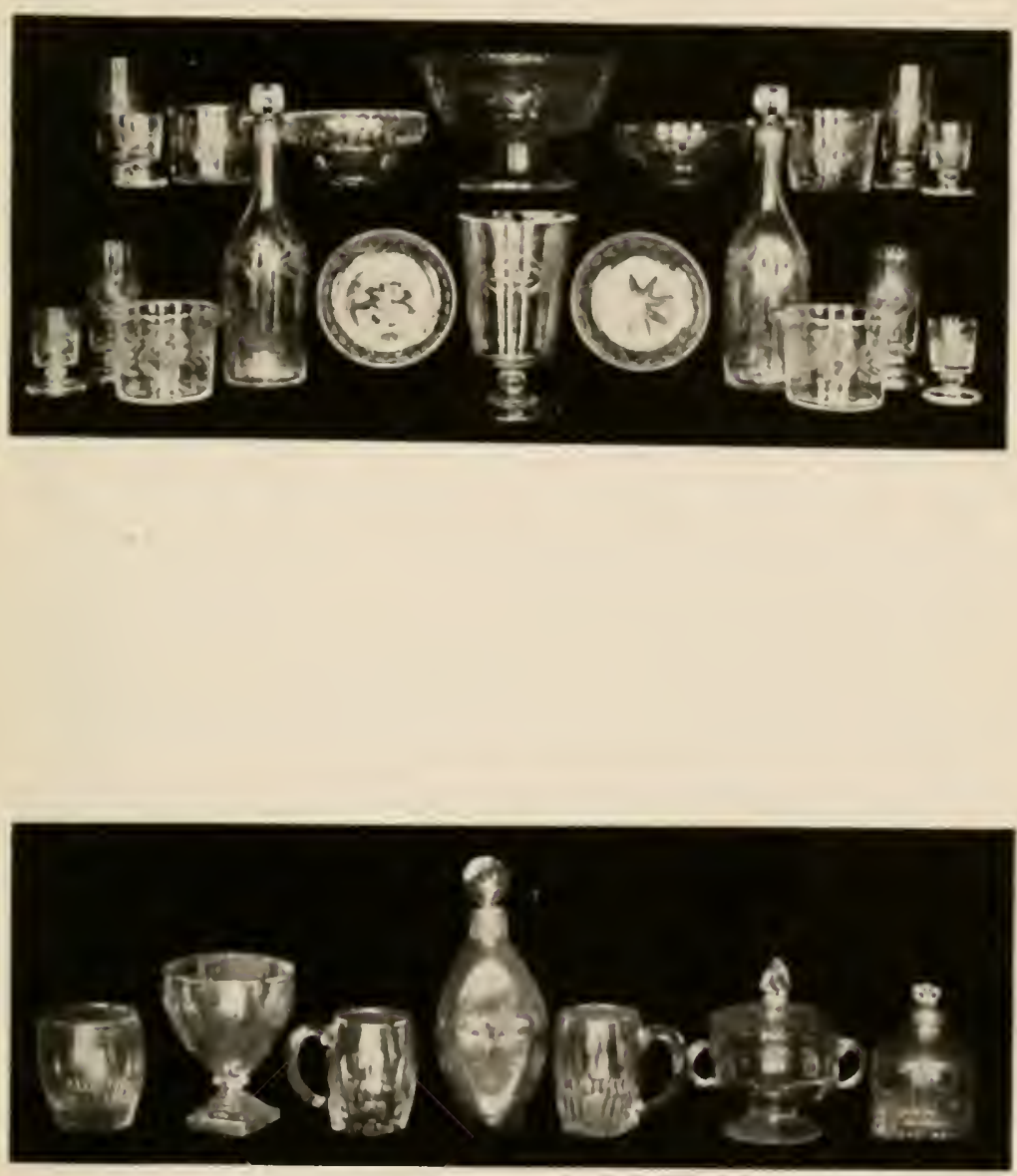
Table Service of Engraved Coris Glass, early Adam period. Glass older than the engraving.

In the collection of Mr. Robert Frank. 


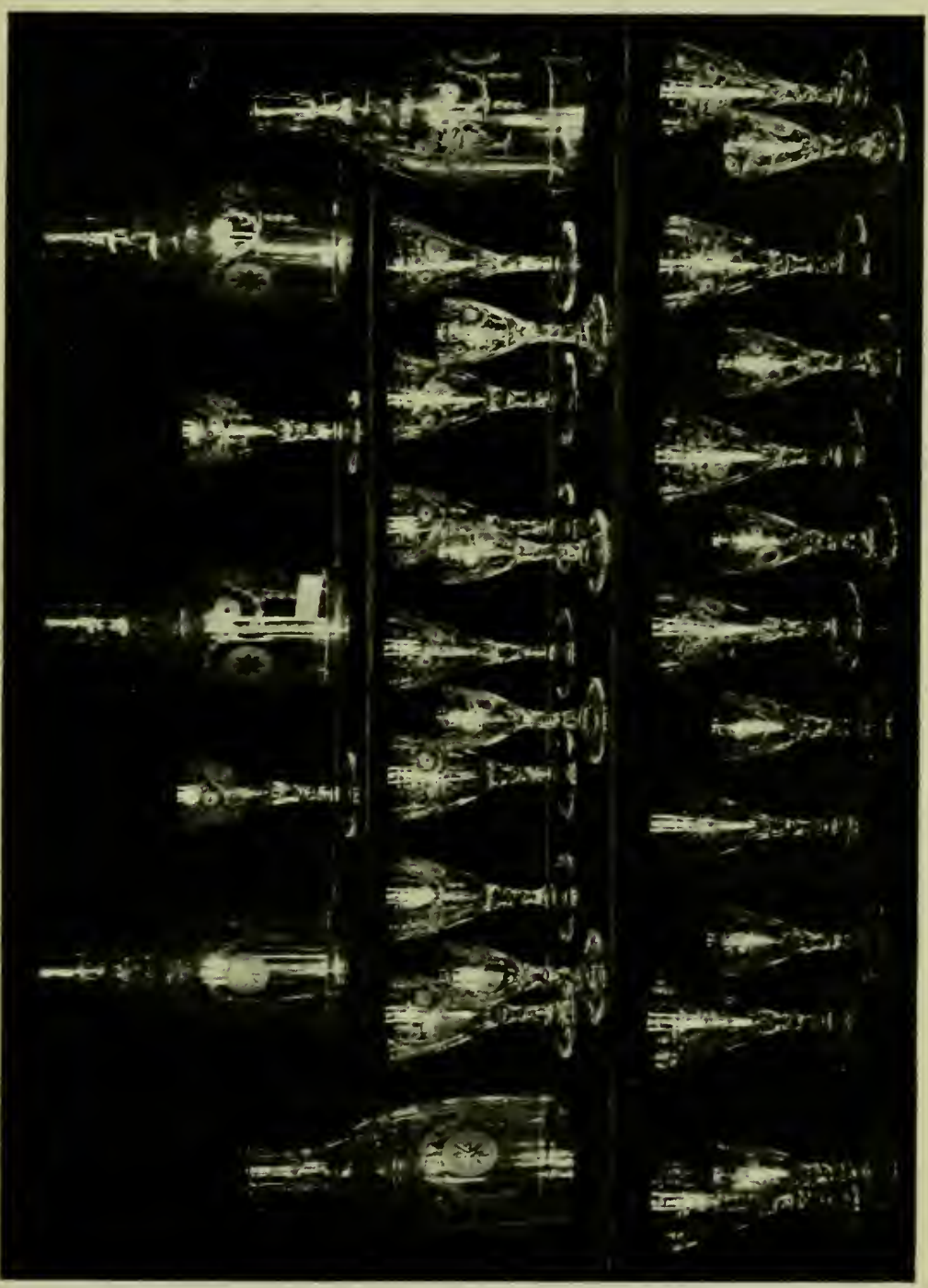




\section{URNS, HONEY POTS, SALTS, ETC.}

Four tall URNs, Cork and Waterford. Those on left and right are exceptional, being $22 \mathrm{in}$. high, and very early.

In the collection of Commander Swithinbank, R.N. 

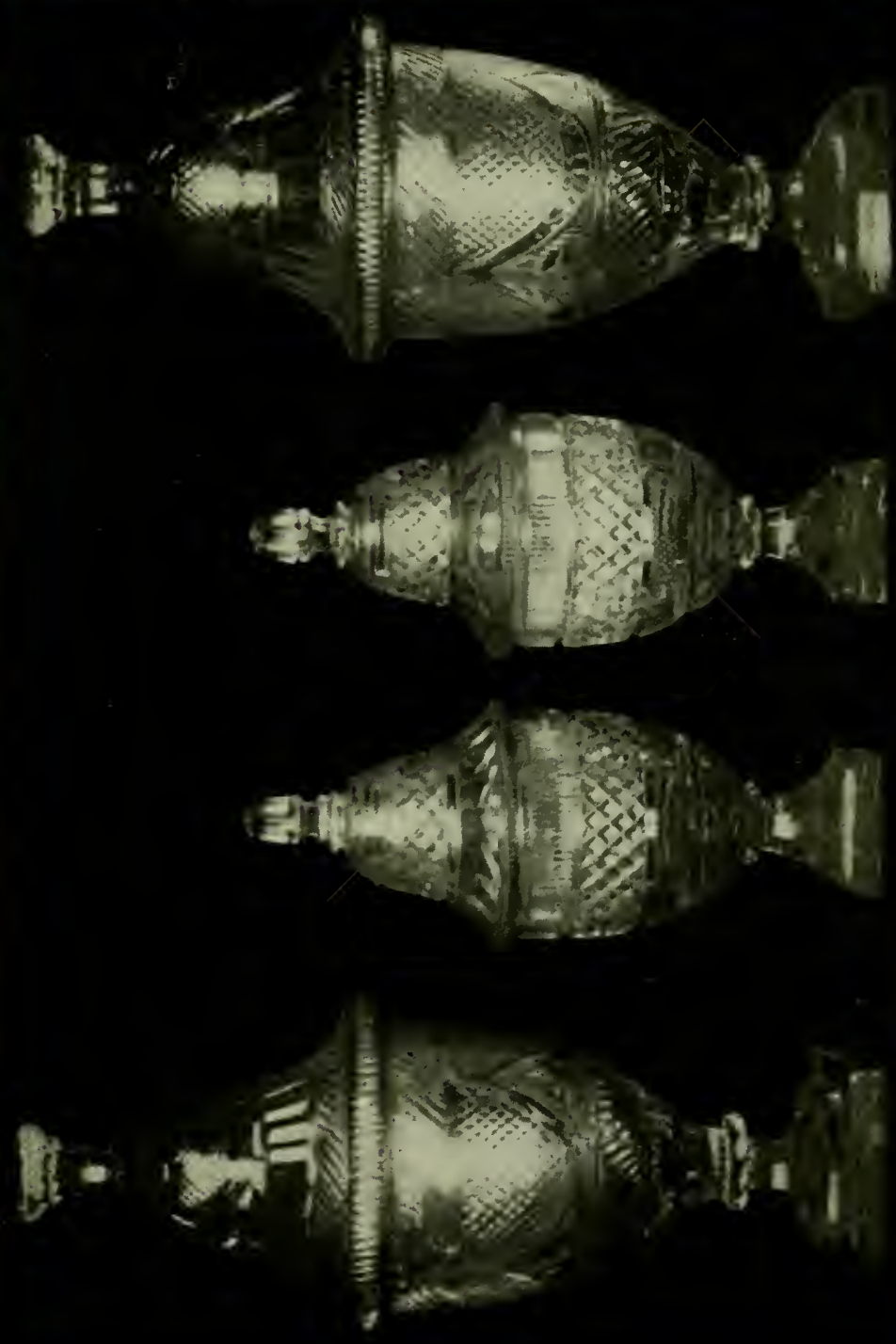
Collection of tall URis. Cork and Waterford, circa 1780. In the collection of Commander Swithinbank, R.N. 


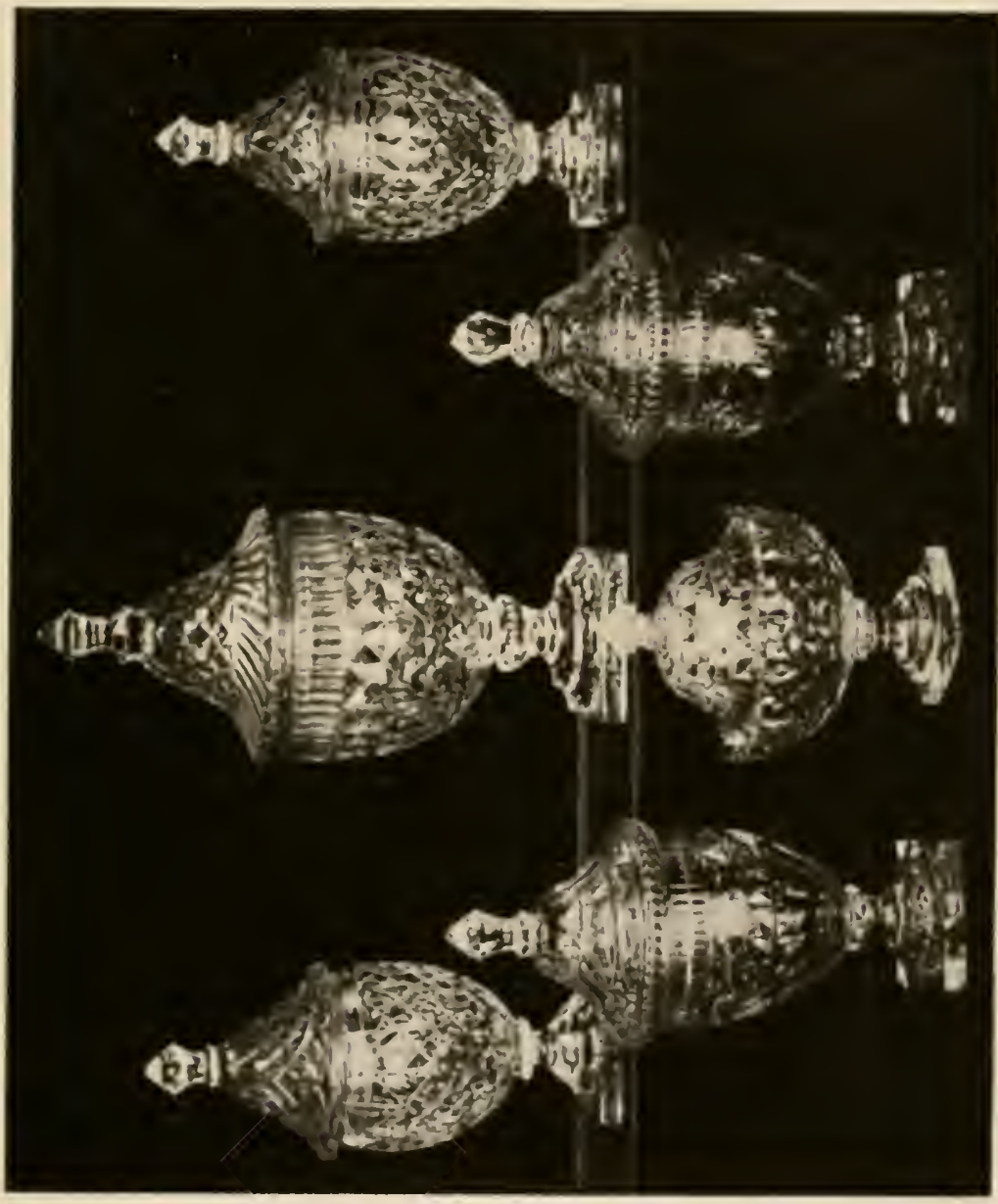


Fine Munster Glass.

In the collection of $\mathrm{Mr}$. Hunt.

Crean or ICE Pails, Irish, circa 1825-35. A wonderful example of deep step cutting, with feather handles. The glass is nearly $\frac{3}{4}$ in. thick.

In the possession of Mrs. McBean. 

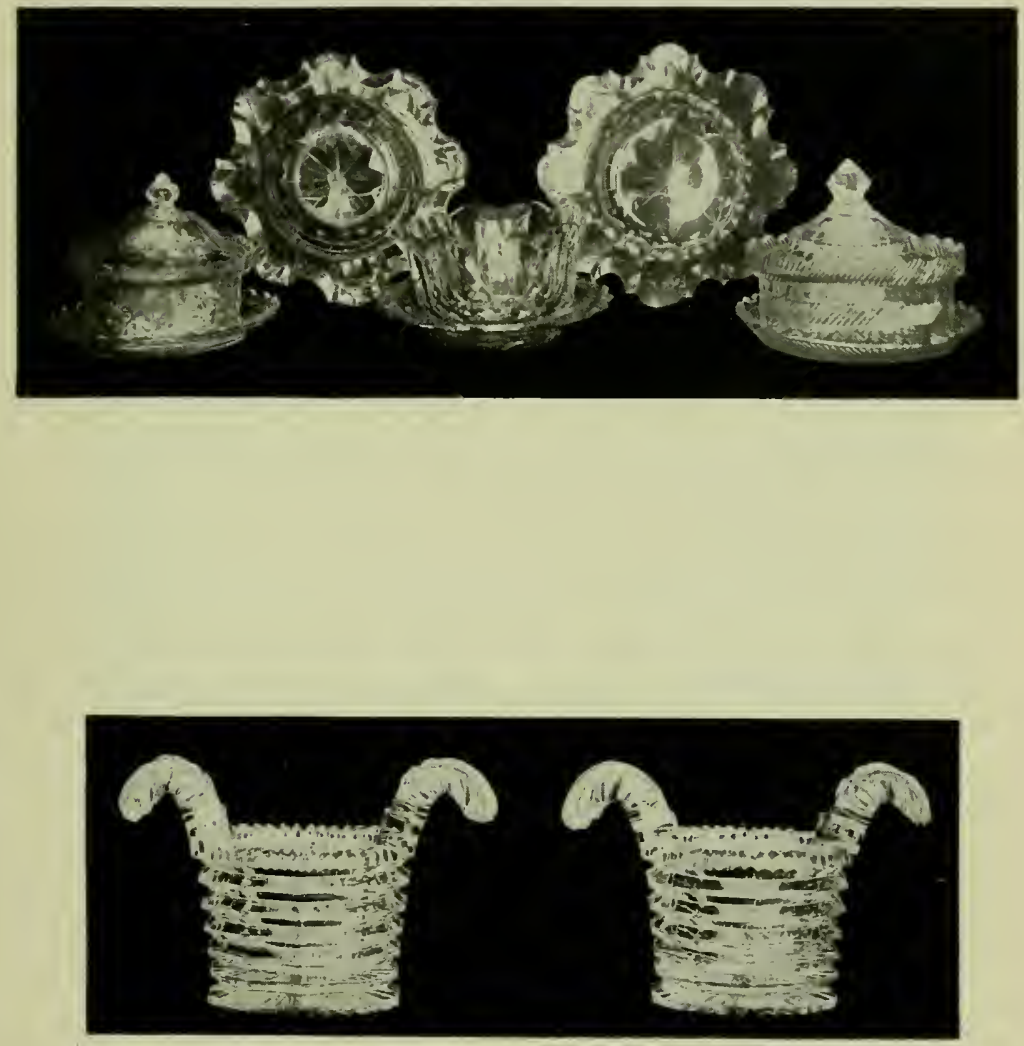
Set of three WATERFORD URns, circa 1780. Very fine examples of flat cutting.

In the collection of Mrs. Hall. 


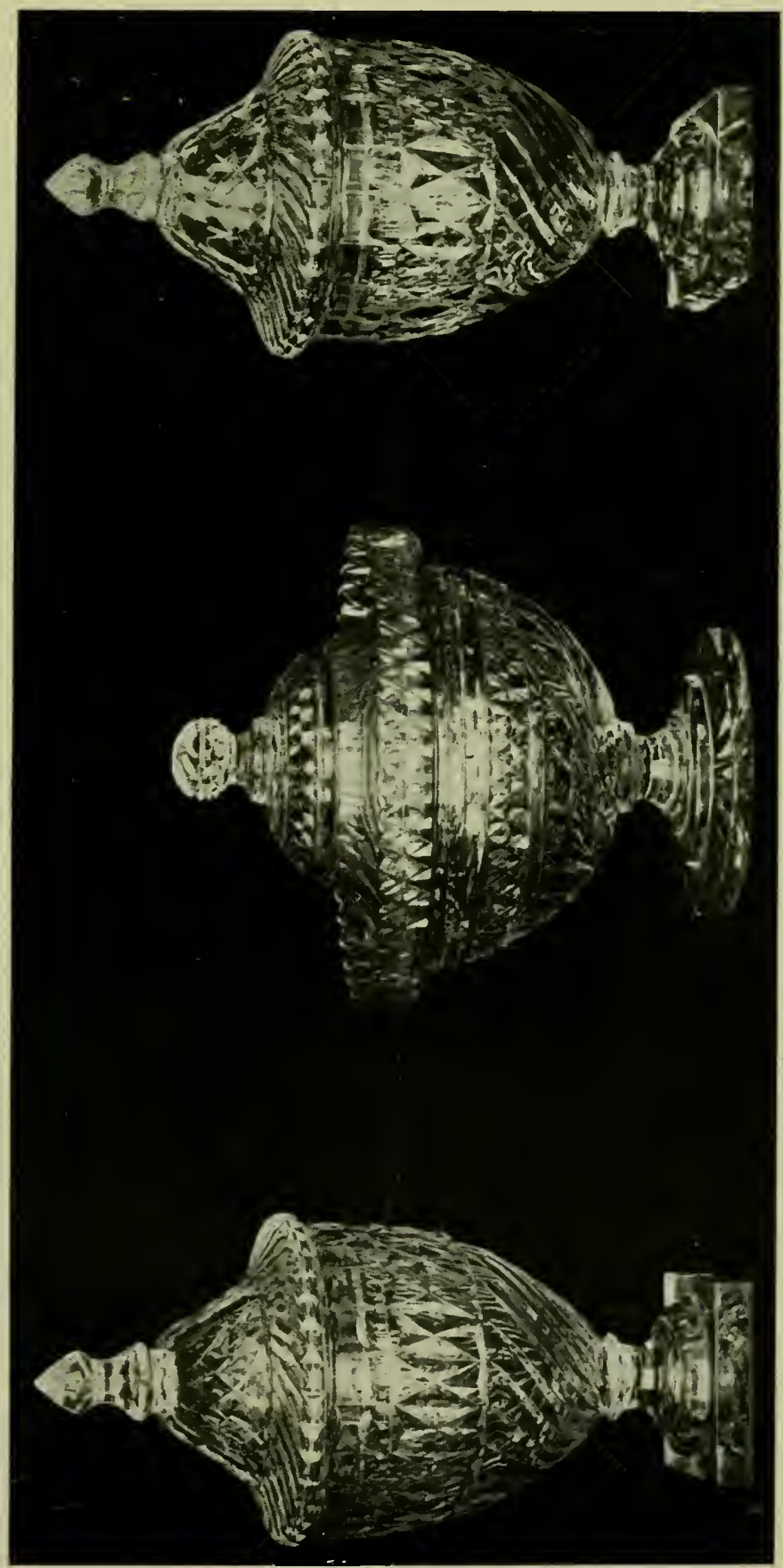


Typical Waterford Cruets and Cruet Bottles.

Old Strawberry Cut Dublin Teapot. In Mrs. Day's collection.

Old Munster Glass Teapot, moulded. In the Author's collection.

TеAPоT. IVaterford, circa 1780.

In Mr. Robert Frank's collection. 

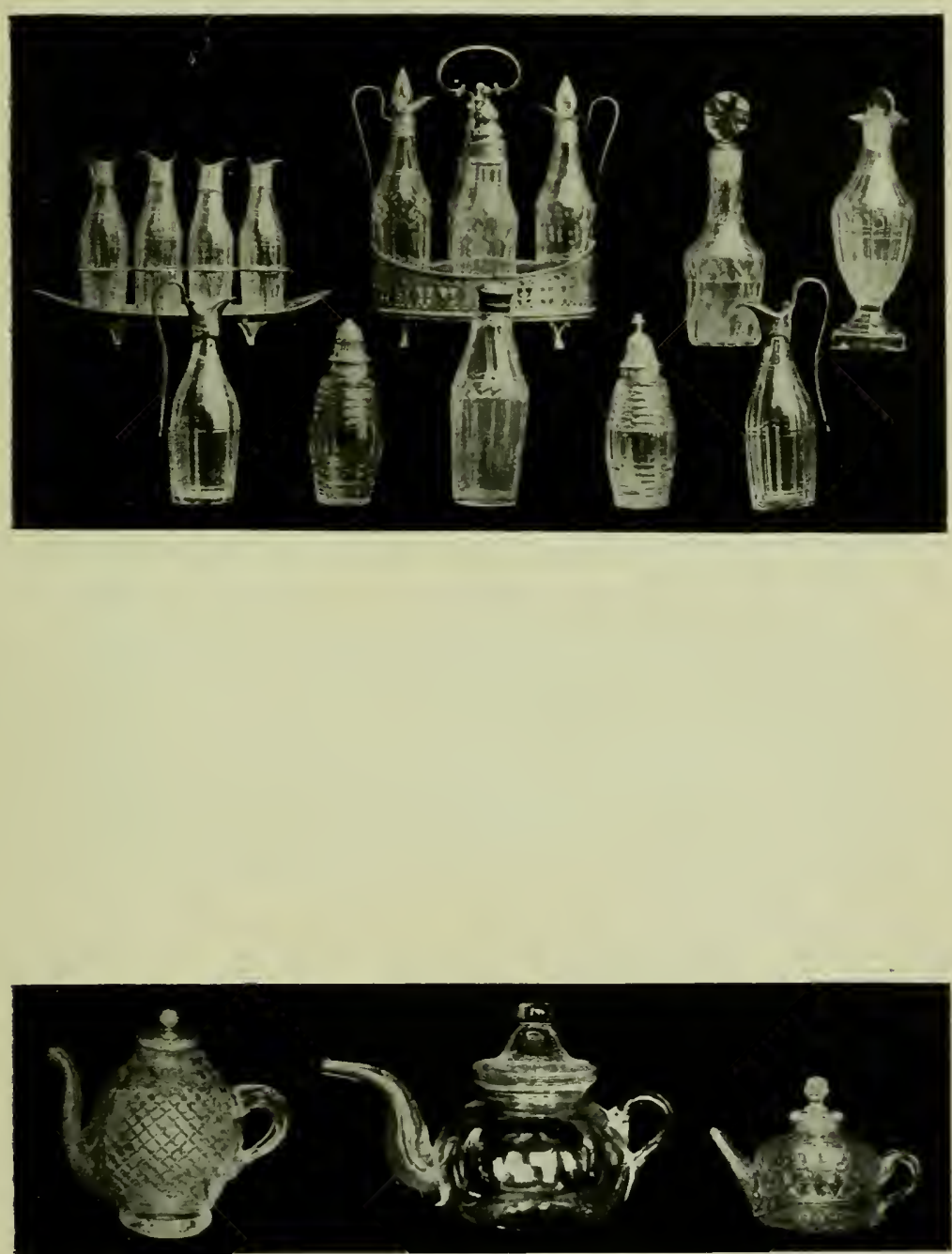
Trpical Irish Salt-Cellatrs, and a set of Four, Heavily DIAMOND-CUT LEMON Holders of a much later period. 1815-50.

Trical IRIsh Honey axd dan Pots, Mlunster glass. $1780-1815$. 

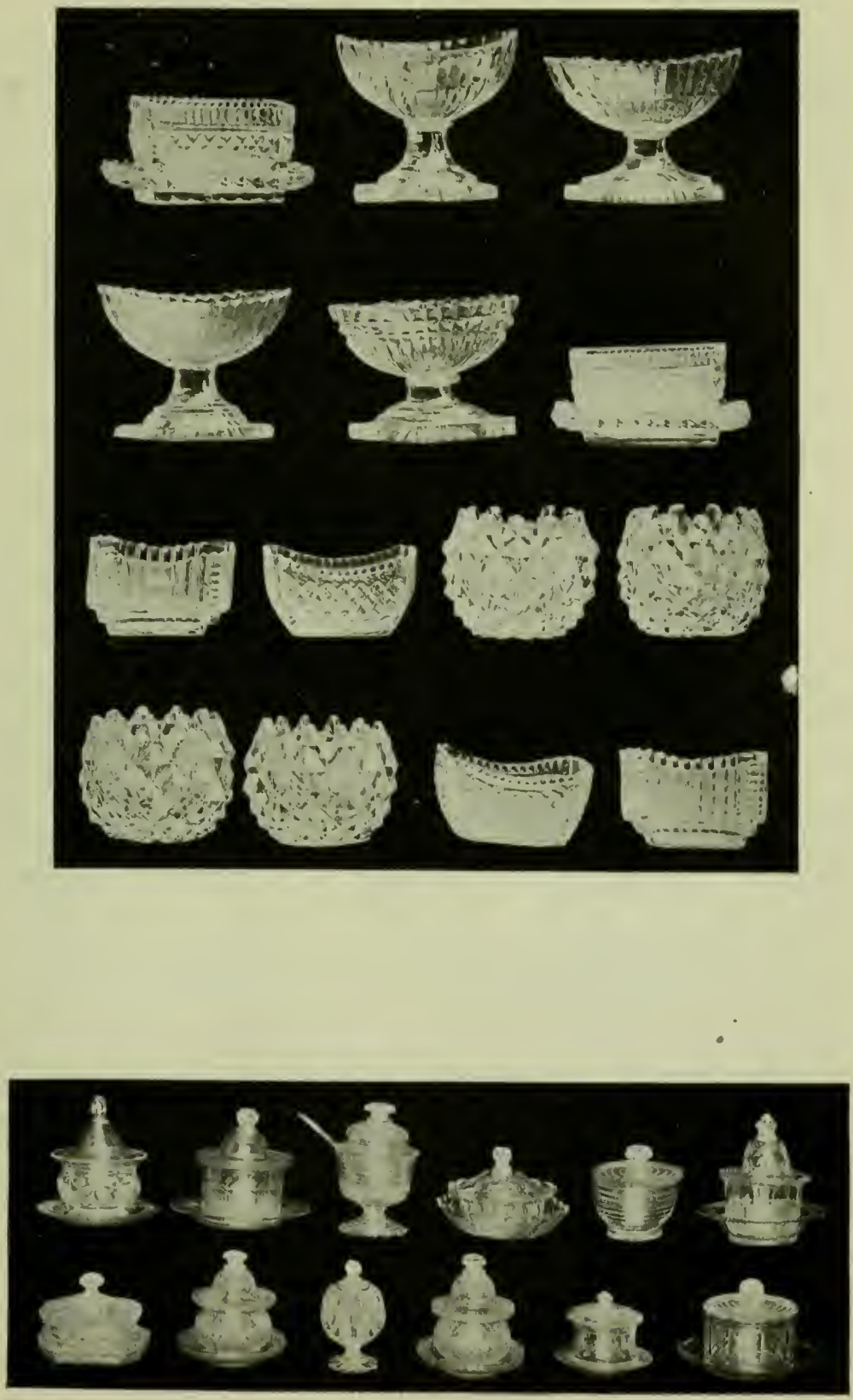


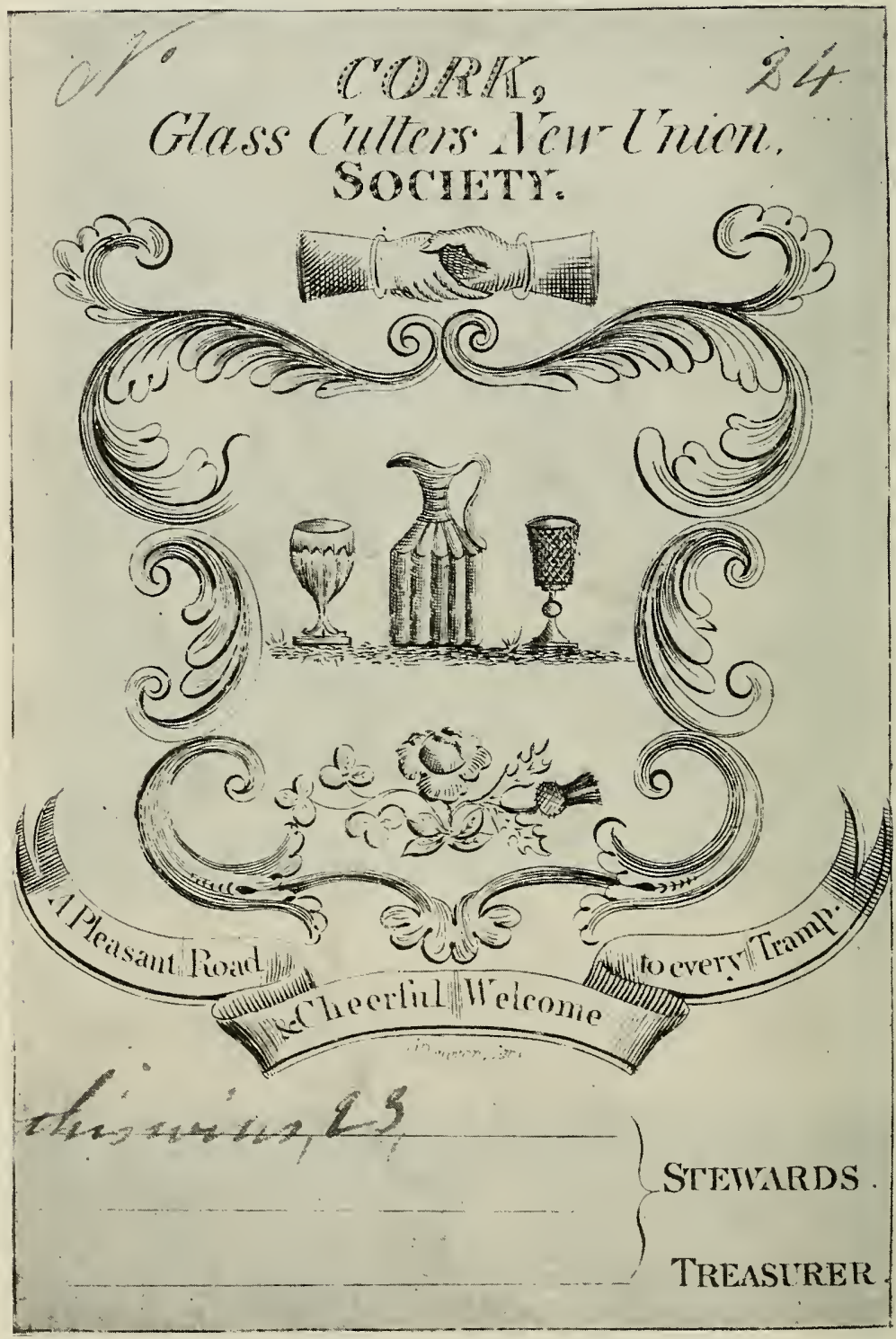

Card of Membership of the Cork Glass Cutters' Union. 
RUBBINGS 
A very carly husk or leaf cutting from an early Irish wine-glass, circor 1760 . This is one of the earliest cuttings.
A variation of the early leaf cutting, somewhat later, therefore a little sharper and more symmetrical.

Flat "leaf," one of the Cutting from a rare Waterfirst ideas of cutting. It ford bowl. "Leaf," "shalis so soft that to the low diamond," and "flute." touch it is almost like This early cutting was moulding.

very irregular, and so shallow that it is little deeper than heavy engraving. 

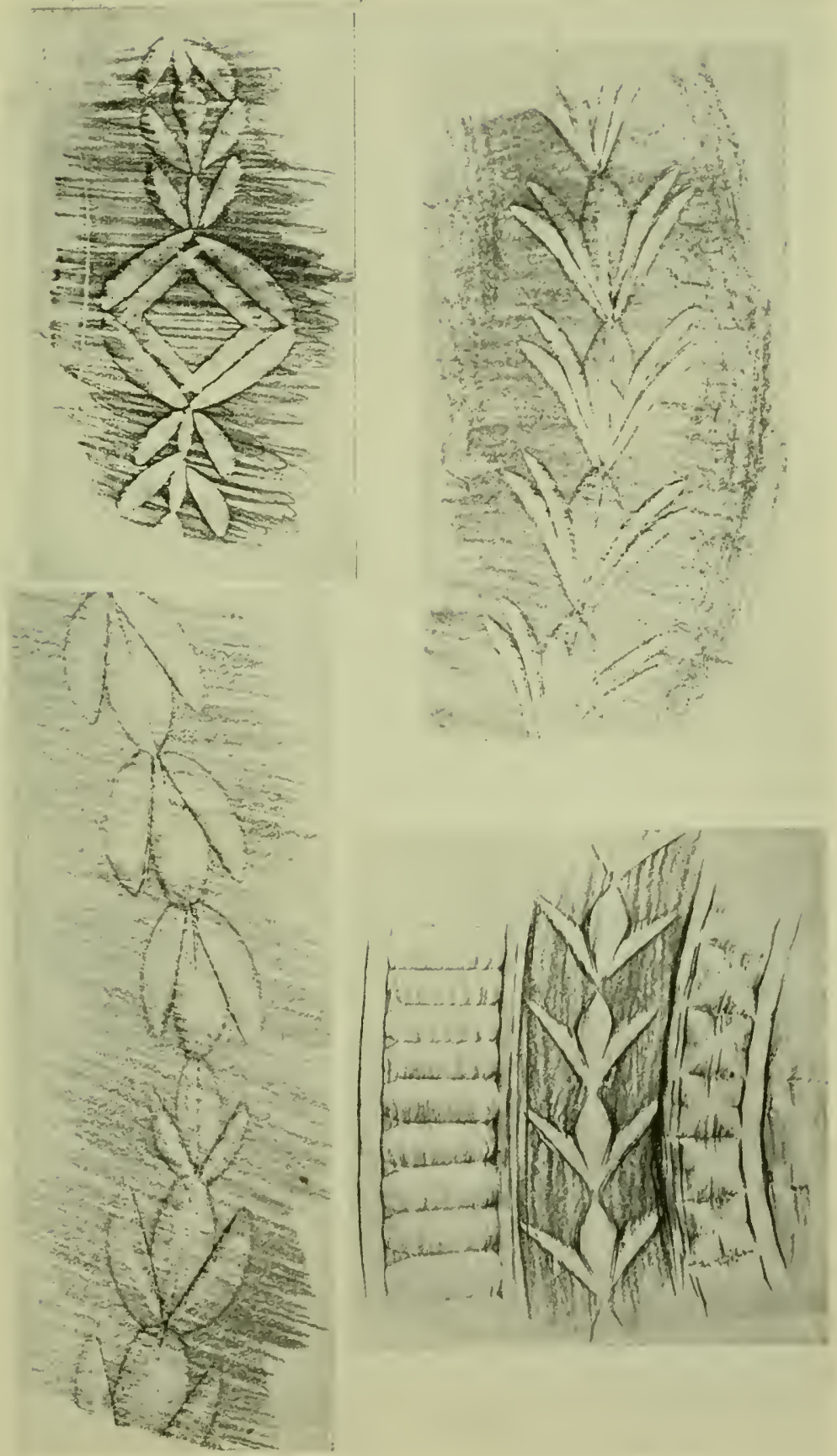
Flat diamond. This was a shallow cutting from circa 1768 onwards; after 1790 it became much deeper and sharper, the centre coming out to a sharp point.

"Double," or "long" diamond, so often called in England "lozenge." It was a very soft shallow cutting till after 1780 , when it became bolder and deeper.

A most rave and very shallow adaptation of diamond cutting from an old lrish chalice, circo 1770. 

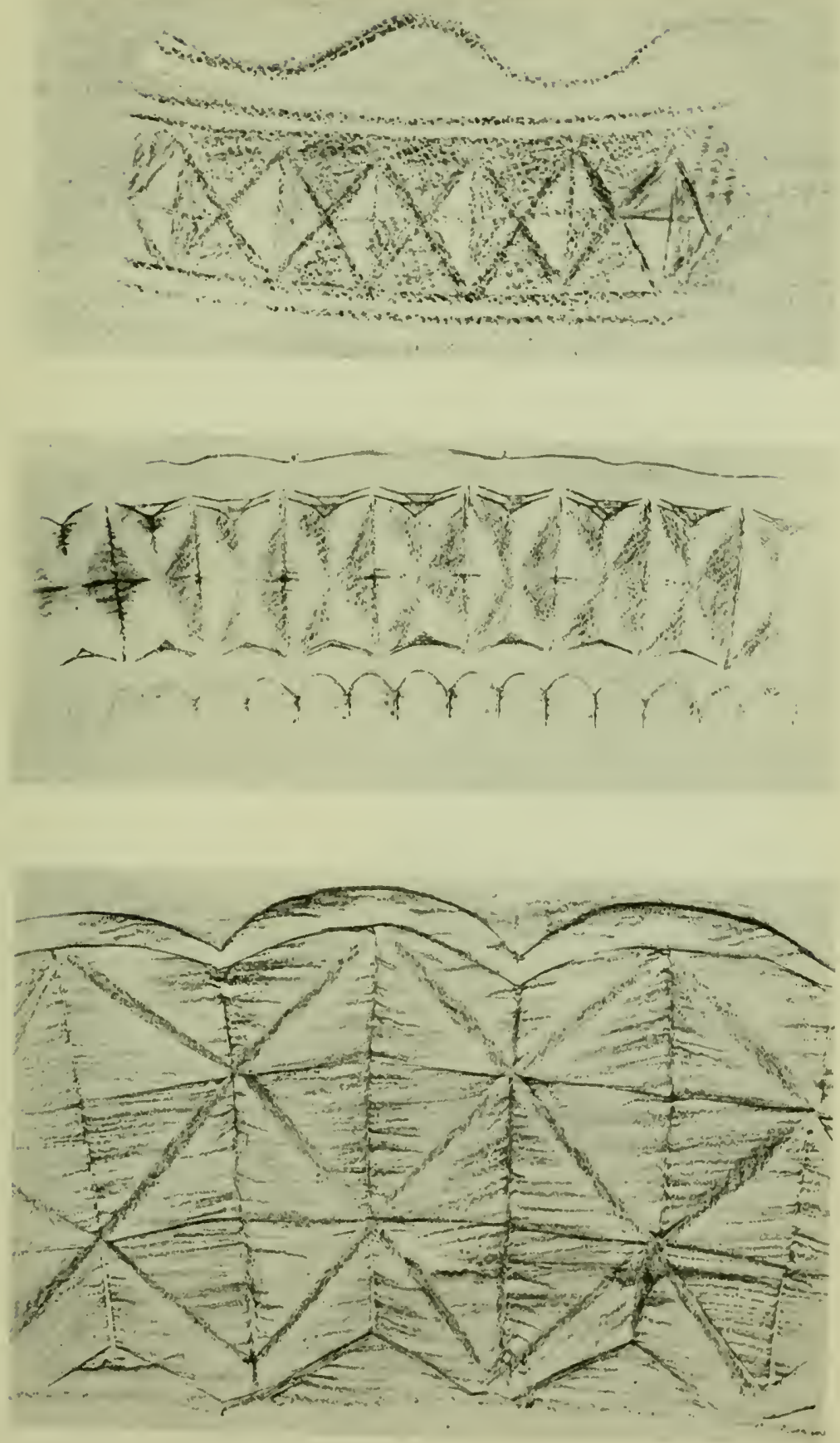
A very beautiful shallow-cut star from a Waterford dish, about 1780 .

Another star, somewhat later.

A soft early star found on the bottoms of finger-bowls and decanters, circa 1750 . Note the remarkable variation from the given centre. 


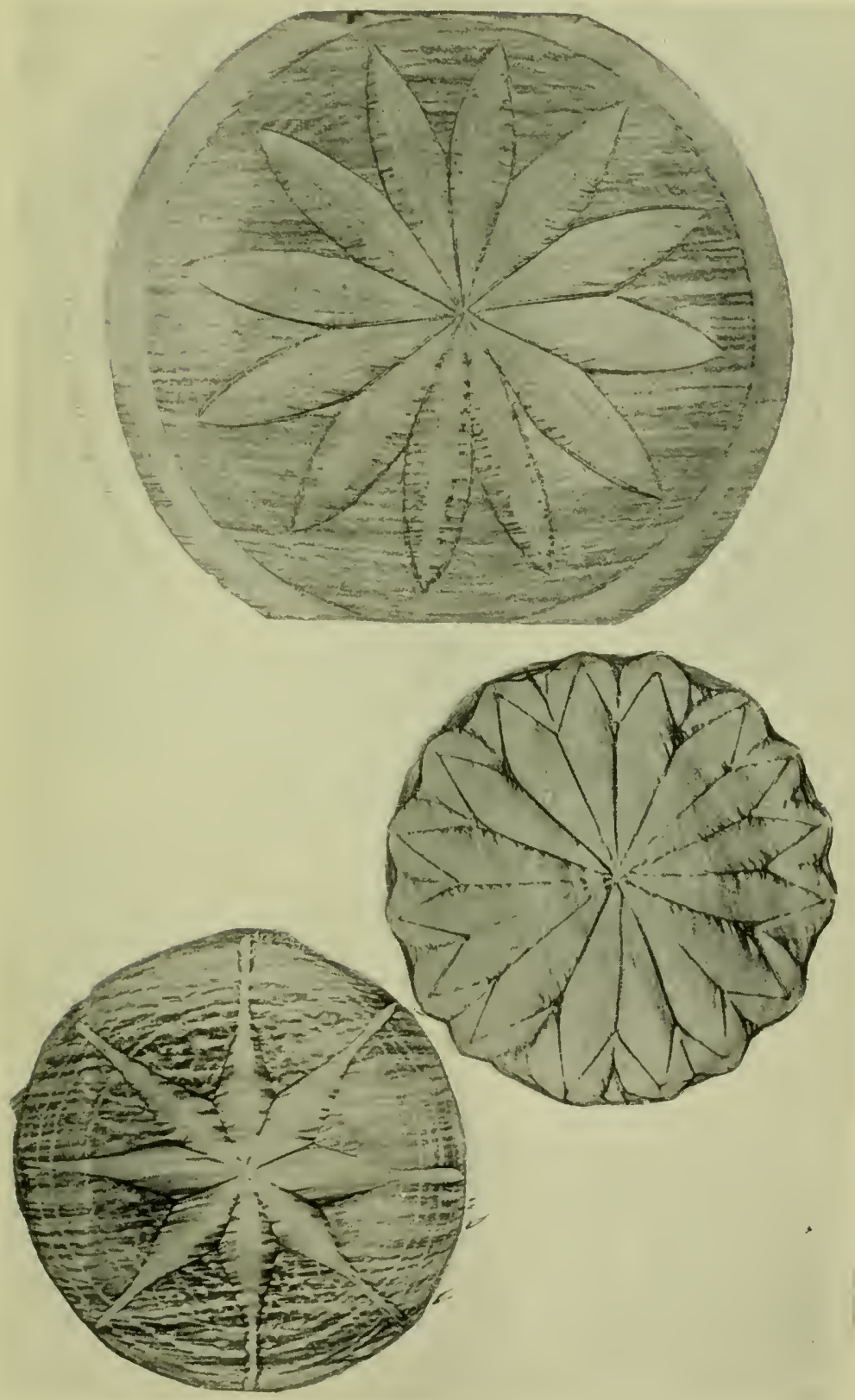


The only cutting on a rare canoe-shaped Waterford bowl in the author's collection. "Flutes" also a very early idea, but became deeper and smaller and sharper as time went on.

Vandylic cutting, more commonly linown as "bull's-eye." A cutting very much done between 1770 and 1800 , and probably more copied both abroad and in England than any other cutting.

A very beautiful fan edge from a fine Waterford bowl of circa 1815 . 


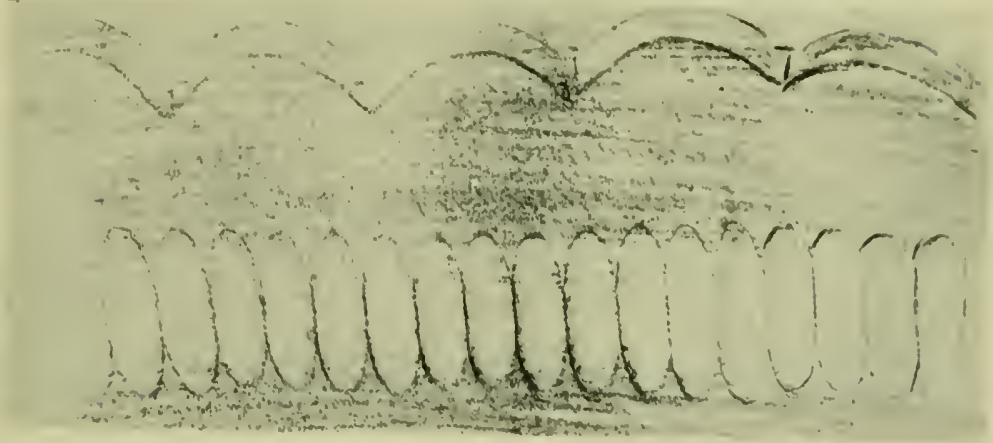

(f)

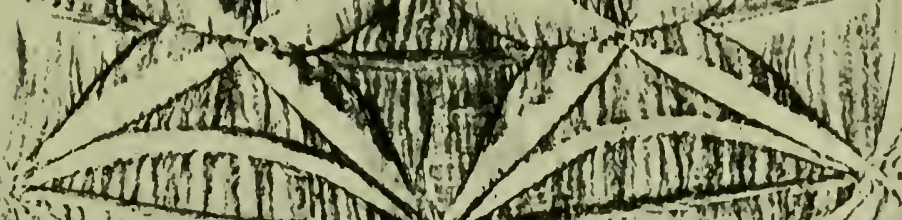

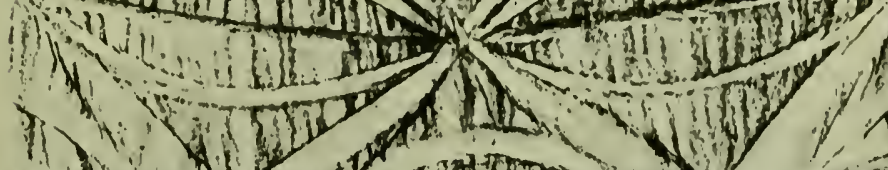

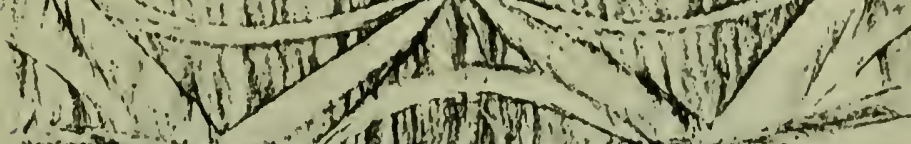

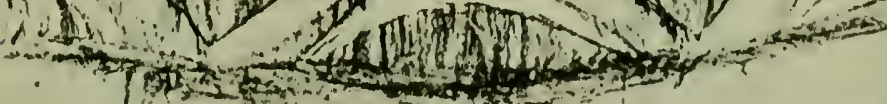

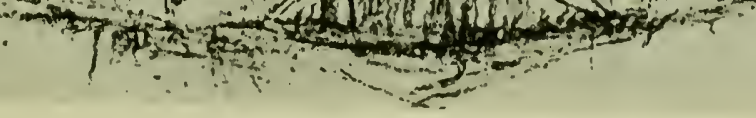
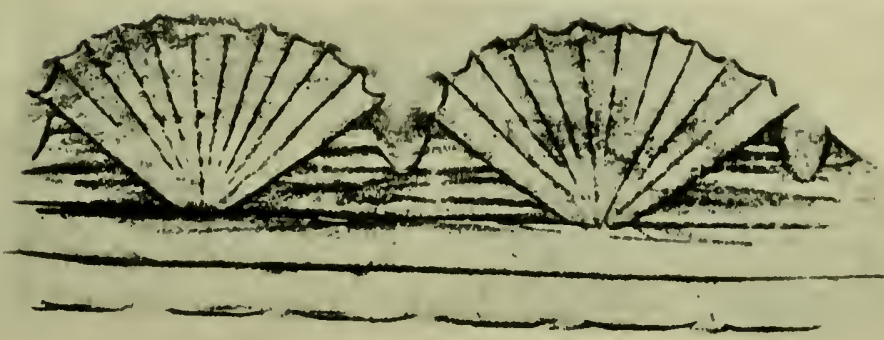
Beautiful swag and line cutting with fan edge. This is an early effort, probably 1765 ; but there is a fine example on a Waterford dessert service in the possession of Colonel Wike.

Hobnail cutting, late 1830 , so often confused with diamond cutting.

Strawberry cutting, so often confused with hobnail cutting; much used from 1780. This is an early example. Note the unevenness of the lines. 

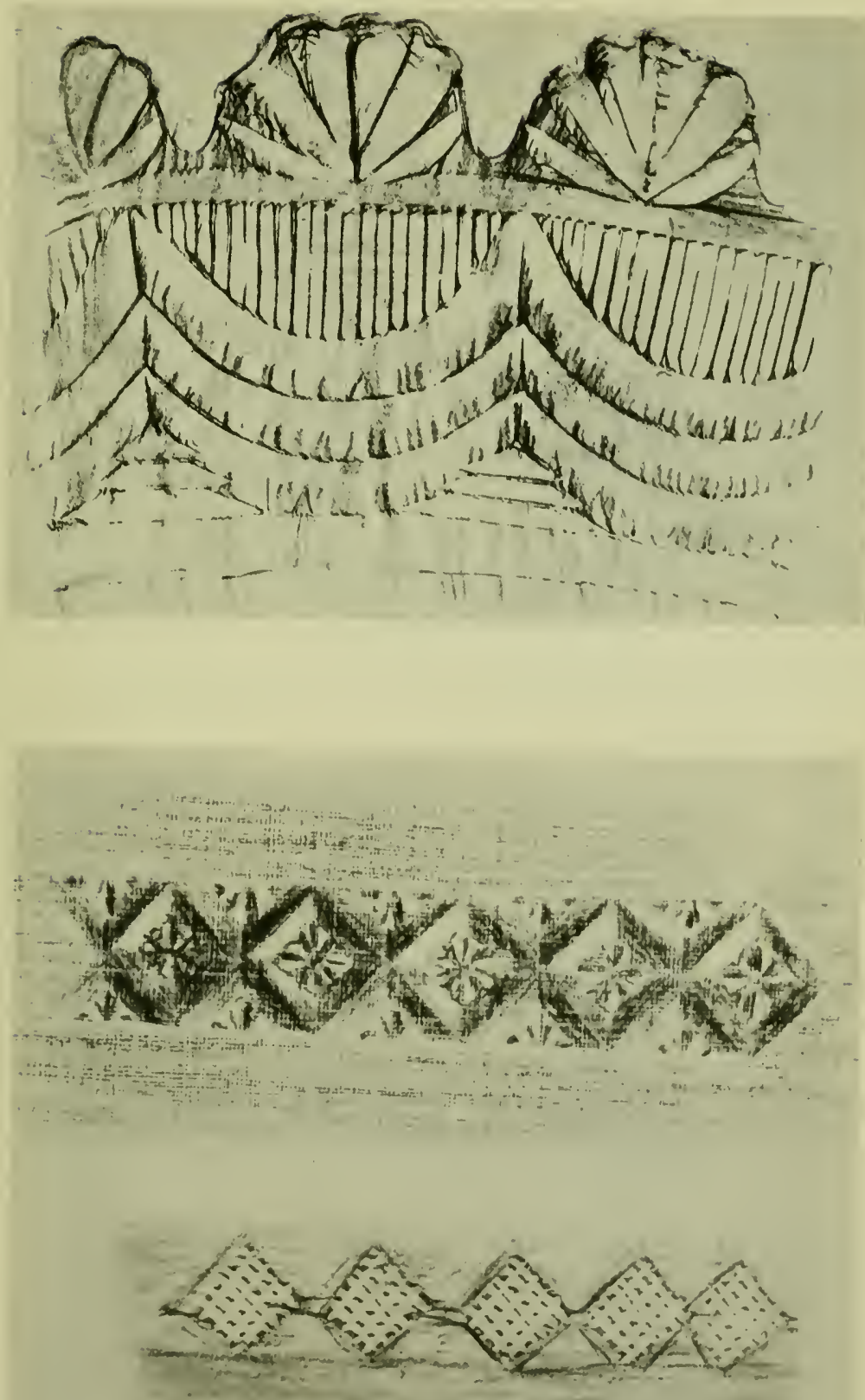
A wonderful example of "lustre" cutting. Dublin, circe 1785.

A most beautiful bit of cutting on a rare early IVaterford mirror in Commander Swithinbank's collection. 

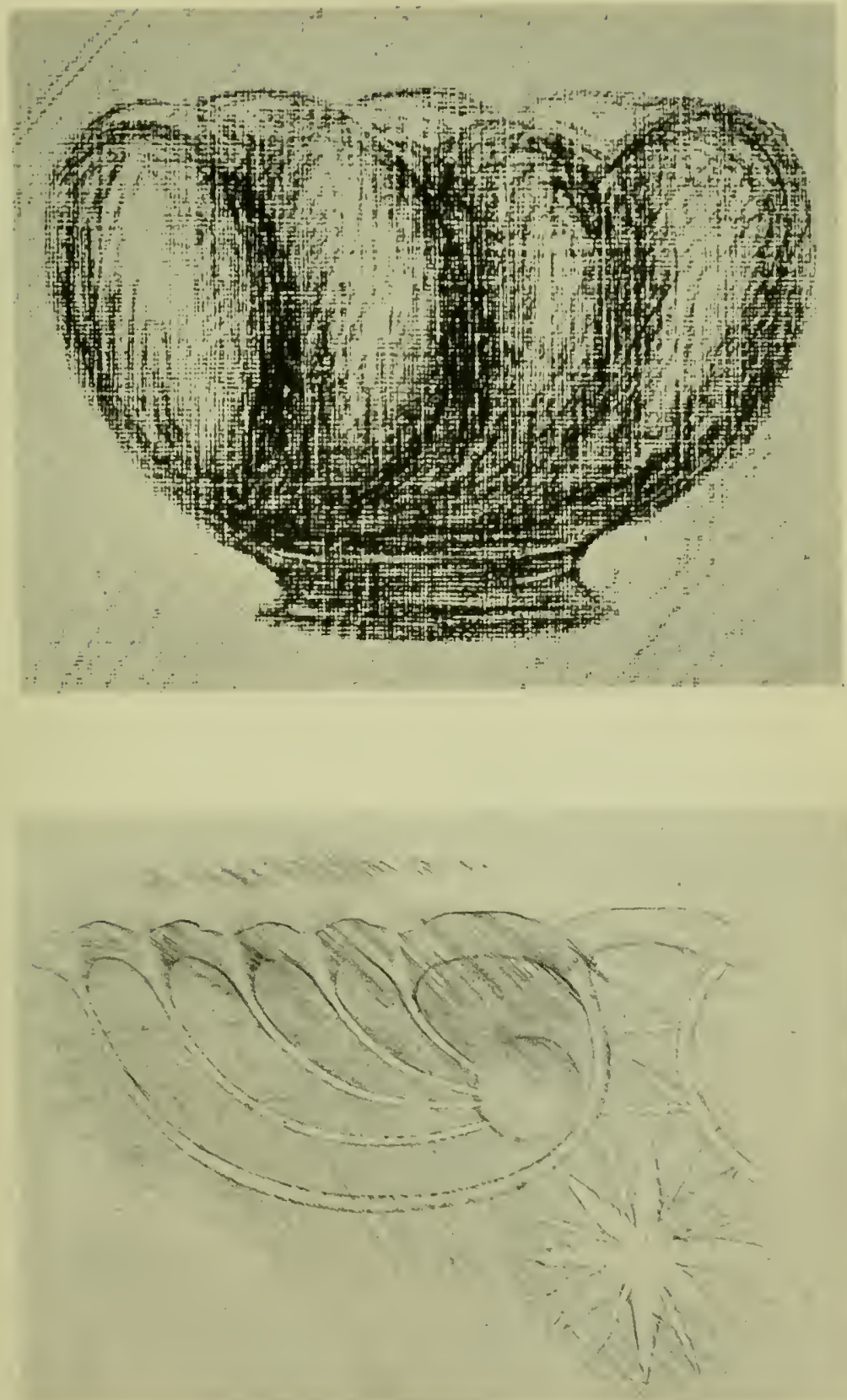
A wonderful special cutting on a "pinched" Waterford boat-shaped bowl a little deeper than engraving. In the Author's collection.

Very early cutting from Mr. IVeguclin's Waterford urns, showing the remarkable inaccuracy of the cutting. 


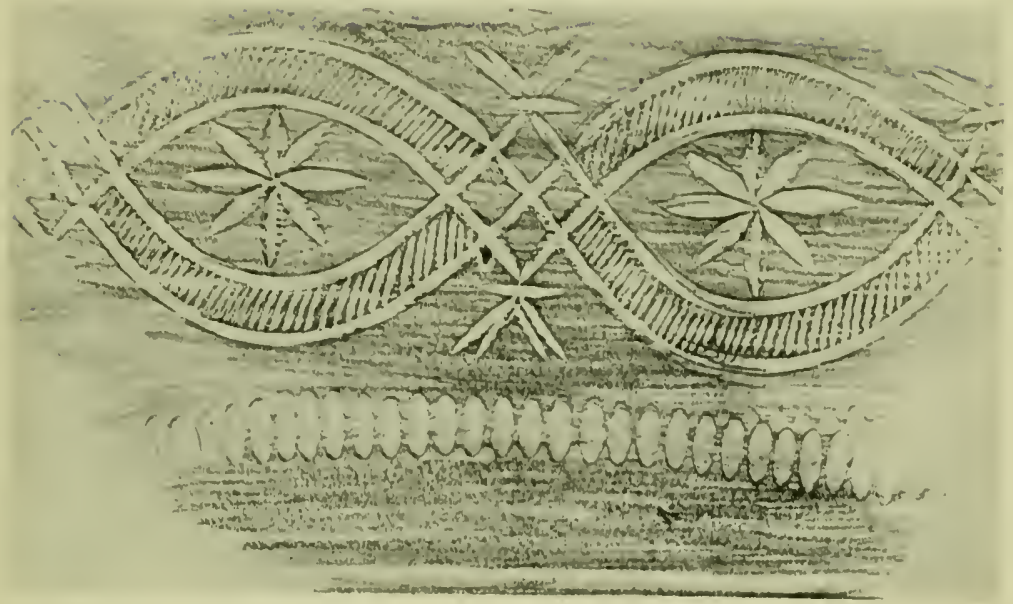
Mph

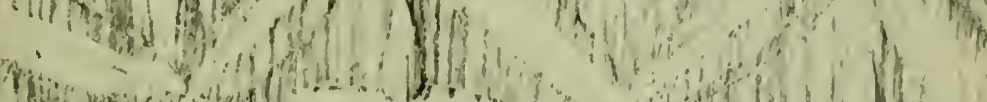
.

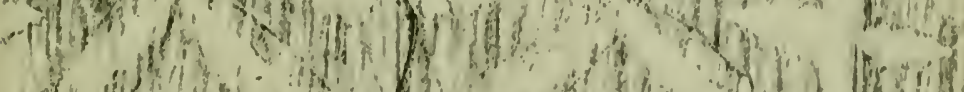
(1)

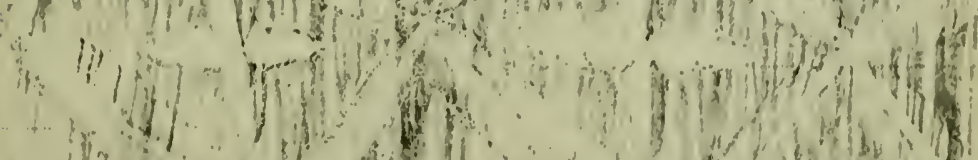

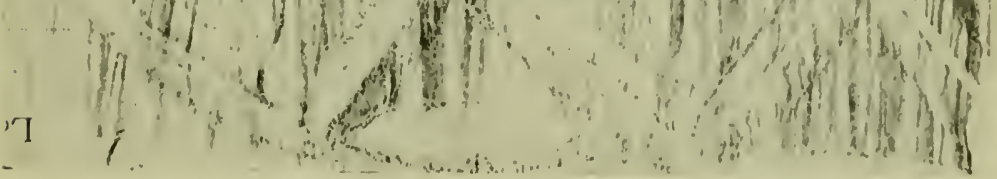


Two of the many adaptations of cutting on Irish glass from 1790 to 1835 . 

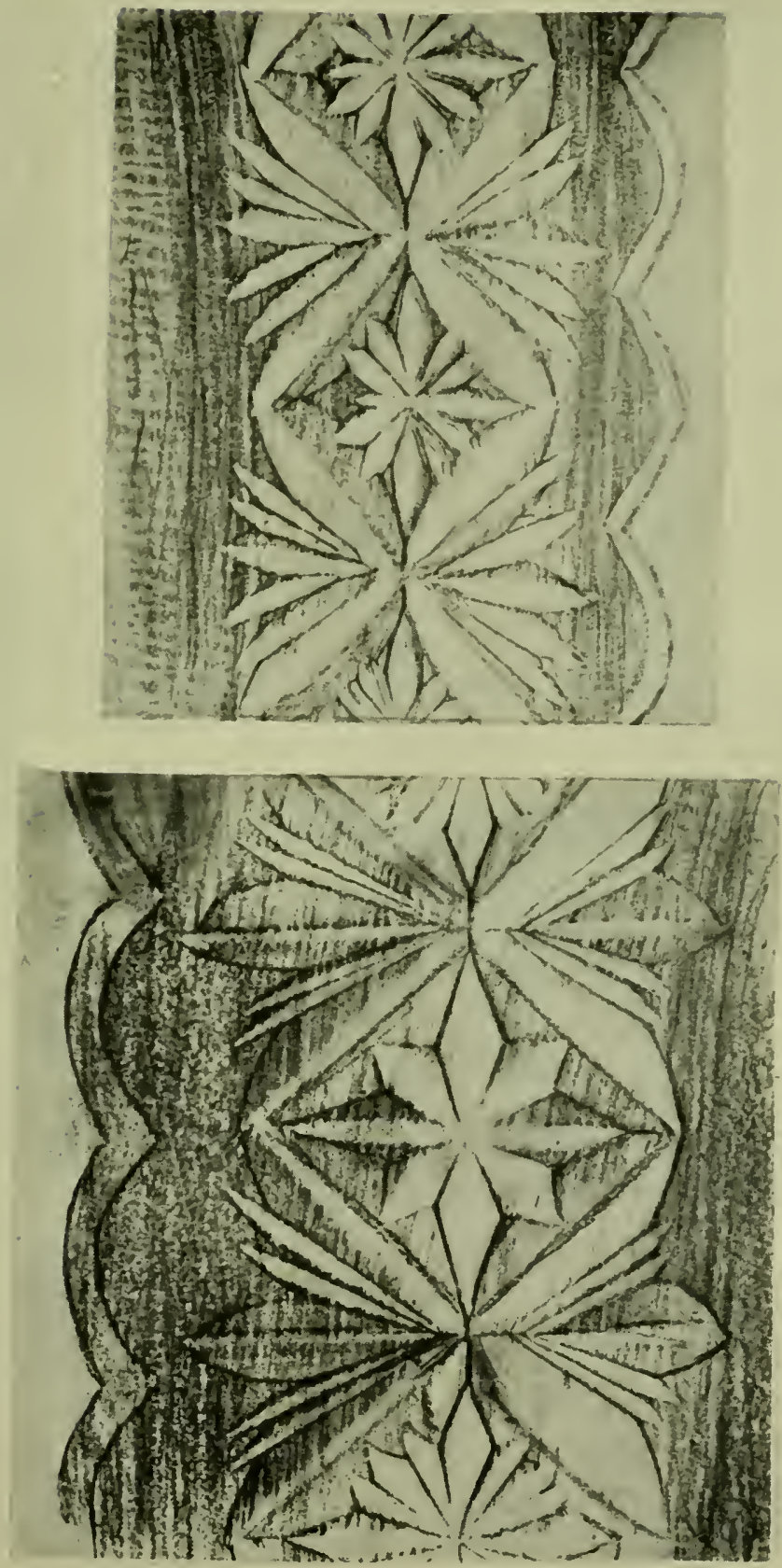
Cutting from an early Waterford canoe-shaped bowl. In the Author's collection.

Cutting, soft and shallow, from a Cork bowl, late eighteenth century.

In the Author's collection. 

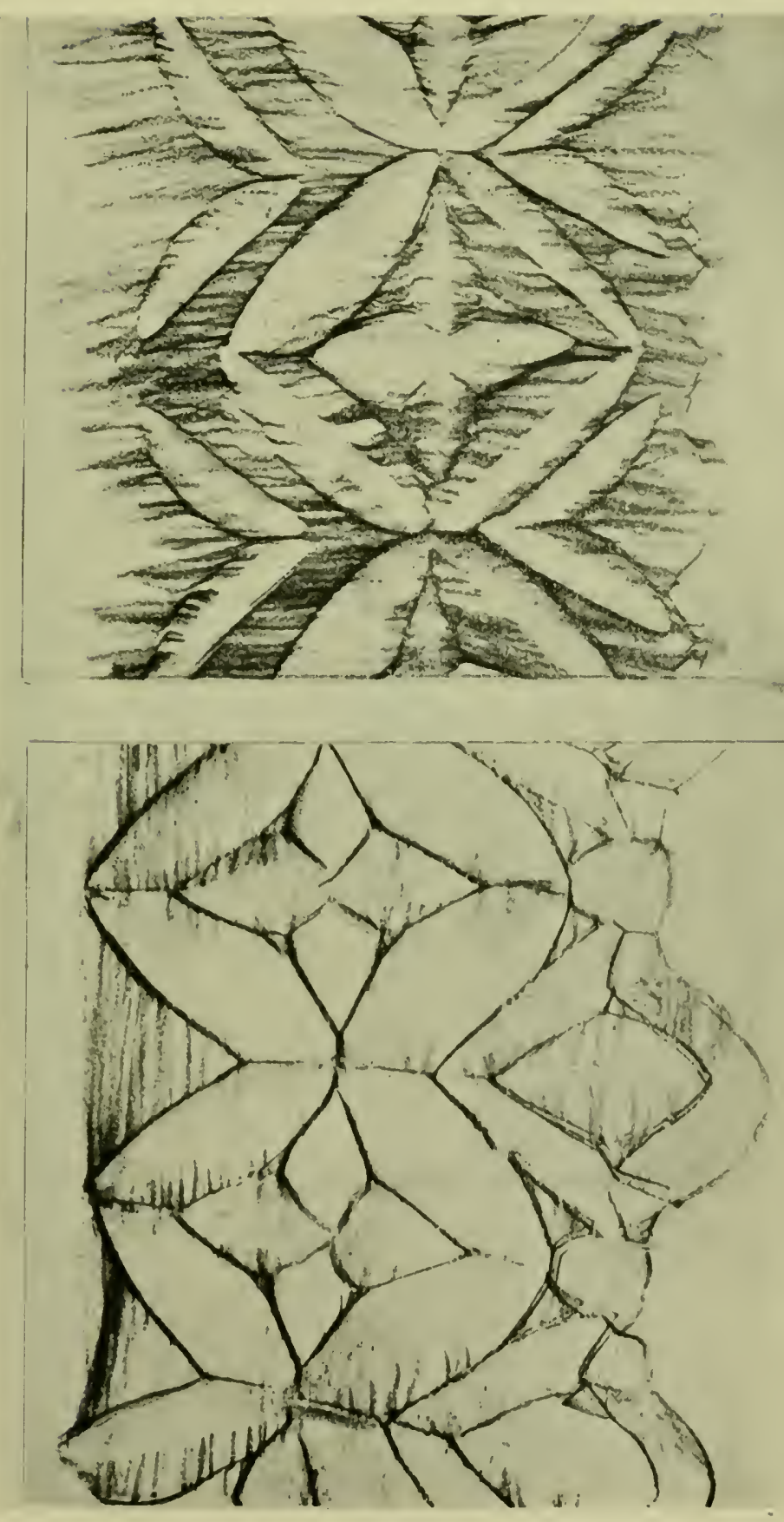
M 
(and NOIINIILSNI NHINOSHIISS SJIYYYG17 LIBRARIES SMITHSONIAI
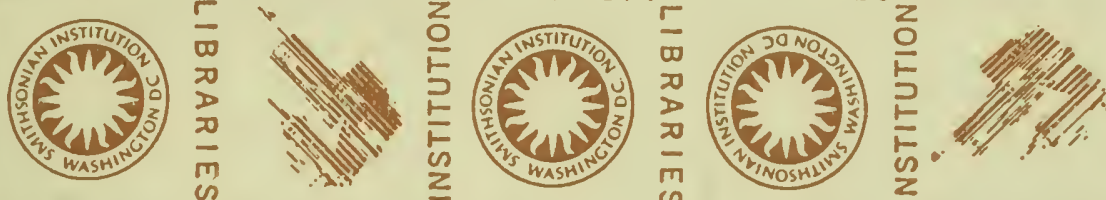

LIBRARIES
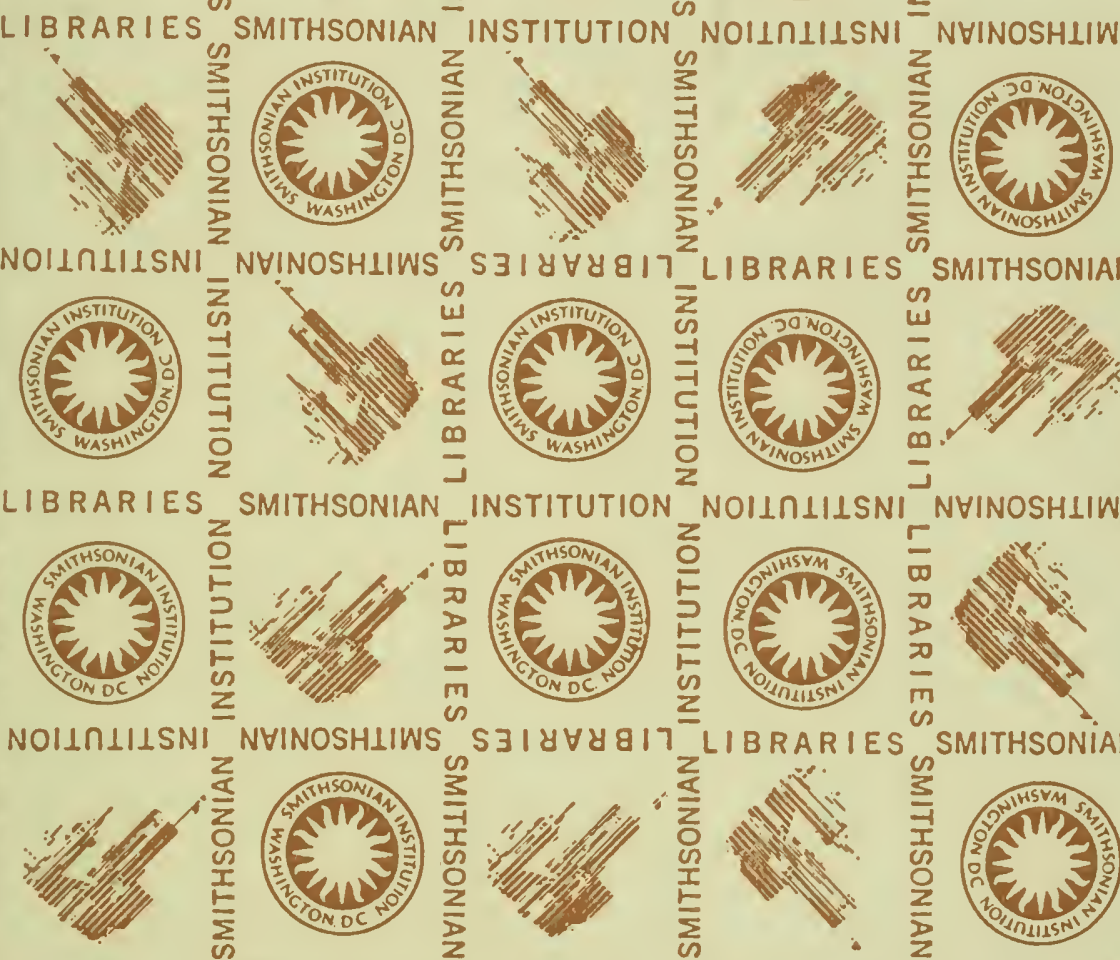

LIBRARIES SMITHSONIAN
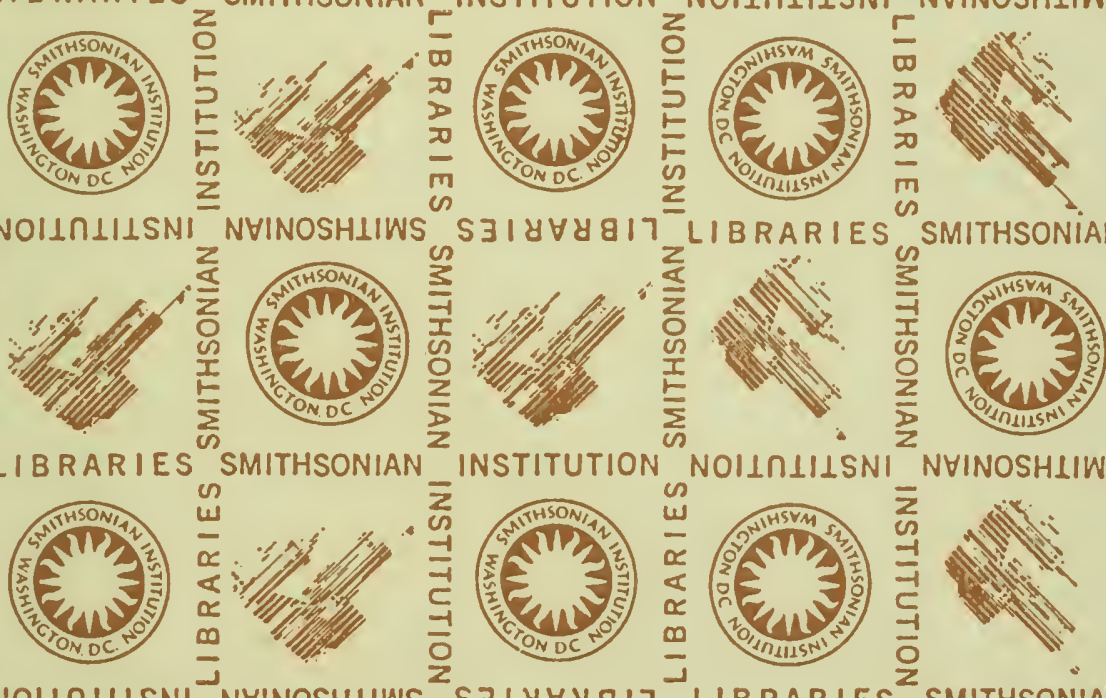

NOIINIIISNI NHINOSHIIWS
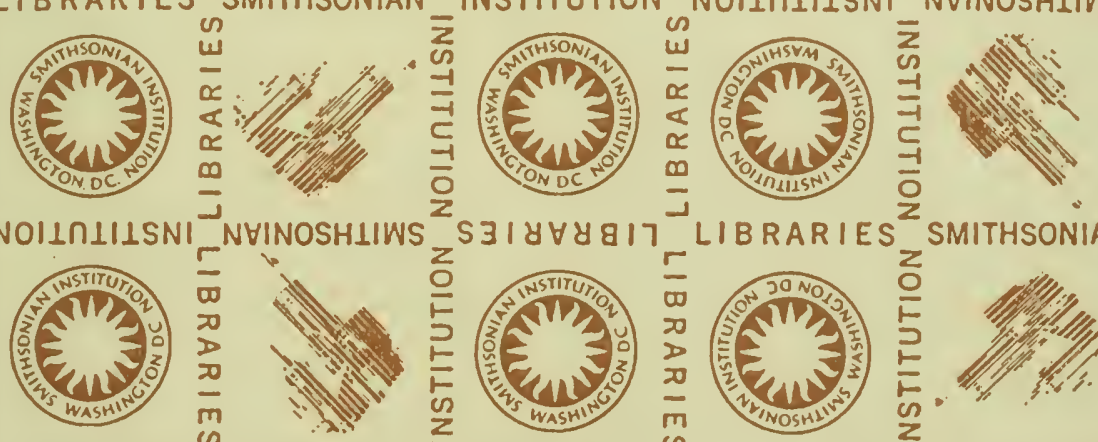

SMITHSONIAI

LIBRARIES SMITHSONIAN

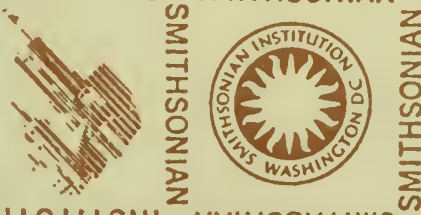

INSTITUTION

NOIIRIIISNI
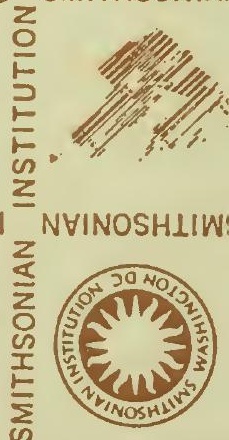

NOIINLIISNI NHINOSHIIWS

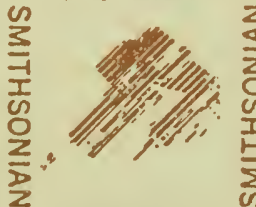

S3I\& $\forall \& 817^{2}$ LIBRARIES SMITHSONIAN 

. 
$\cos 0 \mathrm{C}=0$

in

$m$ ONOCH

$i$ in o

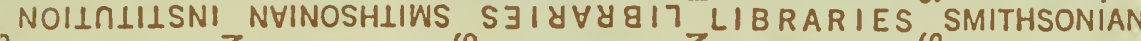
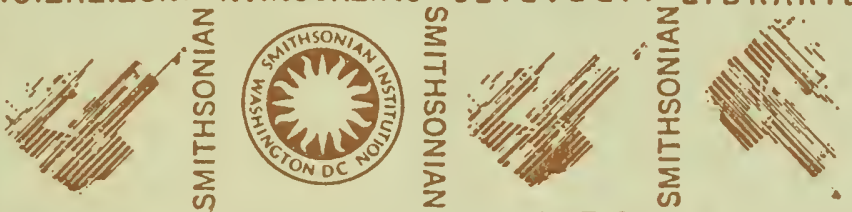

$\frac{n}{3}$

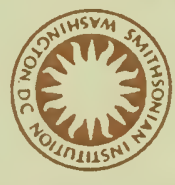

IBRARIES SMITHSONIAN

INSTITUTION NOIINLIISNI

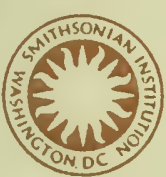

$\frac{w}{\alpha}$
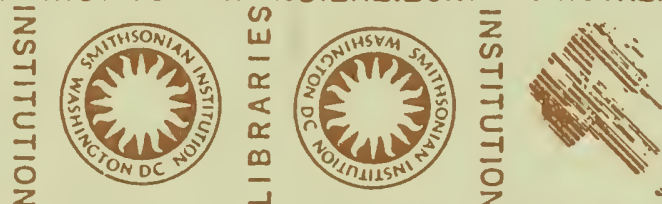

NOIINLILSNI NHINOSHLIWS
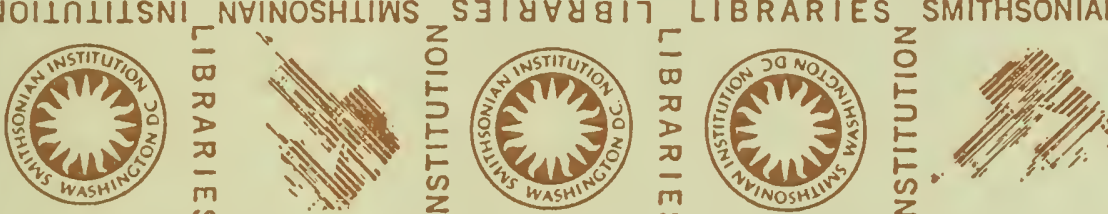

LIBRARIES SMITHSONIAN
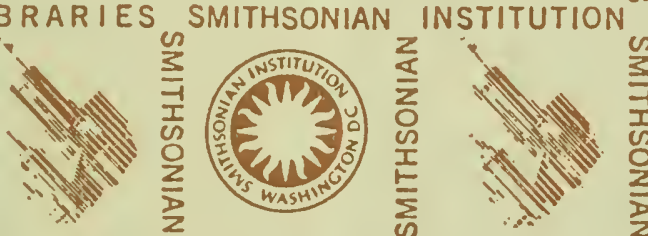

NOIIRIIISNI

NYINOSHIIWS

NOIIRIIISNI NHINOSHIIWS
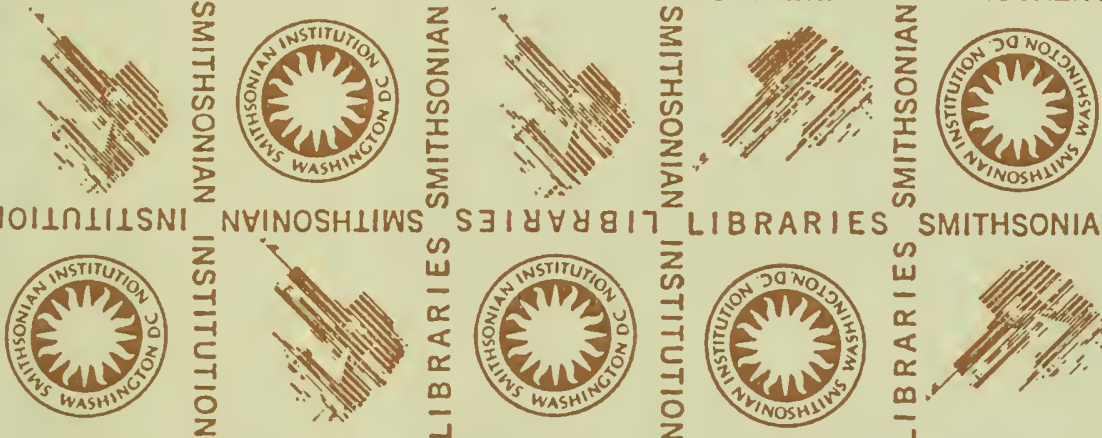

LIBRARIES
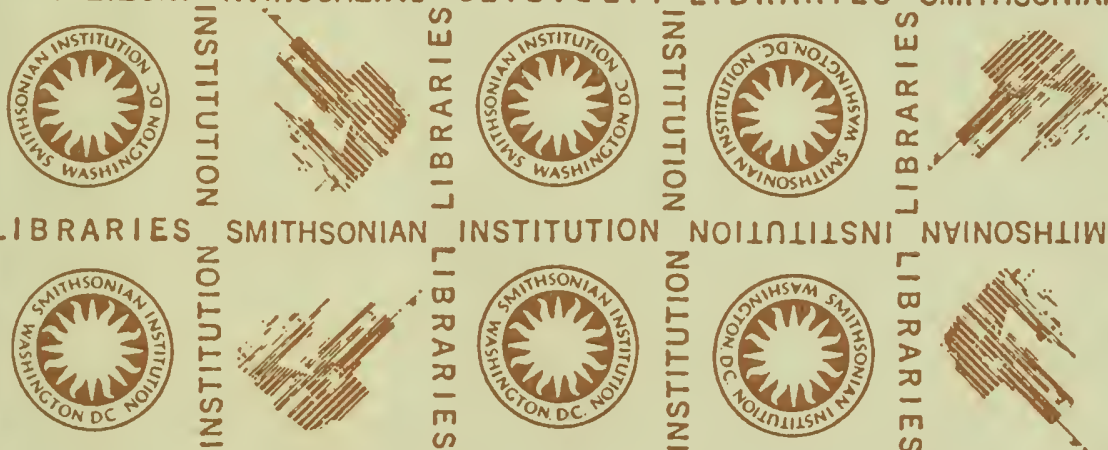

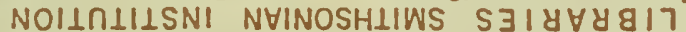
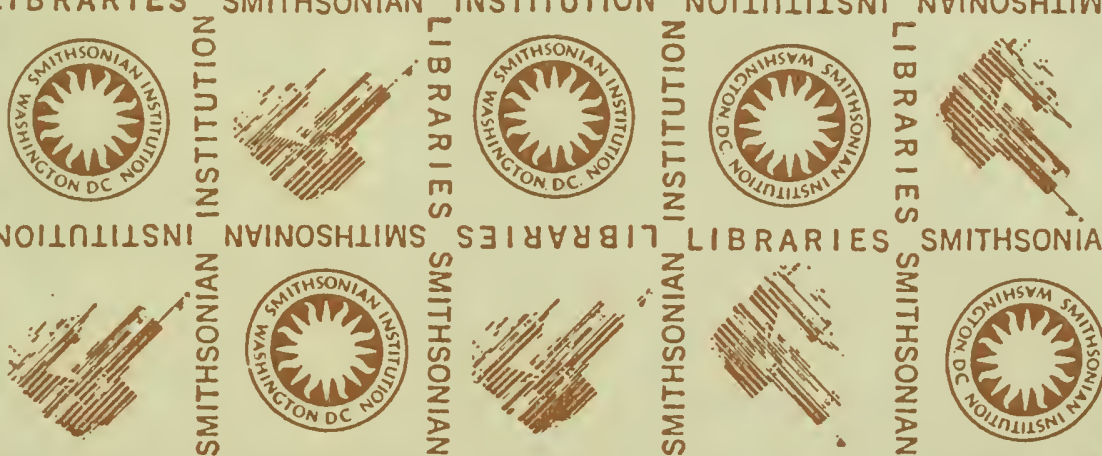

LIBRARIES SMITHSONIAN
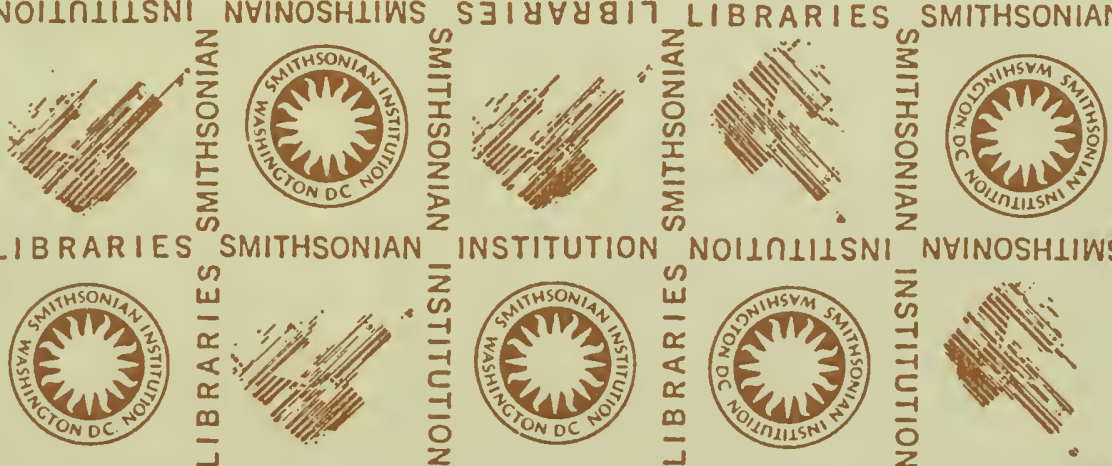

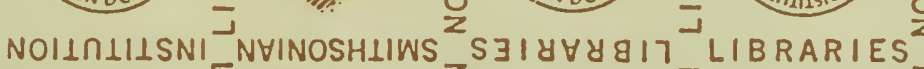

NHINOSHIIW: 

Old lrish glass 

